Georgia State University

ScholarWorks @ Georgia State University

7-23-2007

\title{
Multiple Sclerosis Disease Distribution and Potential Impact of Environmental Air Pollutants in Georgia
}

Anthony Charles Gregory

Follow this and additional works at: https://scholarworks.gsu.edu/iph_theses

Part of the Public Health Commons

\section{Recommended Citation}

Gregory, Anthony Charles, "Multiple Sclerosis Disease Distribution and Potential Impact of Environmental Air Pollutants in Georgia." Thesis, Georgia State University, 2007.

doi: https://doi.org/10.57709/1062234

This Thesis is brought to you for free and open access by the School of Public Health at ScholarWorks @ Georgia State University. It has been accepted for inclusion in Public Health Theses by an authorized administrator of ScholarWorks @ Georgia State University. For more information, please contact scholarworks@gsu.edu. 


\section{MULTIPLE SCLEROSIS DISEASE DISTRIBUTION AND POTENTIAL IMPACT OF ENVIRONMENTAL AIR POLLUTANTS IN GEORGIA}

By
ANTHONY CHARLES GREGORY II
B.S. GEORGIA STATE UNIVERSITY

A Thesis Submitted to the Graduate Faculty of the Georgia State University in Partial Fulfillment of the Requirements for the Degree MASTER IN PUBLIC HEALTH

ATLANTA, GEORGIA 
APPROVAL PAGE

\section{MULTIPLE SCLEROSIS DISEASE DISTRIBUTION AND POTENTIAL IMPACT $\mathrm{OF}$}

ENVIRONMENTAL EXPOSURES IN GEORGIA

By

Anthony Charles Gregory II

\section{Approved:}

Dr. Derek G. Shendell

Committee Chair

Dr. Solomon I. Okosun

Committee Member

Dr. Karen. E. Gieseker

Committee Member 


\section{ABSTRACT}

\section{ANTHONY C. GREGORY II}

Multiple Sclerosis Disease Distribution and Potential Impact of Environmental Air Pollutants in Georgia.

Under the direction of Derek G. Shendell, D.Env, MPH

This study's purpose is to examine the potential relationships between MS (Multiple Sclerosis) and environmental outdoor air pollutants in GA (Georgia). We used secondary, cross-sectional data received from the member's list of the National Multiples Sclerosis Society’s GA chapter (NMSS-GA), the U.S. census, and scorecard.org, a database based on the U.S. Environmental Protection Agency (EPA) Toxic Release Inventory (to 2002) and National Emissions Inventory (1999) data. The study population was 9,072,576 including 6,247 self-reported MS cases from NMSS-GA.

Using stepwise multivariate linear regression of census and EPA data, the best predictive model in GA for female or total prevalence rates used per capita income and coarse particles (PM-10); male prevalence rates included only per capita income.

The relationship between MS and PM-10 could be facilitated by influences of PM-10 on the systemic immune response and inflammation. More exposure and basic and clinical research are needed to understand environmental influences on MS. INDEX WORDS: Multiple Sclerosis, Environment, Georgia, Epidemiology, Air Pollutants, Toxicants, Particulate Matter 


\section{ACKNOWLEDGEMENTS}

I thank my committee members, Dr. Shendell (chair), Dr. Okosun and Dr.

Gieseker, for their support throughout this process. Also, I thank Ms. Hilary LaMotte and the National Multiple Sclerosis Society's support of this project. Most of all, I thank my wife, Denise, for her unfailing support and help throughout this process. Without these people supporting this project, this work could not have been done. 


\section{AUTHOR'S STATEMENT}

In presenting this thesis as a partial fulfillment of the requirements for an advanced degree from Georgia State University, I agree that the Library of the University shall make it available for inspection and circulation in accordance with its regulations governing materials of this type. I agree that permissions to quote from, to copy from, or to publish this thesis may be granted by the author or, in his/her absence, by the Associate Dean College of Health and Human Sciences. Such quoting, copying, or publishing must be solely for scholarly purposes and will not involve potential financial gain. It is understood that any copying from or publication of this thesis which involves potential financial gain will not be allowed without written permission of the author.

Anthony C. Gregory II

Signature of the Author. 


\section{NOTICE TO BORROWERS PAGE}

\section{Notice to Borrowers Page}

All theses deposited in the Georgia State University Library must be used in accordance with the stipulations prescribed by the author in the preceding statement.

The author of this thesis is:

Student's Name: Anthony C. Gregory II

Street Address: 6871 Peachtree Dunwoody Rd. NE, Apt 210

City, State, Zip Code: Atlanta, GA, 30328

Professor's Name: Derek Shendell, D. Env, MPH

Department: Institute of Public Health

College: College of Health and Human Sciences

Georgia State University

P.O. Box 4018

Atlanta, Georgia 30302-4018

Users of this thesis who are not enrolled as students at Georgia State University are required to attest acceptance of the preceding stipulation by signing below. Libraries borrowing this thesis for the use of their patrons are required to see that each user records here the information requested.

\begin{tabular}{|l|l|l|c|}
\hline NAME OF USER & ADDRESS & DATE & $\begin{array}{c}\text { TYPE OF USE } \\
\text { (EXAMINATION } \\
\text { ONLY OR COPYING) }\end{array}$ \\
\hline & & & \\
\hline & & & \\
\hline & & & \\
\hline & & & \\
\hline
\end{tabular}


Name: $\quad$ Anthony C. Gregory II

Address: $\quad 6871$ Peachtree Dunwoody Rd. NE, Apt 210

Atlanta, GA, 30328

\section{Education:}

2006 Bachelor of Science, Biology, Concentrations in Molecular Biology and Microbiology, Georgia State University

Honors: National Honor Society; Golden Key Society. Dean's List 2001-2002, 2003-2004. William G. Nolan Memorial Scholarship,

\section{Professional Experience:}

\section{-Masters in Public Health}

- Currently in a Masters in Public Health Program at Georgia State University

\section{-Linguistic}

- Worked as a Spanish Medical Interpreter Volunteer at Grady Memorial Hospital for 2 years

- Fluent in Spanish, native English speaker, also speaks some French

\section{-Laboratory}

- I have conducted research, for 2 years, to categorize the Cytotoxic-T Lymphocyte responses to Herpes viruses.

\section{-Leadership}

- Worked for the US Army reserves for 7 years as a Psychological Operations Specialist which specialized in all forms of communication

\section{EMPLOYMENT HISTORY}

Masters in Public Health Graduate Research Assistant

1/07-Present

Center for Disease Control and Prevention (CDC/ATSDR) intern 3/07-6/07

Spanish Translator Volunteer, Grady Memorial Hospital 5/05-5/07

B Virus Laboratory

$5 / 05-5 / 07$

US Army Reserves

$8 / 01-5 / 05$

US Army Active

$7 / 97-7 / 0$ 
Table of Contents

Chapter

Page

ACKNOWLEDGEMENTS.

iv

List of Tables and Figures................................................

List of Acronyms and Abbreviations..................................... xii

I. INTRODUCTION.................................................. 1

Background.................................................. 1

The Epidemiology of MS ...................................... 2

Research Questions................................................ 3

II Literature Review.................................................... 4

Overview of Factors............................................ 4

Genetic Factors.................................................. 5

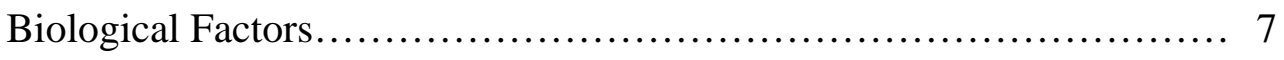

Viruses as Biological Exposure Agents ........................... 8

Sunlight and Vitamin D as Physical and Chemical Agents...................11

Other Environmental Factors........................................ 13

III. METHODOLOGY ................................................... 16

Study Purpose.................................................... 16

Data Sources..................................................... 16

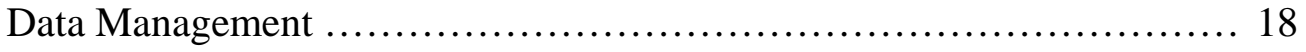

Statistical Analysis............................................. 20

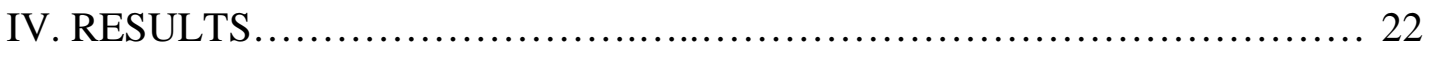

V. DISCUSSION AND CONCLUSIONS................................ 90

Summary of Figures and Tables ................................. 90

Discussion......................................................... 91 
Advantages of This Study's Methods................................ 93

Limitations of This Study's Methods................................ 94

Conclusions and Recommendations for Future Research and Policy........ 95

6. REFERENCES........................................................ 98

APPENDIXES A-C ................................................. 101 


\section{List of Tables and Figures}

Page

Table 1. Multiple Sclerosis in GA by County: Self-Reported Cases and Prevalence Rates per 100,000 Population ...................................................... 22

Figure 1. Total MS Prevalence in GA, by County: Self-Reported Prevalence Rates, November 2006. 32

Figure 2. MS Prevalence among Females in GA, by County: Self-Reported Prevalence Rates, November 2006.

Figure 3. MS Prevalence among Males in GA, by County: Self-Reported Prevalence

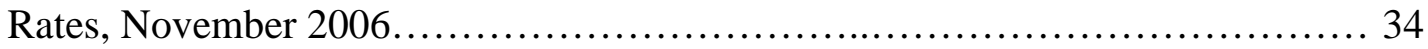

Table 2: Bivariate Linear Regression for Self-Reported Prevalence and County Level Census Data. 36

Table 3: Bivariate Linear Regression for Self-Reported Prevalence versus County Level Emissions Data.

Table 4: Bivariate Linear Regression: Total Self-Reported Prevalence versus Criteria Air Pollutant Data.

Table 5: Multivariate Linear Regression, Total MS Self-Reported Prevalence Rates and Census and NEI air pollutants

Table 6: Multivariate Linear Regression, Female MS Self-Reported Prevalence Rates and Census and NEI air pollutants

Table 7: Multivariate Linear Regression Data, Male MS Prevalence Rates and Census and NEI air pollutants

Table 8: Odds Ratios(OR) and 95\% Confidence Interval (CI) by Quartile: Census Data and Total Self-Reported MS Cases.

Table 9: Odds Ratios(OR) and 95\% Confidence Interval (CI) by Quartile: Census Data and Female Self-Reported MS Cases.

Table 10: Odds Ratios(OR) and 95\% Confidence Interval (CI) by Quartile: Census Data and Male Self-Reported MS Cases.................................. 59

Table 11: Odds Ratios(OR) and 95\% Confidence Interval (CI) by Quartile: County Level Emissions and Total MS Self-Reported Cases. 
Chapter Page

Table 12: Odds Ratios(OR) and 95\% Confidence Interval (CI) by Quartile: County Level Emissions and Female Self-Reported MS Cases....................... 69

Table 13: Odds Ratios(OR) and 95\% Confidence Interval (CI) by Quartile: County Level Emissions and Male MS Self-Reported Cases........................... 74

Table 14: Odds Ratios(OR) and 95\% Confidence Interval (CI) Organized by Quartile: Criteria Air Pollutants and Total MS Self-Reported Cases ...................... 79

Table 15: Odds Ratios(OR) and 95\% Confidence Interval (CI) Organized by Quartile: Criteria Air Pollutants and Female MS Self-Reported Cases ...................... 83

Table 16: Odds Ratios(OR) and 95\% Confidence Interval (CI) Organized by Quartile: Criteria Air Pollutants and Male MS Self-Reported Cases ....................... 87 


\section{List of Acronyms and Abbreviations}

CI: Confidence Interval

CO: Carbon Monoxide

EAE: Experimental Autoimmune Encephalomyelitis (the mouse Multiple Sclerosis model)

EBNA: Epstein-Barr Nuclear Antigen

EBV: Epstein-Barr Virus

EPA: United States (U.S.) Environmental Protection Agency

GA: Georgia

HLA: Human Leukocyte Antigen

HHV: Human Herpes Virus

IRB: Institutional Review Board

IgE: Immunoglobulin Type E

MS: Multiple Sclerosis

NMSS-GA: Multiple Sclerosis Society- Georgia Chapter

NEI: National Emissions Inventory (of the U.S. EPA)

$\mathrm{NO}_{\mathrm{x}}$ : Nitrogen Oxides

OR: Odds Ratio (Please note, in this study, OR signified Prevalence Odds Ratio)

PM: Particulate Matter

RR: Relative Risk

RRMS: Relapsing Remitting Multiple Sclerosis

PPMS: Primary Progressive Multiple Sclerosis

$\mathrm{SO}_{2}$ : Sulfur Dioxide

TRI: Toxic Release Inventory (of the U.S. EPA)

VOC: Volatile Organic Compounds 


\section{Introduction}

Background

Throughout time, physicians and researchers have studied thousands of diseases and conditions. In that process, they have found many causes, influencing factors and treatments. However, some diseases still present challenges with respect to determining their causes. One of those challenges is Multiple Sclerosis (MS), a disease that was first identified hundreds of years ago and that affects millions of people across the globe. MS is the most common demyelinating disease of the central nervous system. In 1992, Anderson et al (Anderson et al. 1992) estimated in the United States between 250,000 and 350,000 people have been affected by this disease.

MS is a disease in which the body’s immune cells attack neuronal myelin sheaths. (Keegan and Noseworthy 2002) In healthy individuals, these sheaths help the neurons to conduct messages to other neurons by covering most of the outside of the neuron's axon. This covering mediates faster neurological signals. Due to continued attacks in MS, the myelin is destroyed, and, hence, the nerves are less efficient in conducting electrical signals. Local inflammation may further damage the neuronal axons, the long extensions that help conduct electrical signals from one part of the neuron to the other. The continued degeneration of the myelin may lead to extreme fatigue and progressively less ability to move. This process is suspected to be mediated largely by T-helper-1 cells (Th1). The degeneration seen in this disease is 
primarily diagnosed by magnetic resonance imaging (MRI); however, MRI specificity makes diagnosis difficult. (Fazekas et al. 1999)

\section{The Epidemiology of MS}

The epidemiology of MS is also important to consider. In areas with higher MS prevalence, like Europe and North America, the prevalence of MS seems to vary from 60 to 200 per 100,00 population, while in lower MS areas, like Japan, these

prevalence rates are around 6-20 per 100,000. Of note, even though the prevalence of MS is lower in Asian countries, Japan has the highest prevalence of MS among Asian countries. Japan is also one of the most developed countries in Asia. Thus, there are geographical differences in the MS distribution. These differences are probably due to a variety of genetic and environmental characteristics of these areas. (Sospedra and Martin 2005; Sospedra et al. 2005)

A descriptive MS study was conducted by Williamson et al. (Williamson 2007) in 19 counties surrounding Lubbock, Texas. This study found the prevalence of MS in this region per 100,000 population was 42.8 overall, 68.6 in females and 16.6 in males. Also, the prevalence per 100,000 population was 56.0 in non-Hispanic whites, 22.1 in non-Hispanic blacks, and 11.2 in Hispanics. They also reported the 40-59 year-old age groups had the highest prevalence of MS; the 40-49 year-old group had 103.1 per 100,000 and the 50-59 year-old group had 119.9 per 100,000 . (Williamson et al 2007) In addition to this, the prevalence of MS has varied widely 
throughout the world (Baum and Rothschild 1981; Mayer 1981) (Rosati 2001) (de la Maza et al. 2000), (Kurtzke 2000)

There seems to be little definitive information as to the etiology of MS. Although there are many theories about the exact role of genetics, immune cells, viruses, and other possible agents, there is little consensus about a single casual element for MS. Thus, it is evident MS is a complex disease, and MS embodies a multitude of genetic and environmental factors like exposure to certain viruses, chemicals, and possibly environmental air pollutants subject to regulation.

Research Questions

The motivation for this study comes from the knowledge of the lack of geographical models of MS and the lack of information as to the potential impacts of environmental air pollutants in MS. With these focuses in mind, several research questions were created for this thesis.

1. What is the distribution of the prevalence of MS in GA?

2. How does this distribution relate to census data?

3. How does the distribution of MS relate to environmental air pollutants?

4. Using both environmental air pollutants and census data, what is the best predictive model for the MS distribution in GA?

5. Is there a dose-response-like relationship between the MS distribution in GA and specific, census selected data characteristics or environmental air pollutants? 


\section{Literature Review}

Overview of Factors

Many factors, both genetic and environmental, have been associated with MS (Hogancamp et al. 1997). Of the genetic factors, twin studies have been instrumental. These studies have compared monozygotic twins (or identical twins, which have identical genetic information) and dizygotic twins (or paternal or non-identical twins, which have different genetic information) to determine if there is a significant genetic role for MS. Gender-related genetic factors have also been identified.

Aside from the genetic role, many biological factors have also been identified through scientific research. This research is commonly done in animal models for MS as a surrogate to conducting these studies in humans.

Environmental factors have also shown significant association with MS. For example, Mayer et al. (1981) found mean annual hours of sunshine and mean annual temperature were protective of MS. Conversely, infection with certain viruses (Keegan et al. 2002, Berti et al. 2002, (Soldan et al. 1997), distance from the equator (Mayer 1981), low average amount of daily sunlight (Freedman et al. 2000), lack of Vitamin D (Cantorna et al. 1996; Cantorna et al. 1998; Spach and Hayes 2005), exposure to heavy metals (Henry et al. 2007), per capita steel consumption (Mayer 1981), number of physicians per capita (Mayer 1981), literacy rate (Mayer 1981), gross energy consumption, gross national product, per capita and food consumption are associated with higher rates of MS (Mayer 1981). Among the many factors that may play a role in MS, viruses have been commonly cited as a common factor that 
may influence the acquisition and progression of MS. More details by category now follow.

\section{Genetic Factors}

There have been several genetic clues to the etiology of MS. Twin studies have been an important part in the etiology of MS, because identical twins have identical genetic information, while fraternal twins do not. Twins are both the same age, and, assuming that they have similar environmental exposures, one can estimate the relative role of genetics in a disease. In twin studies conducted for MS, a significantly higher prevalence of MS was found in monozygotic twins when compared to dizygotic twins (de Rezende and Arruda 1996; Hansen et al. 2005; Keegan and Noseworthy 2002). First-degree relatives of affected people had an about 20 to 50-fold (2\%-5\%) higher risk to develop MS. Also, concordance rates in monozygotic twins varied between $20 \%$ and 35\% in different studies, and recent studies estimated the concordance rate at 25\%. (Dyment et al. 2004) (Ebers et al. 1996) This higher prevalence of MS in monozygotic twins suggested there was a significant role of genetics in MS.

The population of people affected by MS has been categorized. Females are more susceptible than males (1.6:1), but this difference is evident in Relapsing Remitting Multiple Sclerosis (RRMS), in which the person recovers completely, but not in Primary Progressive Multiple Sclerosis (PPMS), in which the patient never completely recovers. (Keegan and Noseworthy 2002) (Thompson et al. 1997) (Weinshenker 1998) 
Aside from the higher risk of MS in women, other studies have supported the notion female hormones may play a role in MS. In one of these studies, Runmarker and Anderson (1995) analyzed the risk of MS before, during and after pregnancy in a cohort of Swedish women. They found there was a significantly decreased risk of MS during pregnancy. Furthermore, they found after birth the risk did not differ significantly from periods when the women were not pregnant. Also, they found women who have given birth had a lower risk of MS than women who had not given birth. Lastly, they found a significantly lower risk of progressing from RRMS to PPMS in the group of women who became pregnant after the onset of MS, when compared to non-pregnant control patients.

These findings suggested there may be some role of pregnancy hormones in MS, and other studies have also reported this same relationship. Sicotte et al. (2002) found treatment of RRMS patients with estradiol (a pregnancy hormone) resulted in significant decreases in the number of lesions found during monthly magnetic resonance imaging. This same protective effect of estradiol was seen in a later experiment conducted by Soldan et al. (Soldan 2003). Both studies surmised this change may be due to the hormone's effect of changing T-helper 1 immune responses to T-helper-2 immune responses. (NL Sicotte 2002; Soldan 2003)

In addition to gender-roles, some racial and ethnic groups have been associated with generally higher rates of MS. According to Rosati et al. (2001), MS was rare among Samis, Turkmen, Uzbeks, Kazakhs, Kirghizis, native Siberians, North and South Amerindians, Chinese, Japanese, African blacks and New Zealand 
Maoris. Contrarily, they also saw a higher risk for MS among Sardinians, Parsis and Palestinians. Also, other researchers have reported a significantly higher risk for MS in people of Northern European descent, although there was a lower prevalence of MS in New Zealand (Keegan and Noseworthy 2002).

Biological Factors

Scientific experiments have been used to attempt to discover more biological clues to the cause of MS. The animal-model of MS is known as Experimental Autoimmune Encephalomyelitis (EAE). To induce EAE in mice, scientists exposed them to myelin basic protein, a protein similar to proteins found in myelin of most animals. Thus, the immune cells will react to this protein and also to natural myelin surrounding murine neurons. Catorna et al. (1996, 1998) and Spach et al. (2005) conducted experiments in the mouse model for Multiple Sclerosis.

EAE studies have been largely a part of determining the immunological basis for MS. Through EAE studies, scientists determined that CD4+ T-helper 1 cells might be mediating this disease. This determination was made upon realizing that transferring these CD4 Th1 cells could transfer EAE from an affected mouse to an unaffected mouse. Transferring antibodies has not been effective for transferring EAE, and transferring CD8+ cells has only been effective in transferring EAE in two instances. The genetic sequence of human leukocyte antigen (HLA) class II molecules is the strongest genetic risk for MS, and some studies also supported the idea that CD4 Th1 mediates MS. (Sospedra and Martin 2005; Sospedra et al. 2005) (Oksenberg et al. 2001) Furthermore, there may be variation in these HLA genes, as 
Ito et al. (Ito et al. 1998) found increased susceptibility with the western-type MS but not with the Japanese-type MS.

Viruses as Biological Exposure Agents

In addition to the EAE animal model, there is Theiler's murine encephalomyelitis virus model, in which a virus is deposited into susceptible mice, the mice develops an encephalomyelitis, and this leads to neuron and myelin degeneration (Dal Canto et al. 1995).

In addition to the virus-mediated animal MS model, several authors have proposed viruses may cause or exacerbate MS. Soldan and others (1997) showed that IgM, a common antibody for early stages of infection for Human Herpes virus 6 (HHV-6), was increased in RRMS when compared to PPMS. They also showed HHV-6 serum DNA in MS patients (Soldan et al. 1997). Berti et al. (2002) confirmed the presence of HHV-6 DNA in MS patients, and they stated the presence of HHV-6 DNA was correlated with MS progression. These studies, together, suggested there may be a role of HHV-6 in MS. In addition, the association between the viral DNA titers and MS progression suggested as the amount of total virus burden increased, there may also be increased severity of MS. (Berti et al. 2002)

Several other studies also lend credibility to the role of HHV-6 in the etiology of MS (Akhyani et al. 2000; Kong et al. 2003; Tejada-Simon et al. 2003; Virtanen et al. 2005). In a previous study, Berti et al. (2000) found an increased frequency of HHV-6 DNA in the serum, saliva, urine, and peripheral blood lymphocytes when compared to controls. Kong et al. (2003) found HHV-6 may play a role in 
degenerating oligodendrocytes, the cells that help to nurture and create myelin. Tejad-Simpson et al. (2003) found 50\% of T-cells were treated with HHV-6 residues cross-reacted with myelin basic protein. This suggested T-cells that have seen foreign HHV-6 proteins may have mistakenly learned that myelin was also foreign; therefore, these T-cells may have mounted an immune response to neuronal myelin. In a study about MS and control brain tissue, Virtanen et al. (2005) found HHV-6 in the same place as MS lesions more often then in control brains.

One study found HHV-6 was not related to MS. In this study, Tuke et al. (2004) found there was no difference in distribution, virus type, or quantity of HHV-6 in MS patients when compared with control patients.

In addition to the possible role of HHV-6, Epstein Barr Virus (EBV) has also been associated with MS. (Hernan et al. 2001; Levin et al. 2003) They determined the presence of a Epstein Barr Virus Nuclear Antigen (EBNA) was associated with an increased risk of MS (Hernan et al. 2001). In a similar study, Levin et al. (2003) also found the risk of MS increased as the antibody titer to EBV antigens increased. When these authors compared the lowest EBNA titer level with the highest, they found the relative risk for MS was 33.9 (95\% CI=4.1-283) (Levin et al. 2003; Levin et al. 2005). Another researcher, Lunemann et al. (2006), found EBNA-specific CD4+ memory T Cells (T-helper cells) were much more common than any other type of EBV antigen in MS patients who were seropositive for EBV.

Several other authors have presented studies supporting the role of EBV in the etiology of MS. (Cepok et al. 2005; Haahr et al. 2004; Lunemann et al. 2006; Sumaya 
et al. 1985; Wandinger et al. 2000) Sumaya et al. (1985) found a greater antibody response to EBV antigen in MS patients when compared to controls. Furthermore, Wandinger et al. (2000) found antibodies to EBV in 100\% of all the MS patients in their study. Cepok et al. (2005) found immune-cell reactivity for EBNA was much higher in the serum and cerebrospinal fluid of MS patients when compared with control patients. Haahr et al. (2004) found a high-MS prevalence area had more than one third of children who were seronegative for EBV. They also found 100\% of MS patients in their sample were positive for EBV. Thus, they posited EBV was transmitted to a large portion of the population during or after puberty in the high-MS prevalence area. Finally, Wagner et al. (2004) found there was an increased risk of MS in people who have EBV in the serum, even after adjusting or smoking, ancestry, and latitude of residence.

There seems to be some similarities between both HHV-6 and EBV. Both viruses are herpes viruses, and they both replicate slowly. Beta herpes viruses, like HHV-6, are known for infecting cells, and cells infected typically become larger. EBV, also known as Human Herpes Virus 4, is a gamma herpes virus, which is known for being associated with lymphocytes. Also, gamma herpes viruses were found to be able to induce cell-proliferation. This is important because T-cell proliferation and activation usually precedes T-cell immune responses. Also, proliferation and activation of other cells may lead to the characteristic inflammation found in many MS patients. (Hong et al. 2000; Levin et al. 2005) 


\section{Sunlight and Vitamin D as Physical and Chemical Agents}

Other environmental exposures like mean hours of sunshine and vitamin D have been associated with a lower prevalence of MS (Mayer 1981; Munger et al. 2004) Mayer et al. (1981) found mean annual hours of sunshine and mean annual temperature. Freedman et al. studied the deaths from MS for the years of 1984 and 1995 in 24 states of the U.S. (2000), and found a 43\% decrease in MS rates amongst those with the highest category of sun exposure. Through their analysis, they also found under high sunlight exposures black and white men and women received a protective effect of sunlight. This information suggested sunlight had a significant physiological role that helped to mitigate MS in these two racial groups.

Several authors supported the potential role of average incident sunlight in MS by showing a gradually increasing diagnosis of MS in the higher latitudes (Keegan et al. 2002, Mayer et al. 1981, Rosati et al. 2001). Seasonal fluctuations may influence MS, with most attacks occurring in the most extreme temperatures of summer and winter (Ogawa et al. 2004). Taken together, these authors suggested some environmental factors related to sunlight may affect MS prevalence.

To characterize the relationship between sunlight and the incidence of MS, Munger et al. (2004) studied the role of vitamin D, which is primarily produced by the body through sunlight exposure or ingested in the form of daily vitamins. Through the Nurses Health Study I and II, they analyzed the role of behaviors, like taking daily vitamins, on the incidence of several diseases. They found there was a significantly lower relative risk $(R R=0.59 ; 95 \% C I=0.38$ to $0.91 ; p$ for trend $=0.006)$ 
for MS in women who are taking 400 IU of vitamin D per day, when compared to those who did not take this supplement. They also found this relationship was not seen for vitamin D taken through food, and this relationship was dose dependent. These analyses suggested the ingested daily vitamin may have protective effects for MS. The dose response suggested environmental exposure of sunlight and the dose of vitamin D both have effects on the incidence and prevalence of MS.

Cantorna et al (1996) found 20 ng/day of Vitamin D completely prevented disability in EAE induced mice; the mice were given a calcium diet, but only the experimental mice were given 20 ng of vitamin D. Also, this regimen seemed to halt progression of EAE after it reached the earliest stage (limp tail in mice), and when the vitamin D was removed, EAE progression returned to the normal level. Cantorna et al (1998) further categorized the role of vitamin D in a later experiment, where they reported systemic and local increases in two anti-inflammatory cytokines, facilitated by Vitamin D, may be responsible for blocking EAE. These experiments suggested that vitamin D may not only prevent Multiple Sclerosis in some cases, but also vitamin D may be able to halt or slow the progression of MS in mice. Although we are unsure if this experiment has the same effects in humans, it provides great insight into the interaction between vitamin D and MS.

In a separate EAE experiment, Spach et al. (2005) found ultraviolet-light exposed, vitamin D(3)-fed female mice had less clinical, histopathological and immunological signs of EAE than ovariectomized females or intact or castrated males. They summarized this effect seemed to show synergy between vitamin D and 
ovarian tissue with regard to EAE inhibition. They further hypothesized an ovarian hormone inhibited CYP24A1 expression, which encodes a vitamin D inactivating enzyme, in the spinal cord, and so 1,25-dihydroxyvitamin D (vitamin D) accumulated and resolved the inflammation before severe EAE developed. Lastly, they speculated sunlight deprivation would increase the MS risk more significantly in women than in men, which may contribute to the unexplained higher MS incidence in women than in men. (Spach and Hayes 2005) If this study can be extrapolated to humans, it may suggest women may benefit more than men from taking vitamin D, and it may help to partially explain the higher incidence of MS in women.

Other Environmental Factors

Several other types of environmental exposures have been shown to be potentially associated with the prevalence and incidence rates of MS. Seasonal fluctuations have been associated with MS in a study conducted in Japan by Ogawa et al. (2004). They found optico-spinal and brain MS complications were significantly higher in Japan during the coldest (January and February) and hottest months (July and August) of the year. They also theorized common infections occurring during the cold season, such as sinusitis, may play a role in these seasonal fluctuations of MS. (Ogawa et al. 2004)

In another study, Edwards et al. (1998) suggested there was a relationship between infections and MS exacerbations. They reported a twofold increase in MS exacerbations ( $\mathrm{p}=0.004$, OR 2.0, CI 1.3-3.2) during symptomatic upper respiratory track infections that lasted more than 24 hours when compared to periods without 
symptomatic upper respiratory tract infections. Thus, these researchers found upper respiratory tract infections, which may be caused by viruses, may also affect the frequency of MS symptoms.

Henry et al. (2007) analyzed MS in cohorts based in two Texas schools. They reported 22 of the women in their study had MS, and they found a crude prevalence estimate of 411 per 100,000 population. Also, they established three of the 22 women, who had childhood hair samples collected and archived to test for heavy metals exposure, had elevated levels of lead and mercury in their childhood hair. Several authors have also proposed a potential role of heavy metals in new clusters of MS cases (Ingalls 1986) (Landrigan et al. 1975). In addition to this, Williamson and Henry (2004) acknowledged there has been community concern over the possible role of toxins from hazardous waste sites in new cases of MS.

Few studies have focused on the roles of environmental air in the incidence and progression of MS. One study on this subject was conducted in Finland by Oikonen et al. (2003). In this study, the role of ambient air quality was found to be associated with MS prevalence. In this study, the researchers found MS relapse was associated with PM-10 concentrations in southern Finland. They found there was a strong interaction between PM-10, $\mathrm{CO}$ and acidic gases $\left(\mathrm{NO}_{\mathrm{x}}\right.$ and $\left.\mathrm{SO}_{2}\right)$. Thus, they used multivariate logistic regression to attempt to differentiate the roles of acidic gases and the roles of PM-10 from each other. They found the odds of relapse was $4.143(\mathrm{p}<0.001)$ following a one-month lag after peak levels of PM-10. They also found an even larger odds ratio for acidic gases one month after peak levels 
(OR=9.285, 95\% CI=2.744, 31.418). These results, however, must be interpreted with caution due to small sample sizes and crude exposure estimates.

Also, another study found that environmental exposure to radon may be a contributory factor in MS. In this study, Bolviken et al (Bolviken et al. 2003) assessed the correlation between radon exposure and MS, and they found a positive correlation $(\mathrm{p}<0.01)$. They surmised that Radon inhaled in air maybe contributory factor to MS.

These data suggested that MS relapse may be associated with high rates of environmental air pollutants in Finland. With this in mind, the purpose of this study will be to assess the suspected role of environmental air pollutants in MS, using data on source emissions and MS in the state of Georgia by county. 


\section{Methods}

The GSU Institutional Review Board (IRB) approved this study in February 2007 (approved protocol \# H07341). To receive approval, the methodology and supporting documents were submitted to GSU through an on-line system, IRBWise.

Study purpose

This study is designed to estimate the county-level prevalence and distribution of MS throughout Georgia (GA). In addition, this study will determine if the distribution of MS in GA is associated with the distribution of census data, toxic release inventory (TRI) data and source emission to outdoor air from the National Emissions Inventory database (NET) of criteria air pollutants. Also, this study will attempt to determine which of these three data relate best to the distribution of MS in

GA. Lastly, this study will endeavor to determine if there is a dose response relationship between the distribution of MS and the census or air pollutant data.

Data Sources

The data for this study comes from the National Multiple Sclerosis Society (NMSS), the United States Census Bureau, and Scorecard.org, by Environmental Defense, which assimilated county-level air and water emissions data in the United States. (US Census 2005, Scorecard 2005) The final population for this study was 9,072,576 people, including 6247 self-reported MS cases from the NMSS-GA chapter. 
MS data were received from the National Multiples Sclerosis Society’s GA chapter in November 2006. These data included the self-reported MS cases of the current MS Society member's list as of November 2006. The data obtained for this study includes the number of people diagnosed with multiple sclerosis, their gender, and their county of residence. The NMSS, as part of their membership questionnaire, originally received this information.

Selected census data were retrieved for each of the 159 Georgia counties. These data included the total county population, the percent female in 2005, the 2005 female and male population estimates, the percent white and the percent black. In addition, the percent living in the same house in 1995 and 2000, the per capita income, in 1999, the square miles land area in 2000, and the people per square mile in 2005 was also obtained for this study.

Also, using scorecard.org, which provided a database of Toxic Release Inventory (TRI) source emissions from the U.S. Environmental Protection Agency (EPA) for various categories of toxicants and criteria air pollutants, county level air pollutant emissions were obtained. The data used for this study included 2002 source emissions in pounds: recognized carcinogens, suspected carcinogens, suspected cardiovascular or blood toxicants, recognized developmental toxicants, suspected developmental toxicants, suspected endocrine toxicants, suspected endocrine toxicants, suspected immunotoxicants, suspected kidney toxicants, suspected gastrointestinal or liver toxicants, suspected muscoskeletal toxicants, suspected 
neurotoxicants, recognized reproductive toxicants, suspected reproductive toxicants suspected respiratory toxicants, suspected skin and sense toxicants, acetaldehyde, ammonia, formaldehyde, manganese, and lead and lead compounds.

In addition to these, the National Emissions Inventory (NEI) Air Pollutant Emissions Trends data, which were measurements led by the U.S. EPA, were obtained through scorecard.org. NEI is a collection of source emissions to outdoor air from state, local, tribal and industrial measures. From NEI, this study used criteria air pollutants reported for 1999 in tons: carbon monoxide, nitrogen oxides, particulate matter (PM) 2.5, PM 10, sulfur dioxide, and volatile organic compounds (total, selected individual). Each compound was surveyed for mobile, area, and point sources; the three source categories together were termed "all sources."

It is important to state this study did not assume source emissions are the same as measured concentrations in outdoor air or actual human exposure. Rather, this study used source emissions as a surrogate measure for exposure to environmental air pollution, selected groups of toxicants and criteria air pollutants subject to regulation.

\section{Data Management}

For this study, a MS case was defined as a person being diagnosed previously with MS, according to the NMSS entrance survey, and residing in GA. Furthermore, the number of controls was calculated using the 2005 U.S. Census population for each county, minus the number of MS cases in that county. Lastly, prevalence signified the county self-reported case prevalence per 100,000 population. 
Several assumptions were necessary for this analysis. We assumed the NMSS-GA member list included accurate data members answered truthfully as to their diagnosis of MS and their gender. Also, we assumed the TRI and NEI data were received and displayed in scorecard.org's website and it was accurately reported by the private and public sector per the Emergency Planning and Community Right-toKnow Act of 1986, which established TRI.

This study used cross-sectional data at several different time points. The study was designed to determine the prevalence of MS in GA and to explore the relationship between environmental air pollutants and MS in GA. With that purpose in mind, we used November 2006 cross sectional data from the MS Society’s GA chapter. These data were compared to the county-level emissions data using both regression (a measurement of association) and odds ratios.

Female and male prevalence rates were calculated for each of the counties in GA by dividing the number of cases in each county by the total county population and multiplying this number by 100,000 . Thus, each of the prevalence ratios shows a population-density-controlled rate for each county. The database was stored in both SPSS version 14 (SPSS 2005) and Microsoft Excel 2004 (Microsoft-Corporation 2004). These prevalence rates were made into a geographical image using CorelDraw by tracing the image of a map of GA and placing the prevalence rates in their respective counties. After this was done, each county was shaded according to 
the county’s prevalence rate. This same process was done for total, female, and male, MS rates in GA per 100,000 population.

Statistical Analysis

Statistical analysis was done using both SPSS version 14 (2005) and Microsoft Excel 2004 (Microsoft-Corporation 2004). Bivariate linear regression was used to determine association between the prevalence rates and each of the census data or emissions data variables. Standardized beta values were calculated for each of these associations, and the statistical significance was calculated using a two-tailed ttest. Finally, R-squared values were also calculated for each model. R-squared represents the amount of variance in the model (this model's female self reported MS prevalence in GA) that can be attributed to the study characteristic (eg. Percent female 2005).

Stepwise multivariate linear regression was calculated using SPSS. This was done with an entry criterion of a p-value of 0.05 and an exit criterion of a p-value of 0.10. With this method, we analyzed which of the census and NEI variables were most related to the county MS prevalence in GA, overall (total) and by gender.

Odds ratios (ORs) were calculated for each of the census characteristics, each of the toxicants, and each of the criteria air pollutants. It is important to mention the odds ratios in this study referred to the prevalence odds ratio because the cases used in this study indicated prevalence, not incidence. The counties with data for the variable being analyzed were separated into quartiles by SPSS for Windows version 
14. The total number of cases or controls was added for each of the quartiles and these numbers were used to calculate the ORs. The lowest quartile was always used as the reference group. Then, the $2^{\text {nd }}, 3^{\text {rd }}$ and $4^{\text {th }}$ quartiles were compared to the lowest quartile using EPI Info version 6.04 (CDC 2001). Finally, data were analyzed statistically at the $0.05,0.01,0.001$, and 0.0001 levels. Once all of the analyses were done, the tables were constructed using Microsoft Excel 2004. 


\section{Results}

Table 1 shows the Multiple Sclerosis cases and self-reported-case prevalence rates by county. In the 159 counties in GA, the prevalence rates varied widely; the rates were not equally distributed from county to county. Also, these self-reported cases are $71.5 \%$ female, $22.3 \%$ male, and $6.2 \%$ unknown gender.

Table 1. Multiple Sclerosis in GA by County: Self-Reported Cases and Prevalence Rates per 100,000 Population.

\begin{tabular}{|c|c|c|c|c|c|c|c|}
\hline County name & $\begin{array}{l}\text { Nov. } \\
2005 \\
\text { total } \\
\text { cases } \\
(\mathrm{N}= \\
6247) \\
\end{array}$ & $\begin{array}{l}\text { Nov. } \\
2005 \\
\text { female } \\
\text { cases } \\
(\mathrm{N}= \\
4466)\end{array}$ & $\begin{array}{l}\text { Nov. } \\
2005 \\
\text { male } \\
\text { cases } \\
(\mathrm{N}= \\
1392)\end{array}$ & $\begin{array}{l}\text { Nov. } 2005 \\
\text { unknown } \\
\text { gender } \\
\text { cases } \\
(\mathrm{N}=389)\end{array}$ & $\begin{array}{l}\text { Nov. } 2005 \\
\text { total } \\
\text { prevalence } \\
\text { rates* (per }^{*} \\
100,000 \\
\text { people) }\end{array}$ & $\begin{array}{l}\text { Nov. } 2005 \\
\text { female } \\
\text { prevalence } \\
\text { rates* (per }^{*} \\
100,000 \\
\text { women) }\end{array}$ & $\begin{array}{l}\text { Nov. } 2005 \\
\text { male } \\
\text { prevalence } \\
\text { rates }^{*} \text { (per } \\
100,000 \text { men) }\end{array}$ \\
\hline Appling & 3 & 3 & 0 & 0 & 17 & 33 & 0 \\
\hline Atkinson & 2 & 1 & 1 & 0 & 25 & 25 & 25 \\
\hline Bacon & 1 & 1 & 0 & 0 & 10 & 19 & 0 \\
\hline Baker & 0 & 0 & 0 & 0 & 0 & 0 & 0 \\
\hline Baldwin & 18 & 8 & 9 & 1 & 40 & 38 & 37 \\
\hline Banks & 8 & 6 & 2 & 0 & 50 & 76 & 25 \\
\hline Barrow & 41 & 32 & 8 & 1 & 68 & 107 & 27 \\
\hline Bartow & 60 & 44 & 13 & 3 & 67 & 98 & 29 \\
\hline Ben Hill & 7 & 4 & 3 & 0 & 40 & 44 & 36 \\
\hline Berrien & 9 & 7 & 2 & 0 & 54 & 83 & 24 \\
\hline
\end{tabular}




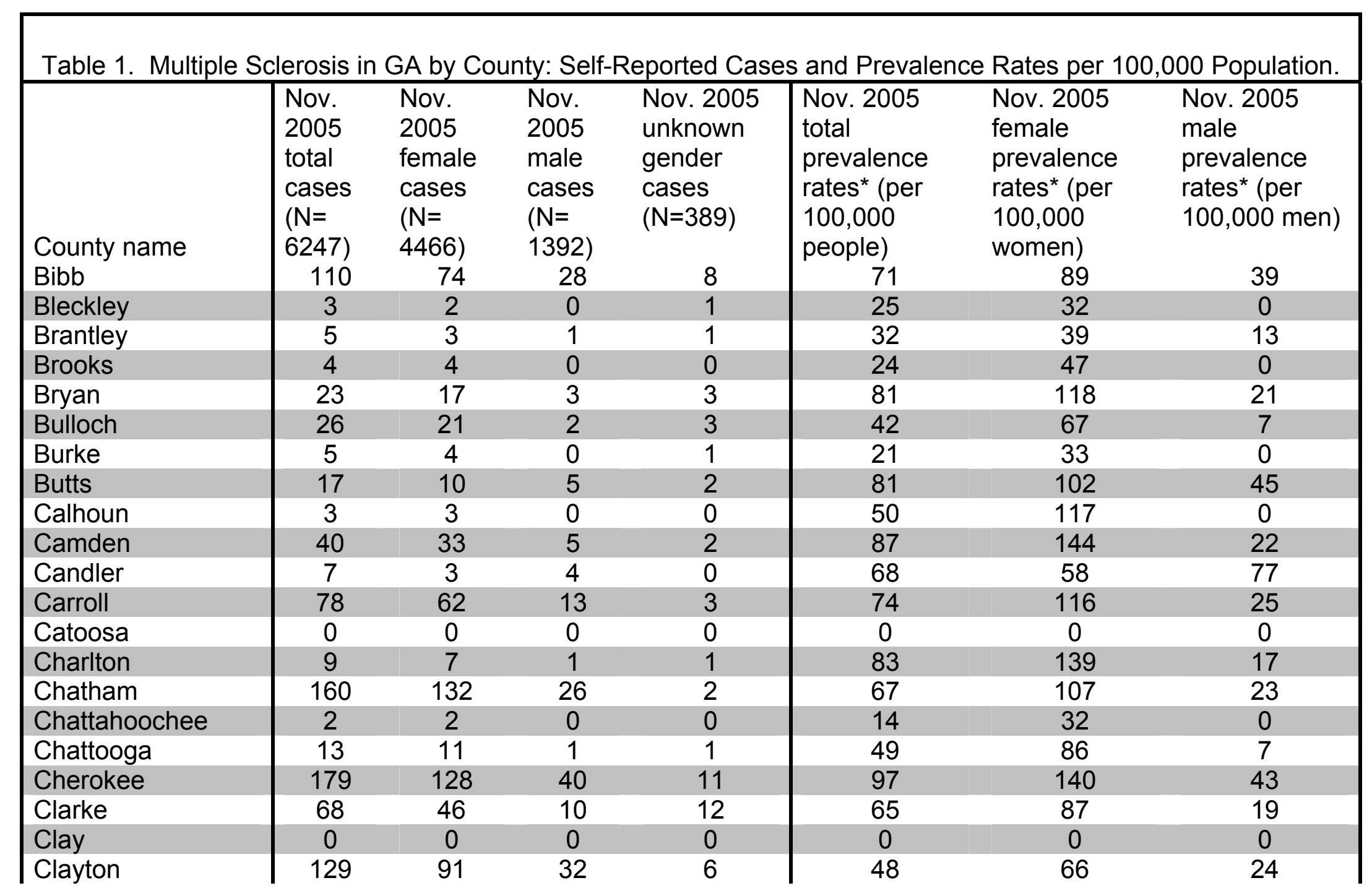




\begin{tabular}{|c|c|c|c|c|c|c|c|}
\hline County name & $\begin{array}{l}\text { Nov. } \\
2005 \\
\text { total } \\
\text { cases } \\
(\mathrm{N}= \\
6247)\end{array}$ & $\begin{array}{l}\text { Nov. } \\
2005 \\
\text { female } \\
\text { cases } \\
(\mathrm{N}= \\
4466)\end{array}$ & $\begin{array}{l}\text { Nov. } \\
2005 \\
\text { male } \\
\text { cases } \\
(\mathrm{N}= \\
1392)\end{array}$ & $\begin{array}{l}\text { Nov. } 2005 \\
\text { unknown } \\
\text { gender } \\
\text { cases } \\
(\mathrm{N}=389)\end{array}$ & $\begin{array}{l}\text { Nov. } 2005 \\
\text { total } \\
\text { prevalence } \\
\text { rates* (per }^{*} 100,000 \\
\text { people) }\end{array}$ & $\begin{array}{l}\text { Nov. } 2005 \\
\text { female } \\
\text { prevalence } \\
\text { rates* (per }^{*} 100,000 \\
\text { women) }\end{array}$ & $\begin{array}{l}\text { Nov. } 2005 \\
\text { male } \\
\text { prevalence } \\
\text { rates* (per }^{*} \\
100,000 \text { men) }\end{array}$ \\
\hline Clinch & 5 & 2 & 3 & 0 & 71 & 57 & 87 \\
\hline Cobb & 670 & 473 & 154 & 43 & 101 & 142 & 47 \\
\hline Coffee & 8 & 6 & 2 & 0 & 20 & 30 & 10 \\
\hline Colquitt & 26 & 17 & 6 & 3 & 59 & 78 & 27 \\
\hline Columbia & 95 & 67 & 21 & 7 & 92 & 126 & 41 \\
\hline Cook & 6 & 6 & 0 & 0 & 37 & 71 & 0 \\
\hline Coweta & 92 & 70 & 12 & 10 & 84 & 127 & 22 \\
\hline Crawford & 6 & 3 & 2 & 1 & 47 & 47 & 31 \\
\hline Crisp & 8 & 6 & 2 & 0 & 36 & 52 & 19 \\
\hline Dade & 0 & 0 & 0 & 0 & 0 & 0 & 0 \\
\hline Dawson & 18 & 12 & 3 & 3 & 91 & 123 & 30 \\
\hline Decatur & 8 & 7 & 1 & 0 & 28 & 47 & 7 \\
\hline Dekalb & 547 & 373 & 138 & 36 & 81 & 107 & 42 \\
\hline Dodge & 9 & 7 & 1 & 1 & 46 & 75 & 10 \\
\hline Dooly & 3 & 1 & 2 & 0 & 26 & 18 & 33 \\
\hline Dougherty & 44 & 38 & 5 & 1 & 46 & 75 & 11 \\
\hline Douglas & 92 & 64 & 26 & 2 & 82 & 112 & 47 \\
\hline Early & 5 & 5 & 0 & 0 & 41 & 78 & 0 \\
\hline Echols & 1 & 0 & 0 & 1 & 24 & 0 & 0 \\
\hline Effingham & 29 & 24 & 4 & 1 & 62 & 102 & 17 \\
\hline Elbert & 9 & 8 & 1 & 0 & 43 & 74 & 10 \\
\hline
\end{tabular}




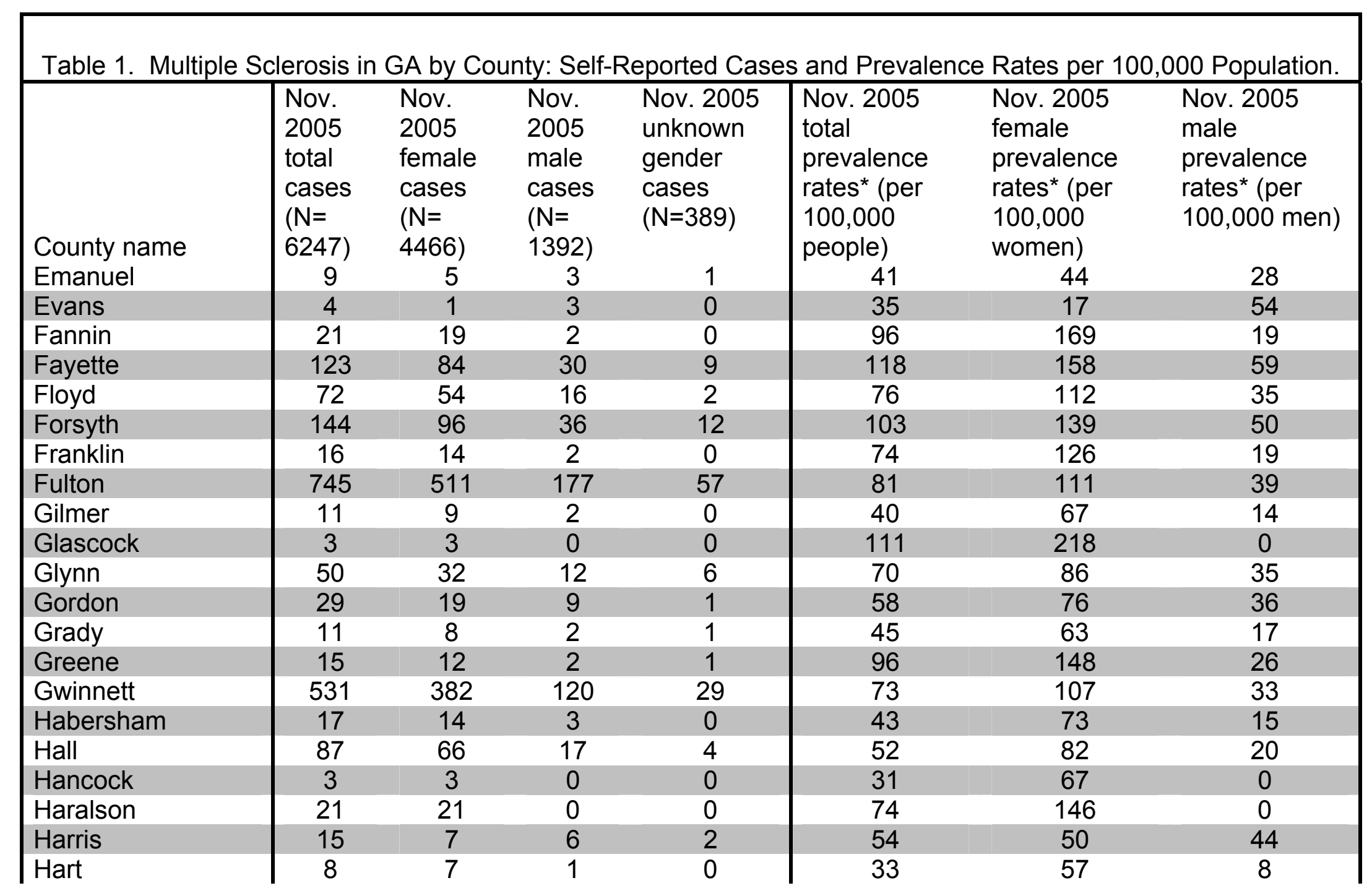




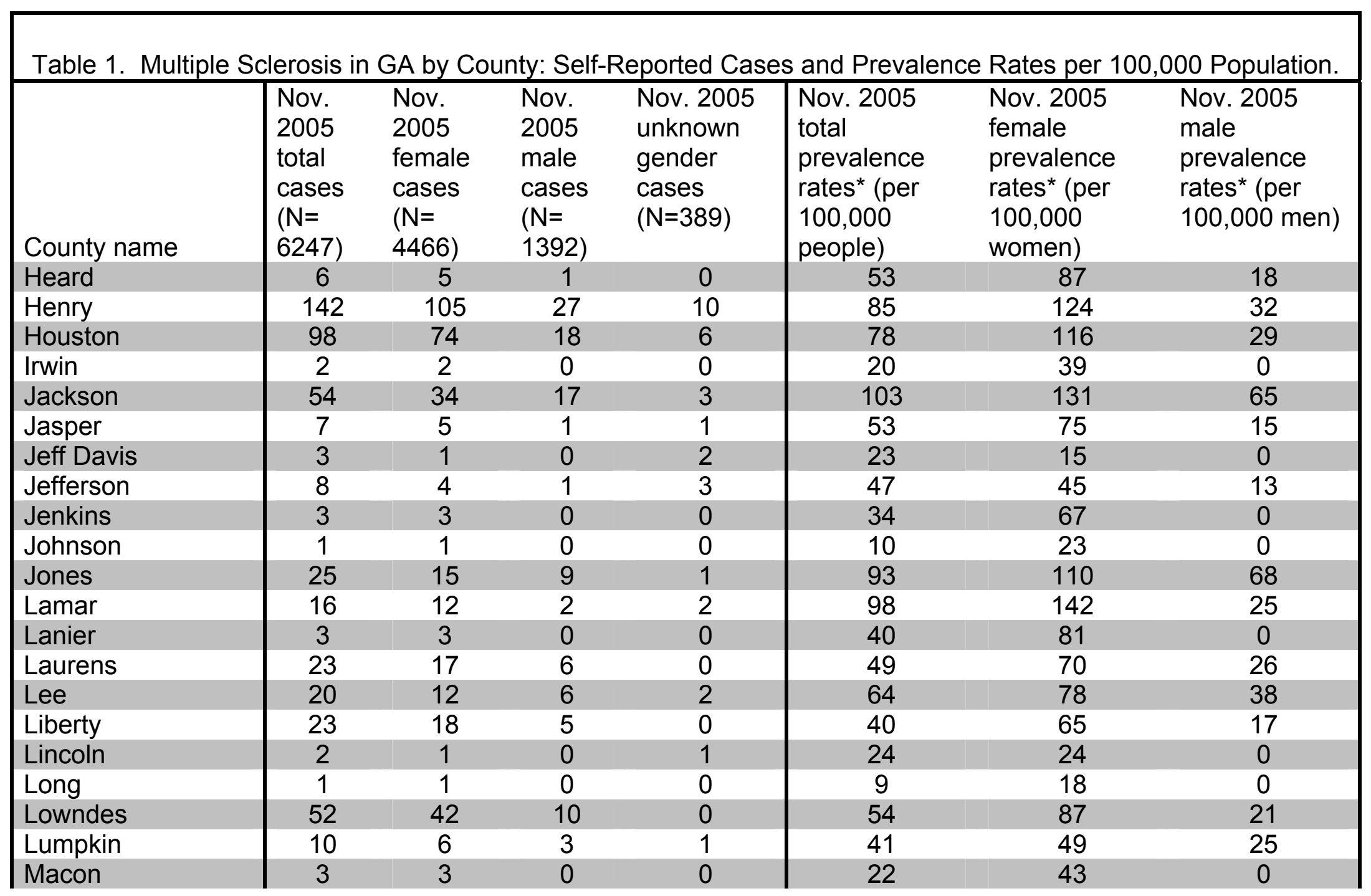




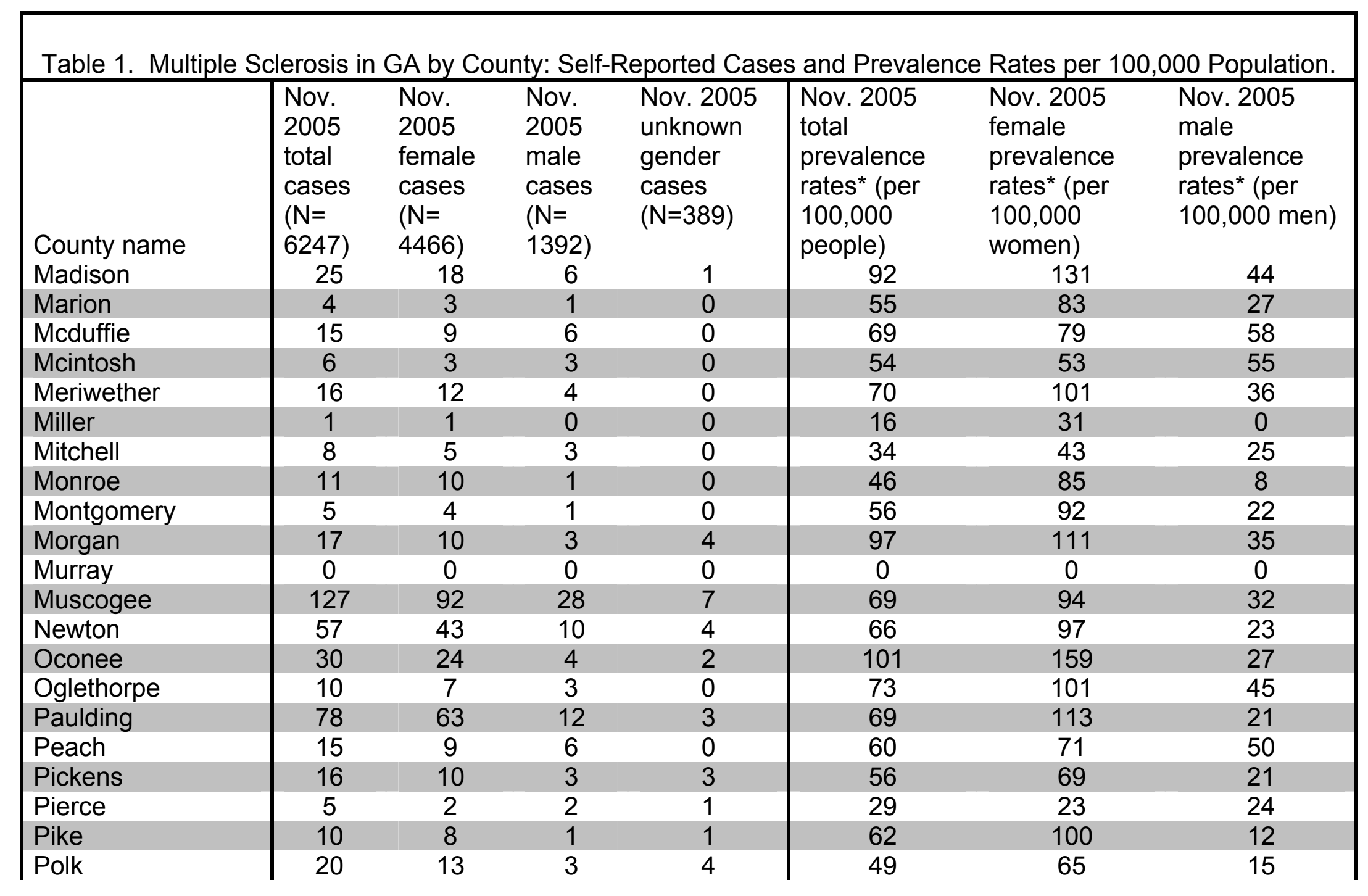




\begin{tabular}{|c|c|c|c|c|c|c|c|}
\hline County name & $\begin{array}{l}\text { Nov. } \\
2005 \\
\text { total } \\
\text { cases } \\
(\mathrm{N}= \\
6247)\end{array}$ & $\begin{array}{l}\text { Nov. } \\
2005 \\
\text { female } \\
\text { cases } \\
(\mathrm{N}= \\
4466)\end{array}$ & $\begin{array}{l}\text { Nov. } \\
2005 \\
\text { male } \\
\text { cases } \\
(\mathrm{N}= \\
1392)\end{array}$ & $\begin{array}{l}\text { Nov. } 2005 \\
\text { unknown } \\
\text { gender } \\
\text { cases } \\
(\mathrm{N}=389)\end{array}$ & $\begin{array}{l}\text { Nov. } 2005 \\
\text { total } \\
\text { prevalence } \\
\text { rates* (per }^{*} 100,000 \\
\text { people) }\end{array}$ & $\begin{array}{l}\text { Nov. } 2005 \\
\text { female } \\
\text { prevalence } \\
\text { rates* (per }^{*} 100,000 \\
\text { women) }\end{array}$ & $\begin{array}{l}\text { Nov. } 2005 \\
\text { male } \\
\text { prevalence } \\
\text { rates* (per }^{*} \\
100,000 \text { men) }\end{array}$ \\
\hline Pulaski & 8 & 6 & 2 & 0 & 82 & 109 & 47 \\
\hline Putnam & 11 & 7 & 4 & 0 & 55 & 70 & 41 \\
\hline Quitman & 1 & 1 & 0 & 0 & 41 & 77 & 0 \\
\hline Rabun & 11 & 7 & 2 & 2 & 68 & 87 & 25 \\
\hline Randolph & 5 & 2 & 3 & 0 & 68 & 51 & 89 \\
\hline Richmond & 133 & 92 & 36 & 5 & 68 & 90 & 38 \\
\hline Rockdale & 62 & 42 & 16 & 4 & 79 & 107 & 41 \\
\hline Schley & 2 & 2 & 0 & 0 & 49 & 94 & 0 \\
\hline Screven & 1 & 1 & 0 & 0 & 6 & 13 & 0 \\
\hline Seminole & 4 & 2 & 1 & 1 & 43 & 41 & 23 \\
\hline Spalding & 35 & 27 & 5 & 3 & 57 & 86 & 17 \\
\hline Stephens & 10 & 7 & 1 & 2 & 40 & 54 & 8 \\
\hline Stewart & 0 & 0 & 0 & 0 & 0 & 0 & 0 \\
\hline Sumter & 14 & 10 & 4 & 0 & 43 & 58 & 25 \\
\hline Talbot & 8 & 6 & 1 & 1 & 119 & 170 & 32 \\
\hline Taliaferro & 0 & 0 & 0 & 0 & 0 & 0 & 0 \\
\hline Tattnall & 9 & 6 & 3 & 0 & 39 & 61 & 22 \\
\hline Taylor & 3 & 3 & 0 & 0 & 34 & 67 & 0 \\
\hline Telfair & 3 & 3 & 0 & 0 & 23 & 53 & 0 \\
\hline Terrell & 4 & 4 & 0 & 0 & 37 & 72 & 0 \\
\hline Thomas & 24 & 21 & 2 & 1 & 54 & 89 & 9 \\
\hline
\end{tabular}




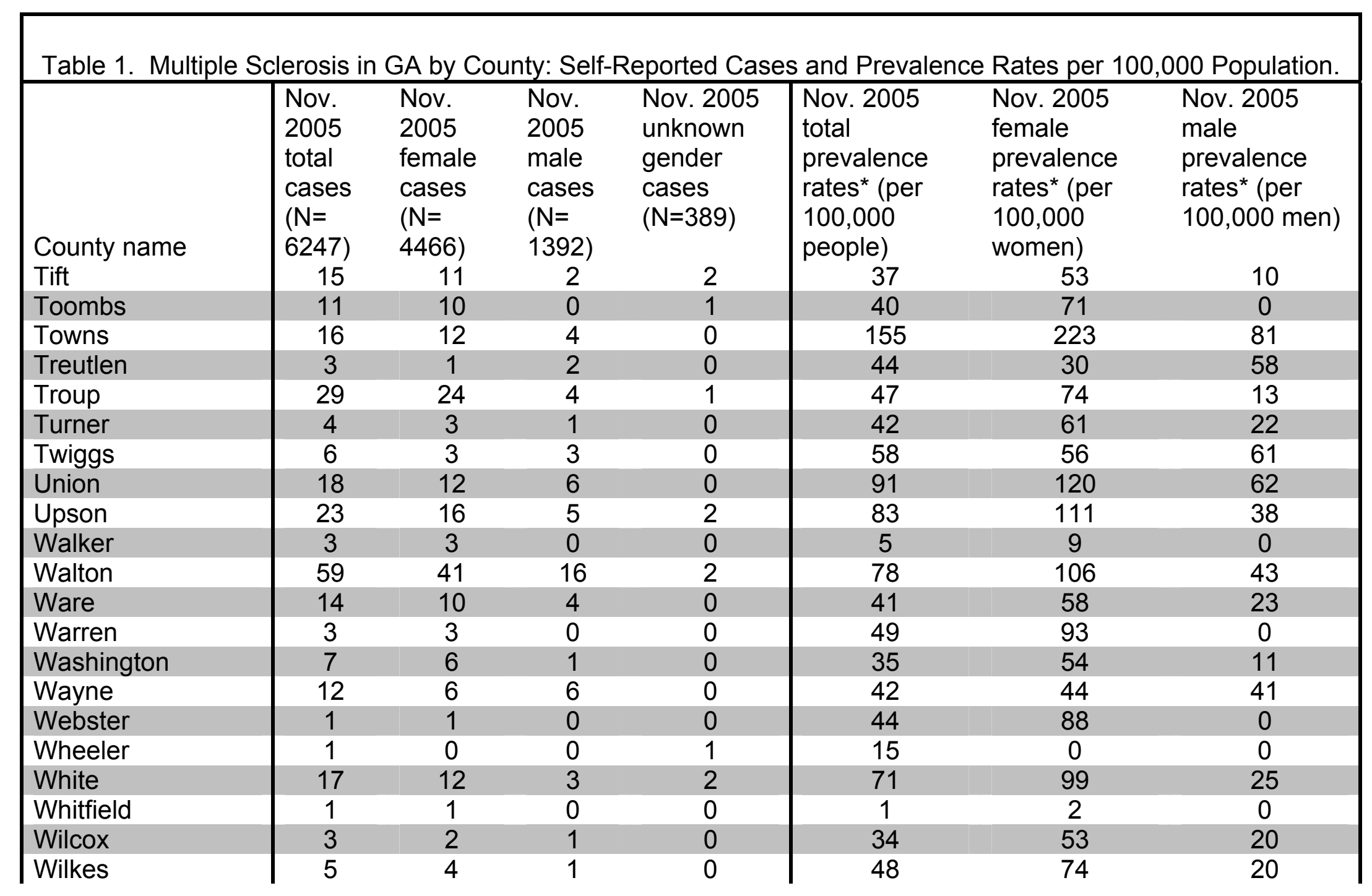




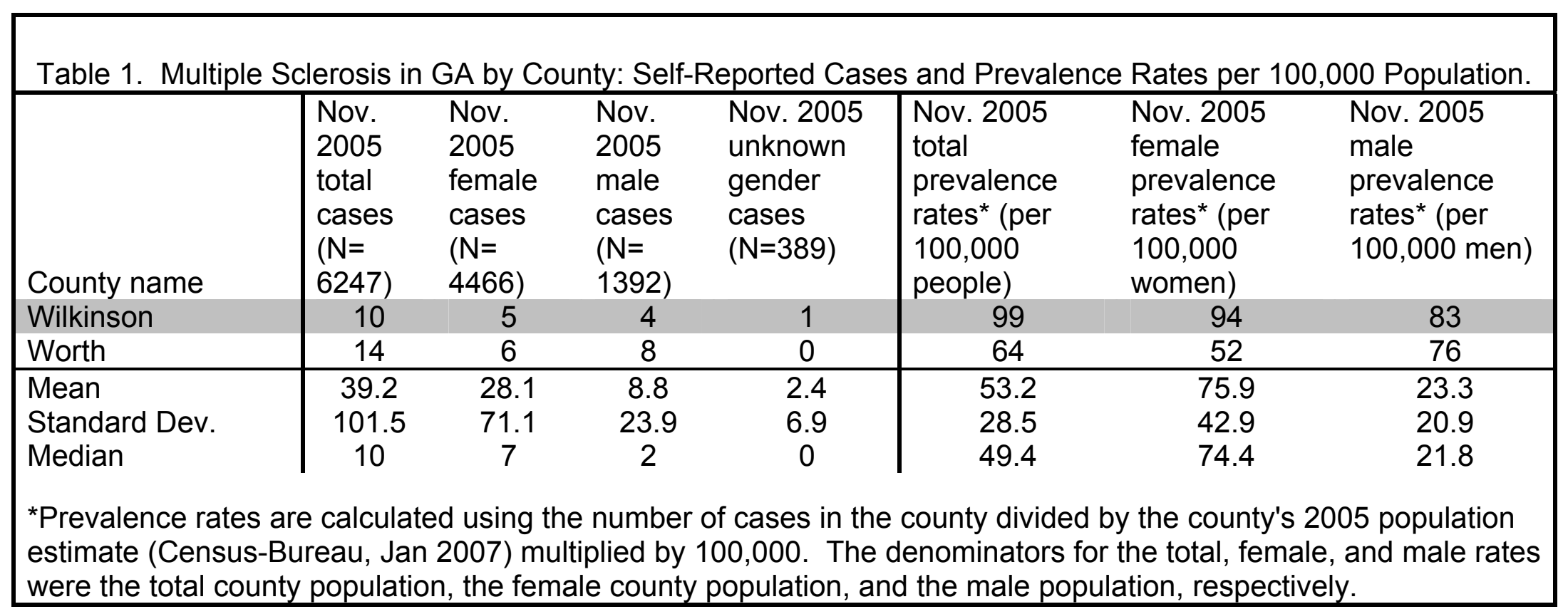


In figure 1, the overall self-reported-case prevalence rates at the county level were usually lower than the rates seen for females (figure 2) and higher than for male rates (figure 3). Also, the darker areas seem to center around Cobb, Fulton and Dekalb County. These counties are counties of metropolitan Atlanta, the most developed and urbanized setting in Georgia.

In figure 2, the self-reported-case prevalence rates are generally higher than those seen in figures 1 and 3, which depict overall self-reported-case prevalence rates and the male self-reported-case prevalence rates, respectively. Also, the dark area seems to center around Cobb, Fulton and Dekalb County. These counties are metropolitan counties of Atlanta, the most developed and urbanized setting in Georgia.

In figure 3 the male MS self- reported case prevalence rates are markedly lower than those seen in the female MS self-reported-case prevalence rates (figure 2). Also, while there is a slight pattern of higher rates around Atlanta, the general pattern seems more dispersed for males than for females. 


\section{Figure 1:}

Total Multiple Sclerosis Self-Reported Prevalence Rates in GA, by County: Crude Rates as of November 2006

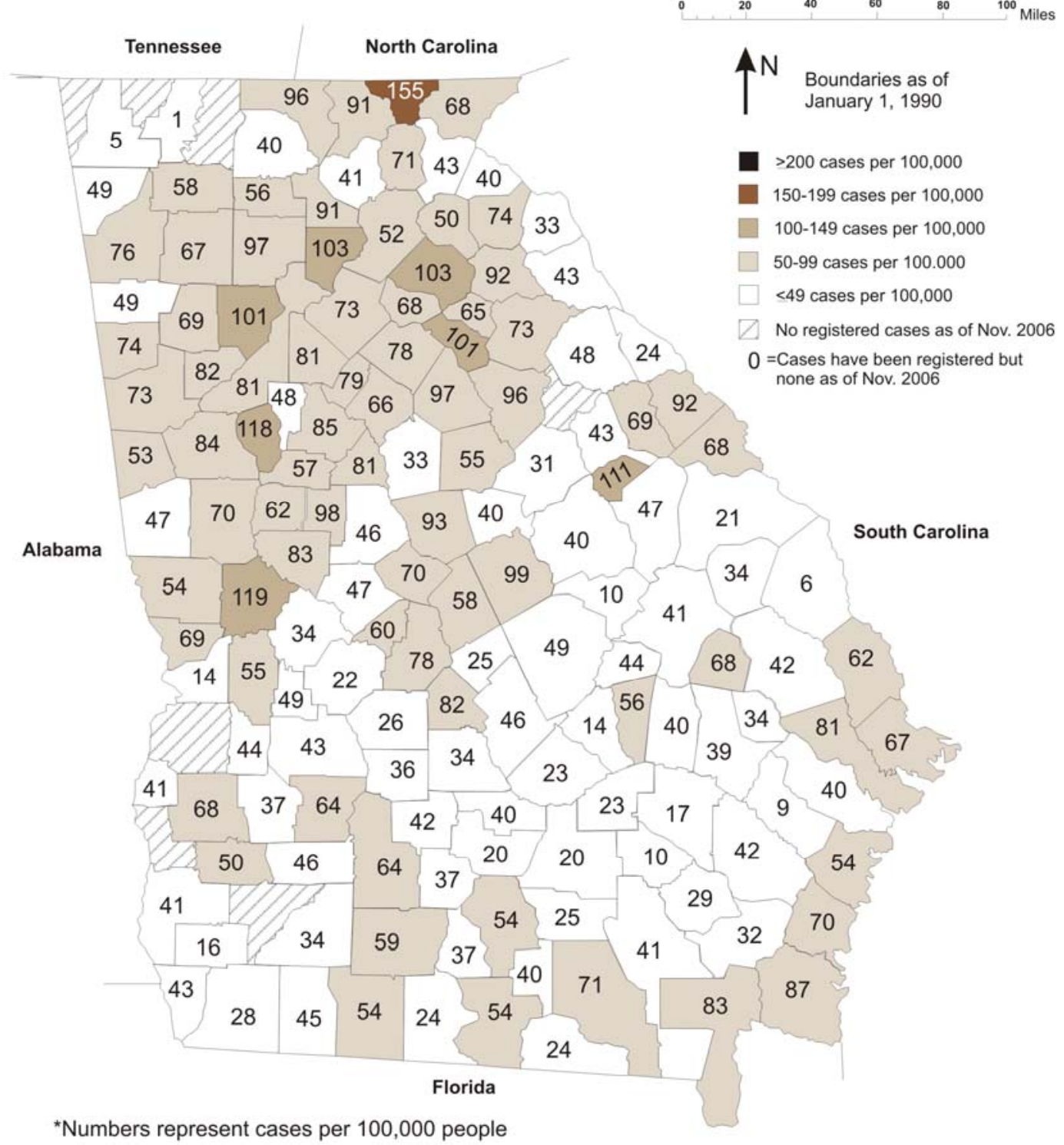


Figure 2:

Multiple Sclerosis Self-Reported Case Prevalence Rates among Females in GA, by County: Crude Rates as of November 2006

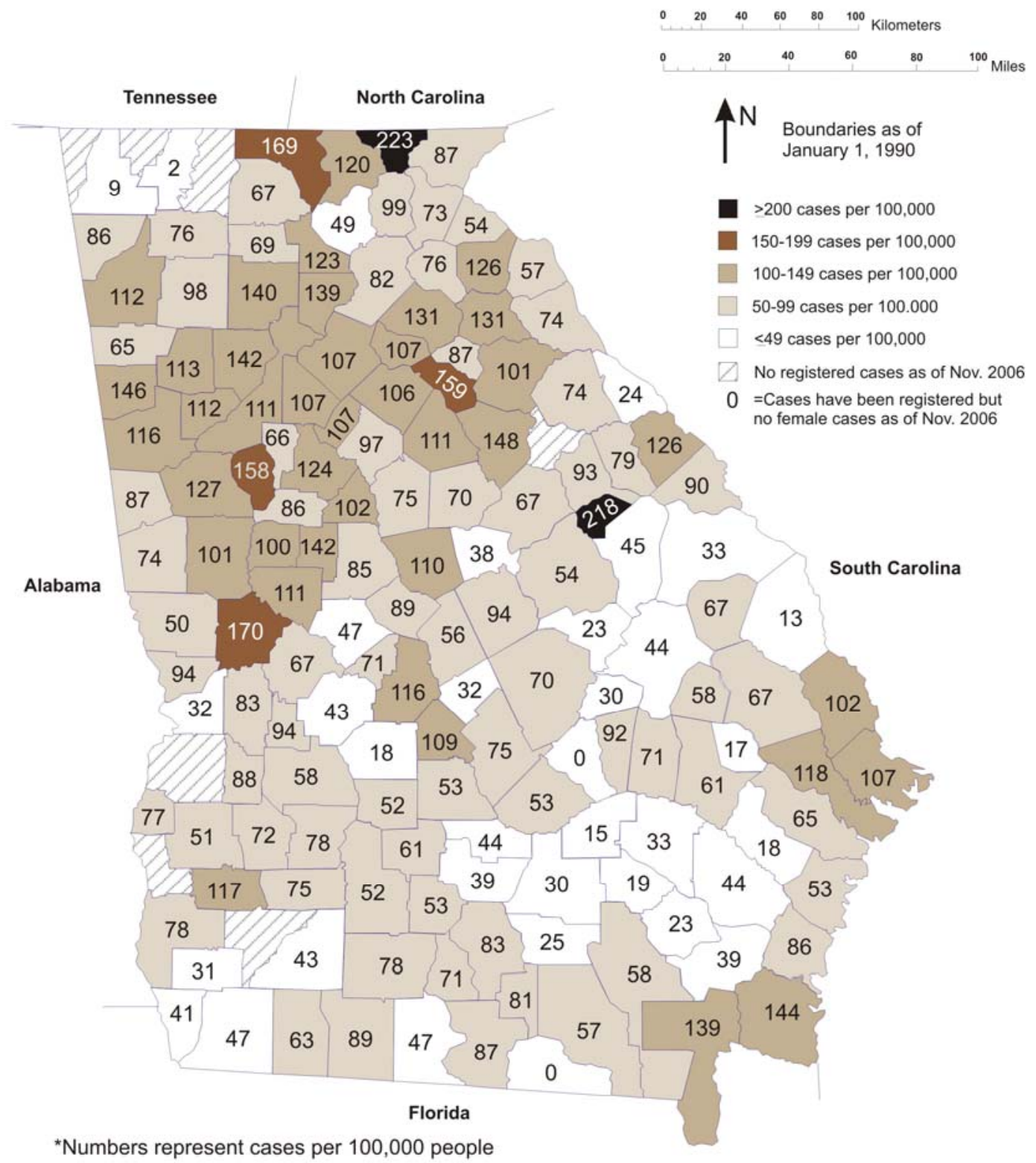


Figure 3:

Multiple Sclerosis Self-Reported Case Prevalence Rates among Males in GA, by County: Crude Rates as of November 2006

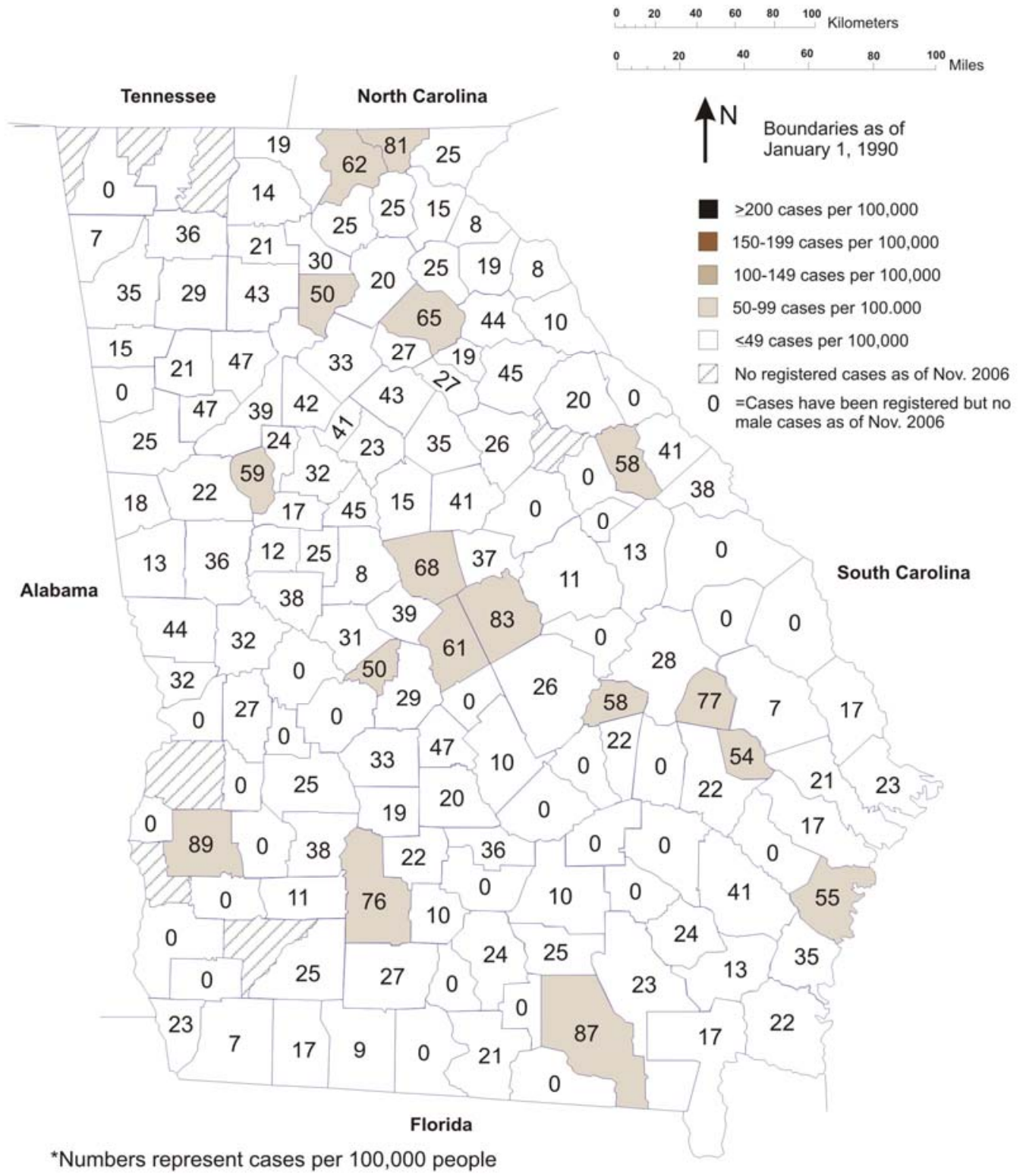


Table 2 shows the results of bivariate linear regression for self-reported prevalence and county level census data. We observed that the strength of the association between total MS rates and census data were largely driven by the female rates. Also, many of the variables show many highly significant values, especially per capita income. For these variables it was unlikely the association between the MS self-reported prevalence and the variable was due to chance alone, given the sample sizes. 
Table 2: Bivariate Linear Regression for Self-Reported-Case Prevalence and County Level Census Data.

\begin{tabular}{|c|c|c|c|c|c|c|c|c|c|c|}
\hline Variable & \begin{tabular}{|l|}
$\mathrm{N}$ \\
(counties \\
included \\
in the \\
analysis)
\end{tabular} & $\begin{array}{l}\text { Total Rates } \\
\text { and } \\
\text { standardized } \\
\text { beta }(\beta)\end{array}$ & $\begin{array}{l}\mathrm{P}- \\
\text { value } \\
\text { of } \\
\text { beta }^{a} \\
\text { (total } \\
\text { rates) }\end{array}$ & $\begin{array}{l}\mathrm{R}^{2} \text { of } \\
\text { the } \\
\text { total } \\
\text { rate }\end{array}$ & $\begin{array}{l}\text { Female } \\
\text { Rates and } \\
\text { standardized } \\
\text { beta }(\beta)\end{array}$ & $\begin{array}{l}\text { P- } \\
\text { value } \\
\text { of } \\
\text { beta }^{a} \\
\text { (female } \\
\text { rates) }\end{array}$ & $\begin{array}{l}\mathrm{R}^{2} \text { of } \\
\text { the } \\
\text { female } \\
\text { Rate }\end{array}$ & $\begin{array}{l}\text { Male rates } \\
\text { and } \\
\text { standardized } \\
\text { beta }(\beta)\end{array}$ & $\begin{array}{l}\mathrm{P}- \\
\text { value } \\
\text { of } \\
\text { beta }^{a} \\
\text { male } \\
\text { rates) }\end{array}$ & $\begin{array}{l}\mathrm{R}^{2} \text { of } \\
\text { the } \\
\text { male } \\
\text { rate }\end{array}$ \\
\hline $\begin{array}{l}\text { Total } \\
\text { population }\end{array}$ & 159 & $0.259 * * *$ & 0.001 & 0.067 & $0.237^{* *}$ & 0.003 & 0.056 & $0.175^{*}$ & 0.027 & 0.031 \\
\hline $\begin{array}{l}\text { Percent } \\
\text { female }\end{array}$ & 159 & 0.143 & 0.073 & 0.02 & 0.098 & 0.217 & 0.010 & 0.142 & 0.075 & 0.020 \\
\hline $\begin{array}{l}\text { Female } \\
\text { population }\end{array}$ & 159 & $0.260^{* * *}$ & 0.001 & 0.068 & $0.238^{* *}$ & 0.003 & 0.056 & $0.176^{*}$ & 0.027 & 0.031 \\
\hline $\begin{array}{l}\text { Male } \\
\text { population }\end{array}$ & 159 & $0.258^{* *}$ & 0.001 & 0.067 & $0.237^{* *}$ & 0.003 & 0.056 & $0.174^{*}$ & 0.028 & 0.03 \\
\hline $\begin{array}{l}\text { Percent } \\
\text { white }\end{array}$ & 159 & 0.036 & 0.655 & 0.001 & 0.007 & 0.934 & 0.000 & 0.085 & 0.284 & 0.007 \\
\hline $\begin{array}{l}\text { Percent } \\
\text { black }\end{array}$ & 159 & $-0.242^{* *}$ & 0.002 & 0.058 & $-0.230^{* *}$ & 0.003 & 0.053 & -0.102 & 0.201 & 0.010 \\
\hline $\begin{array}{l}\text { Percent } \\
\text { living in } \\
\text { the same } \\
\text { house }\end{array}$ & 159 & $-0.264^{* * *}$ & 0.001 & 0.070 & $-0.263^{* * *}$ & 0.001 & 0.069 & $-0.263^{* * *}$ & 0.001 & 0.069 \\
\hline $\begin{array}{l}\text { Per capita } \\
\text { income }\end{array}$ & 159 & $0.522^{* * * *}$ & 0.000 & 0.272 & $0.459^{* * * *}$ & 0.000 & 0.211 & $0.459^{* * * *}$ & 0.000 & 0.211 \\
\hline $\begin{array}{l}\text { Square } \\
\text { miles land }\end{array}$ & 159 & -0.101 & 0.206 & 0.010 & -0.116 & 0.147 & 0.013 & -0.116 & 0.147 & 0.013 \\
\hline
\end{tabular}


Table 2: Bivariate Linear Regression for Self-Reported-Case Prevalence and County Level Census Data.

\begin{tabular}{|c|c|c|c|c|c|c|c|c|c|c|}
\hline Variable & $\begin{array}{l}\mathrm{N} \\
\text { (counties } \\
\text { included } \\
\text { in the } \\
\text { analysis) }\end{array}$ & $\begin{array}{l}\text { Total Rates } \\
\text { and } \\
\text { standardized } \\
\text { beta }(\beta)\end{array}$ & $\begin{array}{l}\text { P- } \\
\text { value } \\
\text { of } \\
\text { beta }^{a} \\
\text { (total } \\
\text { rates) }\end{array}$ & $\begin{array}{l}\mathrm{R}^{2} \text { of } \\
\text { the } \\
\text { total } \\
\text { rate }\end{array}$ & $\begin{array}{l}\text { Female } \\
\text { Rates and } \\
\text { standardized } \\
\text { beta }(\beta)\end{array}$ & $\begin{array}{l}\text { P- } \\
\text { value } \\
\text { of } \\
\text { beta }^{a} \\
\text { (female } \\
\text { rates) }\end{array}$ & $\begin{array}{l}\mathrm{R}^{2} \text { of } \\
\text { the } \\
\text { female } \\
\text { Rate }\end{array}$ & $\begin{array}{l}\text { Male rates } \\
\text { and } \\
\text { standardized } \\
\text { beta }(\beta)\end{array}$ & $\begin{array}{l}\mathrm{P}- \\
\text { value } \\
\text { of } \\
\text { beta }^{a} \\
\text { male } \\
\text { rates) }\end{array}$ & $\begin{array}{l}\mathrm{R}^{2} \text { of } \\
\text { the } \\
\text { male } \\
\text { rate }\end{array}$ \\
\hline $\begin{array}{l}\text { People } \\
\text { per } \\
\text { square } \\
\text { mile }\end{array}$ & 159 & $0.262^{* * *}$ & 0.001 & 0.069 & $0.230^{* *}$ & 0.004 & 0.053 & $0.230^{* *}$ & 0.004 & 0.053 \\
\hline \multicolumn{11}{|c|}{$\begin{array}{l}{ }^{a} \text { P-values are calculated using a two-tailed t distribution } \\
{ }^{*} \text { Values are significant at the } 0.05 \text { level } \\
{ }^{* *} \text { Values are significant at the } 0.01 \text { level } \\
{ }^{* *} \text { Values are significant at the } 0.001 \text { level } \\
{ }^{* * *} \text { Values are significant at the } 0.0001 \text { level }\end{array}$} \\
\hline
\end{tabular}


Table 3 shows the association between toxicants and environmental pollutants as county level emissions data and the total, female, and male self-reported-case prevalence rates of MS using bivariate linear regression. No statistically significant values were found for this table when using an alpha value of 0.05 . However, two of the associations-Total rates and suspected cardiovascular or blood toxicants and suspected developmental toxicant—were very near to statistical significance. 


\begin{tabular}{|c|c|c|c|c|c|c|c|c|c|c|}
\hline Variable & $\begin{array}{l}\mathrm{N} \\
\text { (counties } \\
\text { included } \\
\text { in the } \\
\text { analysis) }\end{array}$ & $\begin{array}{l}\text { Total } \\
\text { rates } \\
\text { and } \\
\text { standard } \\
\text { beta }(\beta)\end{array}$ & $\begin{array}{l}\text { P-value } \\
\text { of } \\
\text { beta }^{a} \\
\text { (total } \\
\text { rates) }\end{array}$ & $\begin{array}{l}\mathrm{R}^{2} \text { of } \\
\text { the } \\
\text { total } \\
\text { rate }\end{array}$ & $\begin{array}{l}\text { Female } \\
\text { rates } \\
\text { and } \\
\text { standard } \\
\text { beta }(\beta)\end{array}$ & $\begin{array}{l}\text { P-value } \\
\text { of beta }^{a} \\
\text { (female } \\
\text { rates) }\end{array}$ & $\begin{array}{l}\mathrm{R}^{2} \text { of } \\
\text { the } \\
\text { female } \\
\text { rate }\end{array}$ & $\begin{array}{l}\text { Male } \\
\text { rates } \\
\text { and } \\
\text { standard } \\
\text { beta }(\beta)\end{array}$ & $\begin{array}{l}\text { P-value } \\
\text { of } \\
\text { beta }^{a} \\
\text { male } \\
\text { rates) }\end{array}$ & $\begin{array}{l}\mathrm{R}^{2} \text { of } \\
\text { the } \\
\text { male } \\
\text { rate }\end{array}$ \\
\hline $\begin{array}{l}\text { Recognized } \\
\text { carcinogens }\end{array}$ & 83 & -0.052 & 0.640 & 0.003 & -0.064 & 0.563 & 0.004 & 0.002 & 0.987 & 0.000 \\
\hline $\begin{array}{l}\text { Suspected } \\
\text { carcinogens }\end{array}$ & 63 & -0.087 & 0.496 & 0.008 & -0.066 & 0.609 & 0.004 & -0.029 & 0.822 & 0.001 \\
\hline $\begin{array}{l}\text { Suspected } \\
\text { cardiovascular } \\
\text { or blood } \\
\text { toxicants }\end{array}$ & 99 & 0.167 & 0.098 & 0.028 & 0.160 & 0.115 & 0.025 & 0.138 & 0.172 & 0.019 \\
\hline $\begin{array}{l}\text { Recognized } \\
\text { development } \\
\text { toxicants }\end{array}$ & 79 & 0.196 & 0.084 & 0.038 & 0.181 & 0.111 & 0.033 & 0.112 & 0.325 & 0.013 \\
\hline $\begin{array}{l}\text { Suspected } \\
\text { developmental } \\
\text { toxicants }\end{array}$ & 94 & 0.022 & 0.831 & 0.000 & 0.004 & 0.973 & 0.000 & 0.107 & 0.303 & 0.012 \\
\hline $\begin{array}{l}\text { Suspected } \\
\text { endocrine } \\
\text { toxicants }\end{array}$ & 64 & -0.049 & 0.705 & 0.002 & 0.001 & 0.991 & 0.000 & -0.072 & 0.574 & 0.005 \\
\hline $\begin{array}{l}\text { Suspected } \\
\text { immunotoxicants }\end{array}$ & 96 & 0.056 & 0.586 & 0.003 & 0.087 & 0.401 & 0.007 & 0.016 & 0.877 & 0.000 \\
\hline
\end{tabular}




\begin{tabular}{|c|c|c|c|c|c|c|c|c|c|c|}
\hline Variable & $\begin{array}{l}\mathrm{N} \\
\text { (counties } \\
\text { included } \\
\text { in the } \\
\text { analysis) }\end{array}$ & $\begin{array}{l}\text { Total } \\
\text { rates } \\
\text { and } \\
\text { standard } \\
\text { beta }(\beta)\end{array}$ & $\begin{array}{l}\text { P-value } \\
\text { of } \\
\text { beta }^{a} \\
\text { (total } \\
\text { rates) }\end{array}$ & $\begin{array}{l}\mathrm{R}^{2} \text { of } \\
\text { the } \\
\text { total } \\
\text { rate }\end{array}$ & $\begin{array}{l}\text { Female } \\
\text { rates } \\
\text { and } \\
\text { standard } \\
\text { beta }(\beta)\end{array}$ & $\begin{array}{l}\text { P-value } \\
\text { of beta }^{a} \\
\text { (female }^{\text {femates) }}\end{array}$ & $\begin{array}{l}\mathrm{R}^{2} \text { of } \\
\text { the } \\
\text { female } \\
\text { rate }\end{array}$ & $\begin{array}{l}\text { Male } \\
\text { rates } \\
\text { and } \\
\text { standard } \\
\text { beta }(\beta)\end{array}$ & $\begin{array}{l}\text { P-value } \\
\text { of } \\
\text { beta }^{a} \\
\text { male } \\
\text { rates) }\end{array}$ & $\begin{array}{l}\mathrm{R}^{2} \text { of } \\
\text { the } \\
\text { male } \\
\text { rate }\end{array}$ \\
\hline $\begin{array}{l}\text { Suspected } \\
\text { kidney toxicants }\end{array}$ & 100 & 0.073 & 0.472 & 0.005 & 0.058 & 0.564 & 0.003 & 0.097 & 0.338 & 0.009 \\
\hline $\begin{array}{l}\text { Suspected } \\
\text { gastrointestinal } \\
\text { or liver toxicants }\end{array}$ & 107 & 0.067 & 0.492 & 0.005 & 0.098 & 0.317 & 0.010 & 0.022 & 0.818 & 0.001 \\
\hline $\begin{array}{l}\text { Suspected } \\
\text { muscoskeletal } \\
\text { toxicants }\end{array}$ & 32 & -0.031 & 0.867 & 0.001 & 0.020 & 0.912 & 0.000 & -0.081 & 0.658 & 0.007 \\
\hline $\begin{array}{l}\text { Suspected } \\
\text { neurotoxicants }\end{array}$ & 104 & 0.020 & 0.837 & 0.000 & 0.023 & 0.819 & 0.001 & 0.034 & 0.734 & 0.001 \\
\hline $\begin{array}{l}\text { Recognized } \\
\text { reproductive } \\
\text { toxicants }\end{array}$ & 70 & -0.010 & 0.933 & 0.000 & 0.005 & 0.968 & 0.000 & 0.008 & 0.945 & 0.000 \\
\hline $\begin{array}{l}\text { Suspected } \\
\text { reproductive } \\
\text { toxicants }\end{array}$ & 103 & 0.030 & 0.767 & 0.001 & 0.036 & 0.721 & 0.001 & 0.036 & 0.721 & 0.001 \\
\hline $\begin{array}{l}\text { Suspected } \\
\text { respiratory } \\
\text { toxicants }\end{array}$ & 103 & 0.064 & 0.518 & 0.004 & 0.096 & 0.332 & 0.009 & 0.022 & 0.823 & 0.000 \\
\hline $\begin{array}{l}\text { Suspected skin } \\
\text { or sense } \\
\text { toxicants }\end{array}$ & 101 & 0.055 & 0.586 & 0.003 & 0.090 & 0.372 & 0.008 & 0.010 & 0.920 & 0.000 \\
\hline
\end{tabular}


Table 3: Bivariate Linear Regression for Self-Reported-Case Prevalence versus County Level Emissions Data.

\begin{tabular}{|c|c|c|c|c|c|c|c|c|c|c|}
\hline Variable & \begin{tabular}{|l}
$\mathrm{N}$ \\
(counties \\
included \\
in the \\
analysis)
\end{tabular} & $\begin{array}{l}\text { Total } \\
\text { rates } \\
\text { and } \\
\text { standard } \\
\text { beta }(\beta)\end{array}$ & $\begin{array}{l}\text { P-value } \\
\text { of } \\
\text { beta }^{a} \\
\text { (total } \\
\text { rates) }\end{array}$ & $\begin{array}{l}\mathrm{R}^{2} \text { of } \\
\text { the } \\
\text { total } \\
\text { rate }\end{array}$ & $\begin{array}{l}\text { Female } \\
\text { rates } \\
\text { and } \\
\text { standard } \\
\text { beta }(\beta)\end{array}$ & $\begin{array}{l}\text { P-value } \\
\text { of beta }^{\text {a }} \\
\text { (female } \\
\text { rates) }\end{array}$ & $\begin{array}{l}\mathrm{R}^{2} \text { of } \\
\text { the } \\
\text { female } \\
\text { rate }\end{array}$ & $\begin{array}{l}\text { Male } \\
\text { rates } \\
\text { and } \\
\text { standard } \\
\text { beta }(\beta)\end{array}$ & $\begin{array}{l}\text { P-value } \\
\text { of } \\
\text { beta }^{a} \\
\text { male } \\
\text { rates) }\end{array}$ & $\begin{array}{l}\mathrm{R}^{2} \text { of } \\
\text { the } \\
\text { male } \\
\text { rate }\end{array}$ \\
\hline Acetaldehyde & 14 & -0.161 & 0.583 & 0.026 & -0.202 & 0.489 & 0.041 & 0.061 & 0.835 & 0.004 \\
\hline Ammonia in & 39 & 0.139 & 0.397 & 0.019 & 0.106 & 0.520 & 0.011 & 0.158 & 0.337 & 0.025 \\
\hline Formaldehyde & 27 & -0.138 & 0.493 & 0.019 & -0.260 & 0.190 & 0.068 & 0.144 & 0.473 & 0.021 \\
\hline $\begin{array}{l}\text { Lead/lead } \\
\text { compounds }\end{array}$ & 49 & -0.146 & 0.318 & 0.021 & -0.050 & 0.734 & 0.002 & -0.164 & 0.260 & 0.027 \\
\hline $\begin{array}{l}\text { Manganese } \\
\text { compounds }\end{array}$ & 30 & 0.046 & 0.810 & 0.002 & 0.126 & 0.506 & 0.016 & -0.062 & 0.744 & 0.004 \\
\hline $\begin{array}{l}\text { Methanol } \\
\text { compounds }\end{array}$ & 34 & 0.051 & 0.775 & 0.003 & 0.008 & 0.965 & 0.000 & 0.214 & 0.224 & 0.046 \\
\hline \multicolumn{11}{|c|}{$\begin{array}{l}\text { The measurements for toxicants and selected produced compounds were reported in pounds for the year } 2002 . \\
{ }^{a} \text { P-values are calculated using a two-tailed t distribution } \\
{ }^{*} \text { Values are significant at the } 0.05 \text { level } \\
{ }^{* *} \text { Values are significant at the } 0.01 \text { level } \\
{ }^{* * *} \text { Values are significant at the } 0.001 \text { level } \\
{ }^{* * *} \text { Values are significant at the } 0.0001 \text { level }\end{array}$} \\
\hline
\end{tabular}


Table 4 shows the associations between selected criteria air pollutants and overall MS self-reported-case prevalence using bivariate linear regression. The highest association and highest significance was observed for PM-10 and PM-2.5 mobile sources. Relatively weaker but still significant associations were observed with nitrogen oxides, carbon monoxide and volatile organic compounds. Finally, the association with these selected criteria air pollutants and female self-reported-case prevalence rates were generally stronger than those observed with male self-reportedcase prevalence rates. 


\begin{tabular}{|c|c|c|c|c|c|c|c|c|c|c|}
\hline Variable & $\begin{array}{l}\mathrm{N} \\
\text { (counties } \\
\text { included } \\
\text { in the } \\
\text { analysis) }\end{array}$ & $\begin{array}{l}\text { Total } \\
\text { rates } \\
\text { and } \\
\text { standard } \\
\text { beta }(\beta)\end{array}$ & $\begin{array}{l}\text { P-value } \\
\text { of beta }^{\text {a }} \\
\text { (total } \\
\text { rates) }\end{array}$ & $\begin{array}{l}\mathrm{R}^{2} \text { of } \\
\text { the } \\
\text { total } \\
\text { rate }\end{array}$ & $\begin{array}{l}\text { Female } \\
\text { rates } \\
\text { and } \\
\text { standard } \\
\text { beta }(\beta)\end{array}$ & $\begin{array}{l}\text { P-value } \\
\text { of beta }^{a} \\
\text { (female } \\
\text { rates) }\end{array}$ & $\begin{array}{l}\mathrm{R}^{2} \text { of } \\
\text { the } \\
\text { female } \\
\text { rate }\end{array}$ & $\begin{array}{l}\text { Male } \\
\text { rates } \\
\text { and } \\
\text { standard } \\
\text { beta }(\beta)\end{array}$ & $\begin{array}{l}\text { P-value } \\
\text { of beta }^{a} \\
\text { male } \\
\text { rates) }\end{array}$ & $\begin{array}{l}\mathrm{R}^{2} \text { of } \\
\text { the } \\
\text { male } \\
\text { rate }\end{array}$ \\
\hline $\begin{array}{l}\text { Carbon } \\
\text { Monoxide } \\
\text { (mobile) }\end{array}$ & 158 & $0.234^{* *}$ & 0.003 & 0.055 & $0.208^{* *}$ & 0.009 & 0.043 & $0.167^{*}$ & 0.036 & 0.028 \\
\hline $\begin{array}{l}\text { Carbon } \\
\text { monoxide } \\
\text { (area) }\end{array}$ & 158 & -0.078 & 0.330 & 0.006 & -0.097 & 0.223 & 0.009 & 0.005 & 0.946 & 0.000 \\
\hline $\begin{array}{l}\text { Carbon } \\
\text { monoxide } \\
\text { (all) }\end{array}$ & 158 & $0.193^{*}$ & 0.015 & 0.037 & $0.170^{*}$ & 0.033 & 0.029 & 0.144 & 0.072 & 0.021 \\
\hline $\begin{array}{l}\text { Nitrogen } \\
\text { oxides } \\
\text { (mobile) }\end{array}$ & 158 & $0.242^{* *}$ & 0.002 & 0.059 & $0.215^{* *}$ & 0.007 & 0.046 & $0.176^{*}$ & 0.027 & 0.031 \\
\hline $\begin{array}{l}\text { Nitrogen } \\
\text { oxides } \\
\text { (area) }\end{array}$ & 158 & -0.003 & 0.974 & 0.000 & 0.03 & 0.705 & 0.001 & -0.041 & 0.606 & 0.002 \\
\hline $\begin{array}{l}\text { Nitrogen } \\
\text { oxides } \\
\text { (all) }\end{array}$ & 158 & $0.212^{* *}$ & 0.007 & 0.045 & $0.213^{* *}$ & 0.007 & 0.045 & 0.130 & 0.103 & 0.017 \\
\hline $\begin{array}{l}\text { PM-2.5 } \\
\text { (mobile) }\end{array}$ & 158 & $0.282^{* * *}$ & 0.000 & 0.079 & $0.264^{* * *}$ & 0.001 & 0.07 & $0.175^{*}$ & 0.028 & 0.030 \\
\hline
\end{tabular}




\begin{tabular}{|c|c|c|c|c|c|c|c|c|c|c|}
\hline Variable & $\begin{array}{l}\mathrm{N} \\
\text { (counties } \\
\text { included } \\
\text { in the } \\
\text { analysis) }\end{array}$ & $\begin{array}{l}\text { Total } \\
\text { rates } \\
\text { and } \\
\text { standard } \\
\text { beta }(\beta)\end{array}$ & $\begin{array}{l}\text { P-value } \\
\text { of beta } \\
\text { (total } \\
\text { rates) }\end{array}$ & $\begin{array}{l}\mathrm{R}^{2} \text { of } \\
\text { the } \\
\text { total } \\
\text { rate }\end{array}$ & $\begin{array}{l}\text { Female } \\
\text { rates } \\
\text { and } \\
\text { standard } \\
\text { beta }(\beta)\end{array}$ & $\begin{array}{l}\text { P-value } \\
\text { of beta }^{a} \\
\text { (female } \\
\text { rates) }\end{array}$ & $\begin{array}{l}\mathrm{R}^{2} \text { of } \\
\text { the } \\
\text { female } \\
\text { rate }\end{array}$ & $\begin{array}{l}\text { Male } \\
\text { rates } \\
\text { and } \\
\text { standard } \\
\text { beta }(\beta)\end{array}$ & $\begin{array}{l}\text { P-value } \\
\text { of beta }^{a} \\
\text { male } \\
\text { rates) }\end{array}$ & $\begin{array}{l}\mathrm{R}^{2} \text { of } \\
\text { the } \\
\text { male } \\
\text { rate }\end{array}$ \\
\hline $\begin{array}{l}\text { PM-2.5 } \\
\text { (area) }\end{array}$ & 158 & -0.093 & 0.247 & 0.009 & -0.107 & 0.182 & 0.011 & -0.001 & 0.992 & 0.000 \\
\hline $\begin{array}{l}\text { PM-2.5 } \\
\text { (all) }\end{array}$ & 158 & 0.107 & 0.179 & 0.012 & 0.073 & 0.363 & 0.005 & 0.142 & 0.076 & 0.020 \\
\hline $\begin{array}{l}\text { PM-10 } \\
\text { (mobile) }\end{array}$ & 158 & $0.276^{* * *}$ & 0.000 & 0.076 & $0.268^{* * *}$ & 0.001 & 0.072 & $0.159^{*}$ & 0.046 & 0.025 \\
\hline $\begin{array}{l}\text { PM-10 } \\
\text { (area) }\end{array}$ & 158 & -0.045 & 0.578 & 0.002 & -0.058 & 0.470 & 0.003 & 0.020 & 0.802 & 0.000 \\
\hline $\begin{array}{l}\text { PM-10 } \\
\text { (all) }\end{array}$ & 158 & $0.192^{*}$ & 0.016 & 0.037 & $0.179^{*}$ & 0.024 & 0.032 & 0.133 & 0.097 & 0.018 \\
\hline $\begin{array}{l}\text { Sulfur } \\
\text { Dioxide } \\
\text { (mobile) }\end{array}$ & 158 & 0.136 & 0.089 & 0.018 & 0.118 & 0.141 & 0.014 & 0.136 & 0.089 & 0.018 \\
\hline $\begin{array}{l}\text { Sulfur } \\
\text { Dioxide } \\
\text { (area) }\end{array}$ & 158 & 0.062 & 0.436 & 0.004 & 0.045 & 0.571 & 0.002 & 0.074 & 0.356 & 0.005 \\
\hline $\begin{array}{l}\text { Sulfur } \\
\text { Dioxide } \\
\text { (all) }\end{array}$ & 158 & 0.083 & 0.297 & 0.007 & 0.105 & 0.189 & 0.011 & 0.034 & 0.675 & 0.001 \\
\hline $\begin{array}{l}\text { VOCs } \\
\text { (mobile) }\end{array}$ & 158 & $0.231^{* *}$ & 0.003 & 0.054 & $0.206^{* *}$ & 0.010 & 0.042 & $0.164^{*}$ & 0.039 & 0.027 \\
\hline $\begin{array}{l}\text { VOCs } \\
\text { (area) }\end{array}$ & 158 & $0.211^{* *}$ & 0.008 & 0.045 & 0.196 & 0.013 & 0.039 & 0.138 & 0.083 & 0.019 \\
\hline
\end{tabular}


Table 4: Bivariate Linear Regression: Total Self-Reported-Case Prevalence vs. Criteria Air Pollutant Data.

\begin{tabular}{|c|c|c|c|c|c|c|c|c|c|c|}
\hline Variable & $\begin{array}{l}\mathrm{N} \\
\text { (counties } \\
\text { included } \\
\text { in the } \\
\text { analysis) }\end{array}$ & \begin{tabular}{|l|} 
Total \\
rates \\
and \\
standard \\
beta $(\beta)$
\end{tabular} & $\begin{array}{l}\text { P-value } \\
\text { of beta }{ }^{a} \\
\text { (total } \\
\text { rates) }\end{array}$ & $\begin{array}{l}\mathrm{R}^{2} \text { of } \\
\text { the } \\
\text { total } \\
\text { rate }\end{array}$ & $\begin{array}{l}\text { Female } \\
\text { rates } \\
\text { and } \\
\text { standard } \\
\text { beta }(\beta)\end{array}$ & $\begin{array}{l}\text { P-value } \\
\text { of beta }^{a} \\
\text { (female } \\
\text { rates) }\end{array}$ & $\begin{array}{l}\mathrm{R}^{2} \text { of } \\
\text { the } \\
\text { female } \\
\text { rate }\end{array}$ & \begin{tabular}{|l|} 
Male \\
rates \\
and \\
standard \\
beta $(\beta)$
\end{tabular} & $\begin{array}{l}\text { P-value } \\
\text { of beta }{ }^{a} \\
\text { male } \\
\text { rates) }\end{array}$ & $\begin{array}{l}\mathrm{R}^{2} \text { of } \\
\text { the } \\
\text { male } \\
\text { rate }\end{array}$ \\
\hline $\begin{array}{l}\text { VOCs } \\
\text { (all) }\end{array}$ & 158 & $0.243^{* *}$ & 0.002 & 0.059 & $0.219^{* *}$ & 0.006 & 0.048 & $0.174^{*}$ & 0.029 & 0.030 \\
\hline
\end{tabular}

${ }^{a} \mathrm{p}$-values are calculated using a two-tailed t distribution

VOCs are volatile organic compounds. Also, the selected air pollutants were measured in 1999 and they were measured in tons of emissions to outdoor air.

*Values are significant at the 0.05 level

**Values are significant at the 0.01 level

$* * *$ Values are significant at the 0.001 level

$* * * *$ Values are significant at the 0.0001 level 
In table 5, using census, NEI and Total self-reported MS prevalence rates, the last model for stepwise multiple linear regression selected two characteristics, percapita income and PM-10 from area sources. Also, these two characteristics together had ability for this model to predict MS rates than per capita income alone. In these models, the beta coefficient was positive. This means as per capita income and PM10 emissions to outdoor air from area sources increased, the total self-reported-case prevalence rates increased. Finally, the r-squared value estimated the ability for the model to predict the total self-reported-case prevalence rates by county. Therefore, in this model $26.2 \%$ of the total self-reported-case prevalence might have been explained by per capita income and PM-10 from area sources. 


\begin{tabular}{|c|c|c|c|}
\hline Model & $\begin{array}{l}\text { Total rates and } \\
\text { standardized beta }(\beta)\end{array}$ & $\begin{array}{l}\text { P-value of beta } \\
\text { (total rates) }\end{array}$ & $\begin{array}{l}\mathrm{R}^{2} \text { of the } \\
\text { total rate }\end{array}$ \\
\hline
\end{tabular}


As with the total rates, using census data and NEI, the final model summarized here for the female MS self-reported prevalence rates (table 6) selected per-capita income and PM-10 emissions to outdoor air from area sources for predicting female self-reported-case prevalence rates using multivariate linear regression. Also, the association was positive. The final model with the r-squared value of 0.225 , suggesting $22.5 \%$ of the variance might be able to be explained using these two variables. 


\begin{tabular}{|lcc|}
\hline Table 6: Multivariate Linear Regression, Female MS Self-Reported-Case Prevalence Rates and Census and NEI air pollutants \\
\hline & $\begin{array}{c}\text { Total Rates and } \\
\text { Model }\end{array}$ & $\begin{array}{c}\text { P-value of Beta }^{\mathrm{a}} \mathrm{R}^{2} \text { of the } \\
\text { (total rates) }\end{array}$ \\
\hline Per capita Income & 0.448 & 0.000 \\
Per Capita Income and PM-10 (area sources, 1999) & 0.474 & 0.201 \\
Per Capita Income & 0.481 & 0.000 \\
PM-10 (area sources, 1999) & -0.158 & 0.030 \\
\hline This analysis was done using stepwise multivariate linear regression with an acceptance p-value of 0.05 and an elimination p- \\
value of 0.10. This analysis included only census data and selected criteria air pollutants.
\end{tabular}


In table 7, using census data, NEI and male MS self-reported prevalence rates, stepwise multivariate linear regression selected only per capita income was included to estimate the self-reported-case prevalence of MS in males. The association calculated by the beta value was less than the association between per capita income and female or total rates. Lastly, the r-squared estimate was 0.114 , or $11.4 \%$ of the variance in male MS rates might have been explained using this model. 


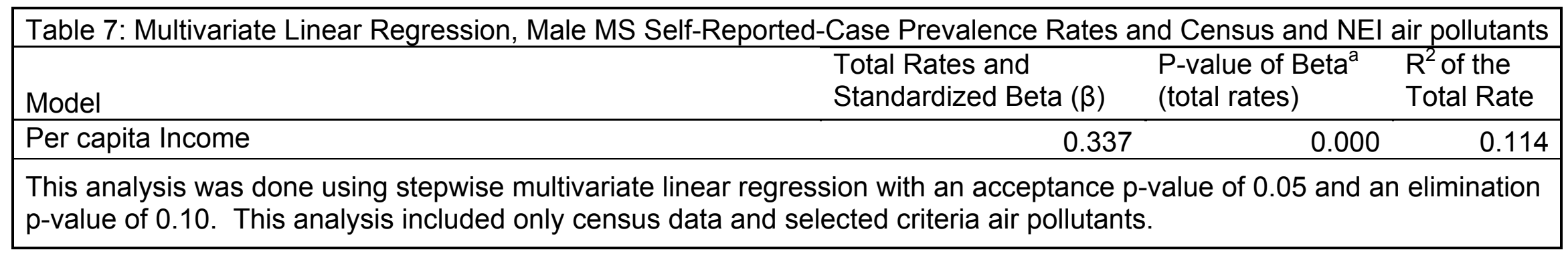


Table 8 shows steadily increasing odds ratios for total MS self-reported-case prevalence for several characteristics derived from U.S. Census data when separated by quartile: total population, male population, per capita income, and people per square mile. Also, the percent black and percent white show significantly strong but varying ORs. Also, people living in the same household in years 2000 and 2005 had ORs less than one. 


\begin{tabular}{|c|c|c|c|c|c|c|c|c|c|c|}
\hline Variable & $\begin{array}{l}\text { OR for } \\
\text { lowest } \\
\text { quartile } \\
\text { (refer- } \\
\text { ence) }\end{array}$ & $\begin{array}{l}\text { OR for } \\
\text { second } \\
\text { quartile }\end{array}$ & $\begin{array}{l}95 \% \mathrm{Cl}^{\mathrm{a}} \text { of } \\
\text { the } \\
\text { second } \\
\text { quartile's } \\
\text { OR }\end{array}$ & $\begin{array}{l}\mathrm{N} \\
\text { (Number } \\
\text { of } \\
\text { people } \\
\text { used for } \\
\text { the OR) }\end{array}$ & $\begin{array}{l}\text { OR for } \\
\text { third } \\
\text { quartile }\end{array}$ & $\begin{array}{l}95 \% \mathrm{Cl}^{\mathrm{a}} \text { of } \\
\text { the third } \\
\text { quartile's } \\
\text { OR }\end{array}$ & $\begin{array}{l}\mathrm{N} \\
\text { (Number } \\
\text { of } \\
\text { people } \\
\text { used for } \\
\text { the OR) }\end{array}$ & $\begin{array}{l}\text { OR for } \\
\text { highest } \\
\text { quartile }\end{array}$ & $\begin{array}{l}95 \% \mathrm{Cl}^{\mathrm{a}} \text { of } \\
\text { the fourth } \\
\text { quartile's } \\
\text { OR }\end{array}$ & $\begin{array}{l}\mathrm{N} \\
\text { (Number } \\
\text { of people } \\
\text { used for } \\
\text { the OR) }\end{array}$ \\
\hline $\begin{array}{l}\text { Total } \\
\text { population }\end{array}$ & 1.00 & 1.04 & $(0.85,1.27)$ & 934957 & 1.04 & $(0.87,1.26)$ & 1509185 & $1.52^{* * * *}$ & $(1.28,1.81)$ & 7208676 \\
\hline $\begin{array}{l}\text { Percent } \\
\text { female }\end{array}$ & 1.00 & $1.19^{* * * *}$ & $(1.11,1.27)$ & 5264143 & 1.04 & $(0.97,1.12)$ & 4278364 & 0.93 & $(0.86,1.02)$ & 3576459 \\
\hline $\begin{array}{l}\text { Female } \\
\text { population }\end{array}$ & 1.00 & 1.05 & $(0.86,1.29)$ & 936425 & 1.09 & $(0.90,1.32)$ & 1508117 & $1.56^{* * * *}$ & $(1.31,1.85)$ & 7209020 \\
\hline $\begin{array}{l}\text { Male } \\
\text { population }\end{array}$ & 1.00 & 1.02 & $(0.83,1.25)$ & 936038 & 1.11 & $(0.92,1.34)$ & 1510076 & $1.55^{* * * *}$ & $(1.31,1.85)$ & 7207260 \\
\hline $\begin{array}{l}\text { Percent } \\
\text { white }\end{array}$ & 1.00 & $0.85^{* * * *}$ & $(0.78,0.92)$ & 4517995 & $1.16^{* * * *}$ & $(1.09,1.23)$ & 6019018 & $0.89^{* *}$ & $(0.82,0.96)$ & 4929913 \\
\hline $\begin{array}{l}\text { Percent } \\
\text { black }\end{array}$ & 1.00 & $1.24^{* * * *}$ & $(1.15,1.33)$ & 4737748 & $0.89 *$ & $(0.81,0.98)$ & 2890160 & $1.09 *$ & $(1.01,1.17)$ & 4967140 \\
\hline
\end{tabular}




\begin{tabular}{|c|c|c|c|c|c|c|c|c|c|c|}
\hline Variable & $\begin{array}{l}\text { OR for } \\
\text { lowest } \\
\text { quartile } \\
\text { (refer- } \\
\text { ence) }\end{array}$ & $\begin{array}{l}\text { OR for } \\
\text { second } \\
\text { quartile }\end{array}$ & $\begin{array}{l}95 \% \mathrm{Cl}^{\mathrm{a}} \text { of } \\
\text { the } \\
\text { second } \\
\text { quartile's } \\
\text { OR }\end{array}$ & $\begin{array}{l}\mathrm{N} \\
\text { (Number } \\
\text { of } \\
\text { people } \\
\text { used for } \\
\text { the OR) }\end{array}$ & $\begin{array}{l}\text { OR for } \\
\text { third } \\
\text { quartile }\end{array}$ & $\begin{array}{l}95 \% \mathrm{Cl}^{\mathrm{a}} \text { of } \\
\text { the third } \\
\text { quartile's } \\
\text { OR }\end{array}$ & $\begin{array}{l}\mathrm{N} \\
\text { (Number } \\
\text { of } \\
\text { people } \\
\text { used for } \\
\text { the OR) }\end{array}$ & $\begin{array}{l}\text { OR for } \\
\text { highest } \\
\text { quartile }\end{array}$ & $\begin{array}{l}95 \% \mathrm{Cl}^{\mathrm{a}} \text { of } \\
\text { the fourth } \\
\text { quartile's } \\
\text { OR }\end{array}$ & $\begin{array}{l}\text { N } \\
\text { (Number } \\
\text { of people } \\
\text { used for } \\
\text { the OR) }\end{array}$ \\
\hline $\begin{array}{l}\text { Percent } \\
\text { living in } \\
\text { the same } \\
\text { house }\end{array}$ & 1.00 & $0.69^{* * * *}$ & $(0.64,0.74)$ & 7847447 & $0.58^{* * * *}$ & $(0.52,0.65)$ & 6858190 & $0.62^{\star * \star *}$ & $(0.54,0.70)$ & 6697317 \\
\hline $\begin{array}{l}\text { Per capita } \\
\text { income }\end{array}$ & 1.00 & 1.17 & $(0.97,1.41)$ & 1293891 & $1.61^{* * * *}$ & $(1.38,1.89)$ & 2656723 & $2.22^{* * * *}$ & $(1.92,2.58)$ & 6158670 \\
\hline $\begin{array}{l}\text { Square } \\
\text { miles land }\end{array}$ & 1.00 & $1.11^{* *}$ & $(1.03,1.19)$ & 4586763 & 1.01 & $(0.93,1.09)$ & 3796684 & 0.94 & $(0.86,1.02)$ & 3818753 \\
\hline $\begin{array}{l}\text { People } \\
\text { per sq. } \\
\text { mile }\end{array}$ & 1.00 & $1.27^{*}$ & $(1.05,1.56)$ & 1099364 & $1.36^{* * *}$ & $(1.13,1.64)$ & 1595362 & $1.90^{* * * *}$ & $(1.60,2.26)$ & 7085554 \\
\hline $\begin{array}{l}\text { Each varia } \\
\text { a } 95 \% \mathrm{Cl} \text { is } \\
* \text { Values ar } \\
* * \text { Values a } \\
{ }^{* * *} \text { Values } \\
* * * \text { Values }\end{array}$ & $\begin{array}{l}\text { unde } \\
\text { alculat } \\
\text { ignific } \\
\text { signifi } \\
\text { signit } \\
\text { e sign }\end{array}$ & $\begin{array}{l}\text { at the } \\
\text { t at the } \\
\text { th at th }\end{array}$ & $\begin{array}{l}\text { Icluded } 159 \\
\text { e case-cont } \\
05 \text { level us } \\
0.01 \text { level us } \\
0.001 \text { level } \\
0.0001 \text { lev }\end{array}$ & $\begin{array}{l}\text { a Chi-s } \\
\text { ng a Ch } \\
\text { sing a }\end{array}$ & $\begin{array}{l}\text { A. } \\
\text { ation } \mathrm{n} \\
\text { red tes } \\
\text { ared te } \\
\text { quared }\end{array}$ & $\begin{array}{l}\text { del } \\
\text { for } 2 \times 2 \mathrm{c} \\
\text { for } 2 \times 2 \\
\text { st for } 2 \times\end{array}$ & $\begin{array}{l}\text { gency } \\
\text { ngenc } \\
\text { tinge }\end{array}$ & $\begin{array}{l}\text { les } \\
\text { bles } \\
\text { tables } \\
\text { cy table }\end{array}$ & & \\
\hline
\end{tabular}


Table 9 shows total population, total female population, total male population, per capita income, and people per square mile had steadily increasing odds ratios for female MS self-reported-case prevalence across increasing quartiles. Also, as in Table 8, the percent living in the same house showed ORs less than one; however, this relationship did not continuously decrease across increasing quartiles for females. 


\begin{tabular}{|c|c|c|c|c|c|c|c|c|c|c|}
\hline \multicolumn{11}{|c|}{$\begin{array}{c}\text { Table 9: Odds Ratios(OR) and 95\% Confidence Interval }(\mathrm{Cl}) \text { by Quartile: Census Data and Female Self-Reported MS } \\
\text { cases }\end{array}$} \\
\hline Variable & $\begin{array}{l}\text { OR for } \\
\text { lowest } \\
\text { quartile } \\
\text { (refer- } \\
\text { ence) }\end{array}$ & $\begin{array}{l}\text { OR for } \\
\text { second } \\
\text { quartile }\end{array}$ & $\begin{array}{l}95 \% \mathrm{Cl}^{\mathrm{a}} \text { of } \\
\text { the } \\
\text { second } \\
\text { quartile } \\
\text { OR }\end{array}$ & $\begin{array}{l}\mathrm{N} \\
\text { (Number } \\
\text { of } \\
\text { people } \\
\text { used for } \\
\text { the OR) }\end{array}$ & $\begin{array}{l}\text { OR for } \\
\text { third } \\
\text { quartile }\end{array}$ & $\begin{array}{l}95 \% \mathrm{Cl}^{\mathrm{a}} \text { of } \\
\text { the third } \\
\text { quartile } \\
\text { OR }\end{array}$ & $\begin{array}{l}\mathrm{N} \\
\text { (Number } \\
\text { of } \\
\text { people } \\
\text { used for } \\
\text { the OR) }\end{array}$ & $\begin{array}{l}\text { OR for } \\
\text { highest } \\
\text { quartile }\end{array}$ & $\begin{array}{l}95 \% \mathrm{Cl}^{\mathrm{a}} \text { of } \\
\text { the fourth } \\
\text { quartile } \\
\text { OR }\end{array}$ & $\begin{array}{l}\mathrm{N} \\
\text { (Number } \\
\text { of } \\
\text { people } \\
\text { used for } \\
\text { the OR) }\end{array}$ \\
\hline $\begin{array}{l}\text { Total } \\
\text { population }\end{array}$ & 1.00 & 1.04 & $(0.82,1.33)$ & 471185 & 1.05 & $(0.84,1.31)$ & 758303 & $1.52^{* * * *}$ & $(1.24,1.86)$ & 3647621 \\
\hline $\begin{array}{l}\text { Percent } \\
\text { female }\end{array}$ & 1.00 & $1.14^{*}$ & $(1.05,1.23)$ & 261 & 0.99 & $(0.9$ & 2140378 & $0.89^{*}$ & $(0.8$ & 1801100 \\
\hline $\begin{array}{l}\text { Female } \\
\text { population }\end{array}$ & 1.00 & 1.08 & $(0.85,1.38)$ & 469590 & 1.11 & $(0.88,1.38)$ & 759228 & $1.55^{* * * *}$ & $(1.27,1.92)$ & 3648235 \\
\hline $\begin{array}{l}\text { Male } \\
\text { population }\end{array}$ & 1.00 & 1.03 & $(0.80,1.31)$ & 473126 & 1.18 & $(0.94,1.48)$ & 759731 & $1.58^{* * * *}$ & $(1.29,1.95)$ & 3645486 \\
\hline $\begin{array}{l}\text { Percent } \\
\text { white }\end{array}$ & 1.00 & $0.88^{*}$ & $(0.80,0.97)$ & 2307722 & $1.20^{* * * *}$ & $(1.12,1.32)$ & 3053523 & 0.95 & $(0.87,1.04)$ & 2501961 \\
\hline $\begin{array}{l}\text { Percent } \\
\text { black }\end{array}$ & 1.00 & $1.21^{* * * *}$ & $(1.11,1.32)$ & 2370527 & $0.87^{*}$ & $(0.77,0.97)$ & 1450737 & 1.02 & $(0.94,1.12)$ & 2522312 \\
\hline $\begin{array}{l}\text { Percent } \\
\text { living in } \\
\text { same } \\
\text { house }\end{array}$ & 1.00 & $0.68^{* * * *}$ & $(0.63,0.74)$ & 3962140 & $0.61^{* * * *}$ & $(0.54,0.70)$ & 3457814 & $0.59^{* * * *}$ & $(0.51,0.69)$ & 3376835 \\
\hline
\end{tabular}




\begin{tabular}{|c|c|c|c|c|c|c|c|c|c|c|}
\hline Variable & $\begin{array}{l}\text { OR for } \\
\text { lowest } \\
\text { quartile } \\
\text { (refer- } \\
\text { ence) }\end{array}$ & $\begin{array}{l}\text { OR for } \\
\text { second } \\
\text { quartile }\end{array}$ & $\begin{array}{l}95 \% \mathrm{Cl}^{\mathrm{a}} \text { of } \\
\text { the } \\
\text { second } \\
\text { quartile } \\
\text { OR }\end{array}$ & $\begin{array}{l}\text { N } \\
\text { (Number } \\
\text { of } \\
\text { people } \\
\text { used for } \\
\text { the OR) }\end{array}$ & $\begin{array}{l}\text { OR for } \\
\text { third } \\
\text { quartile }\end{array}$ & $\begin{array}{l}95 \% \mathrm{Cl}^{\mathrm{a}} \text { of } \\
\text { the third } \\
\text { quartile } \\
\text { OR }\end{array}$ & $\begin{array}{l}\mathrm{N} \\
\text { (Number } \\
\text { of } \\
\text { people } \\
\text { used for } \\
\text { the OR) }\end{array}$ & $\begin{array}{l}\text { OR for } \\
\text { highest } \\
\text { quartile }\end{array}$ & $\begin{array}{l}95 \% \mathrm{Cl}^{\mathrm{a}} \text { of } \\
\text { the fourth } \\
\text { quartile } \\
\text { OR }\end{array}$ & $\begin{array}{l}\mathrm{N} \\
\text { (Number } \\
\text { of } \\
\text { people } \\
\text { used for } \\
\text { the OR) }\end{array}$ \\
\hline $\begin{array}{l}\text { Per capita } \\
\text { income }\end{array}$ & 1.00 & 1.21 & $(0.97,1.51)$ & 648920 & $1.65^{\star * \star *}$ & $(1.37,2.00)$ & 1346989 & $2.23^{* * * *}$ & $(1.86,2.67)$ & 3098085 \\
\hline $\begin{array}{l}\text { Square } \\
\text { miles land }\end{array}$ & 1.00 & $1.12^{*}$ & $(1.03,1.22)$ & 2331699 & 1.07 & $(0.98,1.18)$ & 1911463 & 0.96 & $(0.87,1.06)$ & 1934333 \\
\hline $\begin{array}{l}\text { People } \\
\text { per sq. } \\
\text { mile }\end{array}$ & 1.00 & 1.22 & $(0.96,1.54)$ & 554040 & $1.38^{* *}$ & $(1.11,1.71)$ & 802485 & $1.85^{\star * \star *}$ & $(1.51,2.27)$ & 3585499 \\
\hline \multicolumn{11}{|c|}{$\begin{array}{l}\text { Each variable under analysis included } 159 \text { counties in GA. } \\
\text { a } 95 \% \mathrm{Cl} \text { is calculated using the case-control study estimation model } \\
{ }^{*} \text { Values are significant at the } 0.05 \text { level using a Chi-squared test for } 2 \times 2 \text { contingency tables } \\
{ }^{* * V a l u e s} \text { are significant at the } 0.01 \text { level using a Chi-squared test for } 2 \times 2 \text { contingency tables } \\
{ }^{* * *} \text { Values are significant at the } 0.001 \text { level using a Chi-squared test for } 2 \times 2 \text { contingency tables } \\
{ }^{* * * *} \text { Values are significant at the } 0.0001 \text { level using a Chi-squared test for } 2 \times 2 \text { contingency table }\end{array}$} \\
\hline
\end{tabular}


Table 10 shows MS self-reported-case prevalence for the male population showed no consistent results; however, the total population, the female population, the male population, and the per capita income showed increasing odds ratios starting from the second quartile. Also, the percent living in the same house seems to have a protective effect, i.e. OR and CI consistently less than 1.00 . 


\begin{tabular}{|c|c|c|c|c|c|c|c|c|c|c|}
\hline Variable & $\begin{array}{l}\text { OR for } \\
\text { lowest } \\
\text { quartile } \\
\text { (refer- } \\
\text { ence) }\end{array}$ & $\begin{array}{l}\text { OR for } \\
\text { second } \\
\text { quartile }\end{array}$ & $\begin{array}{l}95 \% \mathrm{Cl}^{\mathrm{a}} \\
\text { of the } \\
\text { second } \\
\text { quartile's } \\
\text { OR }\end{array}$ & $\begin{array}{l}\mathrm{N} \\
\text { (Number } \\
\text { of } \\
\text { people } \\
\text { used for } \\
\text { the OR) }\end{array}$ & $\begin{array}{l}\text { OR for } \\
\text { third } \\
\text { quartile }\end{array}$ & $\begin{array}{l}95 \% \mathrm{Cl}^{\mathrm{a}} \\
\text { of the } \\
\text { third } \\
\text { quartile's } \\
\text { OR }\end{array}$ & $\begin{array}{l}\mathrm{N} \\
\text { (Number } \\
\text { of } \\
\text { people } \\
\text { used for } \\
\text { the OR) }\end{array}$ & $\begin{array}{l}\text { OR for } \\
\text { highest } \\
\text { quartile }\end{array}$ & $\begin{array}{l}95 \% \mathrm{Cl}^{\mathrm{a}} \\
\text { of the } \\
\text { fourth } \\
\text { quartile's } \\
\text { OR }\end{array}$ & $\begin{array}{l}\mathrm{N} \\
\text { (Number } \\
\text { of } \\
\text { people } \\
\text { used for } \\
\text { the OR) }\end{array}$ \\
\hline $\begin{array}{l}\text { Total } \\
\text { population }\end{array}$ & 1.00 & 0.89 & $\begin{array}{l}(0.58 \\
1.37)\end{array}$ & 463772 & 0.97 & $\begin{array}{l}(0.65 \\
1.43)\end{array}$ & 750882 & $1.43^{*}$ & $\begin{array}{l}(1.01 \\
2.05)\end{array}$ & 3561055 \\
\hline $\begin{array}{l}\text { Percent } \\
\text { female }\end{array}$ & 1.00 & $1.22^{* *}$ & $\begin{array}{l}(1.06 \\
1.41)\end{array}$ & 2647012 & 1.1 & $\begin{array}{l}(0.93 \\
1.29)\end{array}$ & 2137986 & 0.99 & $\begin{array}{l}(0.82 \\
1.18)\end{array}$ & 1775359 \\
\hline $\begin{array}{l}\text { Female } \\
\text { population }\end{array}$ & 1.00 & 0.85 & $\begin{array}{l}(0.55 \\
1.31)\end{array}$ & 466835 & 0.98 & $\begin{array}{l}(0.66 \\
1.45)\end{array}$ & 748889 & $1.44^{*}$ & $\begin{array}{l}(1.01, \\
2.06)\end{array}$ & 3560785 \\
\hline $\begin{array}{l}\text { Male } \\
\text { population }\end{array}$ & 1.00 & 0.85 & $\begin{array}{l}(0.56 \\
1.30)\end{array}$ & 462912 & 0.86 & $\begin{array}{l}(0.58 \\
1.15)\end{array}$ & 750345 & 1.36 & $\begin{array}{l}(0.96 \\
1.92)\end{array}$ & 3561774 \\
\hline $\begin{array}{l}\text { Percent } \\
\text { white }\end{array}$ & 1.00 & $0.75^{* *}$ & $\begin{array}{l}(0.63 \\
0.90)\end{array}$ & 2210272 & 1.06 & $\begin{array}{l}(0.93 \\
1.20)\end{array}$ & 2965495 & $0.76^{* * *}$ & $\begin{array}{l}(0.65 \\
0.89)\end{array}$ & 2427952 \\
\hline $\begin{array}{l}\text { Percent } \\
\text { black }\end{array}$ & 1.00 & $1.29^{* *}$ & $\begin{array}{l}(1.10, \\
1.51)\end{array}$ & 2367221 & 1.01 & $\begin{array}{l}(0.81 \\
1.24)\end{array}$ & 1439423 & $1.27^{* *}$ & $\begin{array}{l}(1.08, \\
1.49)\end{array}$ & 2444828 \\
\hline $\begin{array}{l}\text { Percent } \\
\text { living in } \\
\text { same } \\
\text { house }\end{array}$ & 1.00 & $0.70^{* * * *}$ & $\begin{array}{c}(0.60 \\
0.82)\end{array}$ & 3885306 & $0.50^{* * * *}$ & $\begin{array}{l}(0.38 \\
0.65)\end{array}$ & 3400375 & $0.69^{* * *}$ & $\begin{array}{l}(0.53 \\
0.90)\end{array}$ & 3320481 \\
\hline
\end{tabular}




\begin{tabular}{|c|c|c|c|c|c|c|c|c|c|c|}
\hline \multicolumn{11}{|c|}{$\begin{array}{c}\text { Table 10: Odds Ratios(OR) and 95\% Confidence Interval (Cl) by Quartile: Census Data and Male Self-Reported MS } \\
\text { cases }\end{array}$} \\
\hline Variable & $\begin{array}{l}\text { OR for } \\
\text { lowest } \\
\text { quartile } \\
\text { (refer- } \\
\text { ence) }\end{array}$ & $\begin{array}{l}\text { OR for } \\
\text { second } \\
\text { quartile }\end{array}$ & $\begin{array}{l}95 \% \mathrm{Cl}^{\mathrm{a}} \\
\text { of the } \\
\text { second } \\
\text { quartile's } \\
\text { OR }\end{array}$ & $\begin{array}{l}\mathrm{N} \\
\text { (Number } \\
\text { of } \\
\text { people } \\
\text { used for } \\
\text { the OR) }\end{array}$ & $\begin{array}{l}\text { OR for } \\
\text { third } \\
\text { quartile }\end{array}$ & $\begin{array}{l}95 \% \mathrm{Cl}^{\mathrm{a}} \\
\text { of the } \\
\text { third } \\
\text { quartile's } \\
\text { OR }\end{array}$ & $\begin{array}{l}\mathrm{N} \\
\text { (Number } \\
\text { of } \\
\text { people } \\
\text { used for } \\
\text { the OR) }\end{array}$ & $\begin{array}{l}\text { OR for } \\
\text { highest } \\
\text { quartile }\end{array}$ & $\begin{array}{l}95 \% \mathrm{Cl}^{\mathrm{a}} \\
\text { of the } \\
\text { fourth } \\
\text { quartile's } \\
\text { OR }\end{array}$ & $\begin{array}{l}\mathrm{N} \\
\text { (Number } \\
\text { of } \\
\text { people } \\
\text { used for } \\
\text { the OR) }\end{array}$ \\
\hline $\begin{array}{l}\text { Per capita } \\
\text { income }\end{array}$ & 1.00 & 0.96 & $\begin{array}{l}(0.65 \\
1.42)\end{array}$ & 644971 & $1.41^{*}$ & $\begin{array}{l}(1.03, \\
1.95)\end{array}$ & 1309734 & $2.04^{* * * *}$ & $\begin{array}{l}(1.51 \\
2.77)\end{array}$ & 3060585 \\
\hline $\begin{array}{l}\text { Square } \\
\text { miles land } \\
\text { area } 2000\end{array}$ & 1.00 & 1.13 & $\begin{array}{c}(0.97 \\
1.32)\end{array}$ & 2255064 & 0.90 & $\begin{array}{c}(0.76 \\
1.07)\end{array}$ & 1885221 & 0.92 & $\begin{array}{c}(0.78 \\
1.09)\end{array}$ & 1884420 \\
\hline $\begin{array}{l}\text { People } \\
\text { per sq. } \\
\text { mile }\end{array}$ & 1.00 & 1.43 & $\begin{array}{l}(0.93, \\
2.20)\end{array}$ & 545324 & 1.26 & $\begin{array}{c}(0.84 \\
1.91)\end{array}$ & 792877 & $2.01^{* * *}$ & $\begin{array}{l}(1.38, \\
2.94)\end{array}$ & 3500055 \\
\hline $\begin{array}{l}\text { Each vari } \\
\text { a } 95 \% \mathrm{Cl} \\
{ }^{*} \text { Values a } \\
{ }^{* *} \text { Values } \\
{ }^{* * *} \text { Values }\end{array}$ & $\begin{array}{l}\text { le unde } \\
\text { calculat } \\
\text { signific } \\
\text { e signifi } \\
\text { re signif } \\
\text { are sign }\end{array}$ & $\begin{array}{l}\text { nalysis } \\
\text { using } t \\
\text { t at the } \\
\text { it at the } \\
\text { int at th } \\
\text { ant at th }\end{array}$ & $\begin{array}{l}\text { ludes } 15 \\
\text { case-co } \\
5 \text { level } \\
01 \text { level } \\
.001 \text { lev } \\
0.0001\end{array}$ & $\begin{array}{l}\text { counties } \\
\text { ol study } \\
\text { ig a Chi- } \\
\text { ing a Chi } \\
\text { using a C } \\
\text { l using a }\end{array}$ & $\begin{array}{l}\text { GA. } \\
\text { imatio } \\
\text { uared } \\
\text { quarec } \\
\text {-squar } \\
\text { hi-squ }\end{array}$ & $\begin{array}{l}\text { for } 2 x \\
\text { for } 2 x \\
\text { est for } 2 \\
\text { test fol }\end{array}$ & $\begin{array}{l}\text { ntingen } \\
\text { ontinge } \\
\text { conting } \\
2 \text { conti }\end{array}$ & $\begin{array}{l}\text { ables } \\
\text { tables } \\
\text { n tables } \\
\text { ncy table }\end{array}$ & & \\
\hline
\end{tabular}


Table 11 showed increases in the odds ratios for total MS self-reported cases, and tended to increase from the second to the fourth quartiles for county level emissions to outdoor air recognized developmental toxicants, suspected endocrine toxicants, suspected immunotoxicants, suspected kidney toxicants and ammonia. For many of these variables, only the fourth quartile showed statistical significance. Also, there seemed to be statistically significant lower odds ratios for recognized carcinogens. 


\begin{tabular}{|c|c|c|c|c|c|c|c|c|c|c|}
\hline $\begin{array}{l}\text { Variable (\# of } \\
\text { counties in } \\
\text { analysis for } \\
\text { each } \\
\text { variable }^{\text {b }} \text { ) }\end{array}$ & $\begin{array}{l}\text { OR for } \\
\text { lowest } \\
\text { quartile } \\
\text { (refer- } \\
\text { ence) }\end{array}$ & $\begin{array}{l}\text { OR for } \\
\text { second } \\
\text { quartile }\end{array}$ & $\begin{array}{l}95 \% \mathrm{Cl}^{\mathrm{a}} \\
\text { of the } \\
\text { second } \\
\text { quartile } \\
\text { OR }\end{array}$ & $\begin{array}{l}\mathrm{N} \\
\text { (Number } \\
\text { of people } \\
\text { used for } \\
\text { the OR) }\end{array}$ & $\begin{array}{l}\text { OR for } \\
\text { third } \\
\text { quartile }\end{array}$ & $\begin{array}{l}95 \% \\
\mathrm{Cl}^{\mathrm{a}} \text { of } \\
\text { the } \\
\text { third } \\
\text { quartile } \\
\text { OR }\end{array}$ & $\begin{array}{l}\mathrm{N} \\
\text { (Number } \\
\text { of } \\
\text { people } \\
\text { used for } \\
\text { the OR) }\end{array}$ & $\begin{array}{l}\text { OR for } \\
\text { highest } \\
\text { quartile }\end{array}$ & $\begin{array}{l}95 \% \\
\mathrm{Cl}^{\mathrm{a}} \text { of } \\
\text { the } \\
\text { highest } \\
\text { quartile } \\
\text { OR }\end{array}$ & $\begin{array}{l}\mathrm{N} \\
\text { (Number } \\
\text { of } \\
\text { people } \\
\text { used for } \\
\text { the OR) }\end{array}$ \\
\hline $\begin{array}{l}\text { Recognized } \\
\text { Carcinogens } \\
(83)\end{array}$ & 1.00 & $0.43^{* * * *}$ & $\begin{array}{r}(0.40 \\
0.46)\end{array}$ & 2683293 & $0.46^{* * * *}$ & $\begin{array}{l}(0.43 \\
0.49)\end{array}$ & 3977208 & $0.44^{* * * *}$ & $\begin{array}{l}(0.41 \\
0.48)\end{array}$ & 3188848 \\
\hline $\begin{array}{l}\text { Suspected } \\
\text { Carcinogens } \\
\text { (63) }\end{array}$ & 1.00 & $1.15^{\star *}$ & $\begin{array}{c}(1.05) \\
1.27)\end{array}$ & 2800765 & $0.88^{*}$ & $\begin{array}{c}(0.79, \\
0.98)\end{array}$ & 2112213 & $1.15^{* *}$ & $\begin{array}{c}(1.05 \\
1.25)\end{array}$ & 4245365 \\
\hline $\begin{array}{l}\text { Suspected } \\
\text { Cardio- } \\
\text { vascular or } \\
\text { Blood } \\
\text { Toxicants (99) }\end{array}$ & 1.00 & 1.09 & $\begin{array}{c}(0.97, \\
1.23)\end{array}$ & 1796302 & 1.04 & $\begin{array}{c}(0.93 \\
1.15)\end{array}$ & 2975051 & $1.19^{* * *}$ & $\begin{array}{c}(1.08 \\
1.31)\end{array}$ & 4844048 \\
\hline
\end{tabular}




\begin{tabular}{|c|c|c|c|c|c|c|c|c|c|c|}
\hline \multicolumn{11}{|c|}{$\begin{array}{c}\text { Table 11: Odds Ratios(OR) and 95\% Confidence Interval (CI) by Quartile: County Level Emissions and Total Self- } \\
\text { Reported MS cases }\end{array}$} \\
\hline $\begin{array}{l}\text { Variable (\# of } \\
\text { counties in } \\
\text { analysis for } \\
\text { each } \\
\text { variable }^{b} \text { ) }\end{array}$ & $\begin{array}{l}\text { OR for } \\
\text { lowest } \\
\text { quartile } \\
\text { (refer- } \\
\text { ence) }\end{array}$ & $\begin{array}{l}\text { OR for } \\
\text { second } \\
\text { quartile }\end{array}$ & $\begin{array}{l}95 \% \mathrm{Cl}^{\mathrm{a}} \\
\text { of the } \\
\text { second } \\
\text { quartile } \\
\text { OR }\end{array}$ & $\begin{array}{l}\mathrm{N} \\
\text { (Number } \\
\text { of people } \\
\text { used for } \\
\text { the OR) }\end{array}$ & $\begin{array}{l}\text { OR for } \\
\text { third } \\
\text { quartile }\end{array}$ & $\begin{array}{l}95 \% \\
\mathrm{Cl}^{\mathrm{a}} \text { of } \\
\text { the } \\
\text { third } \\
\text { quartile } \\
\text { OR }\end{array}$ & $\begin{array}{l}\mathrm{N} \\
\text { (Number } \\
\text { of } \\
\text { people } \\
\text { used for } \\
\text { the OR) }\end{array}$ & $\begin{array}{l}\text { OR for } \\
\text { highest } \\
\text { quartile }\end{array}$ & $\begin{array}{l}95 \% \\
\mathrm{Cl}^{\mathrm{a}} \text { of } \\
\text { the } \\
\text { highest } \\
\text { quartile } \\
\text { OR }\end{array}$ & $\begin{array}{l}\mathrm{N} \\
\text { (Number } \\
\text { of } \\
\text { people } \\
\text { used for } \\
\text { the OR) }\end{array}$ \\
\hline $\begin{array}{l}\text { Recognized } \\
\text { Develop- } \\
\text { mental } \\
\text { toxicants (79) }\end{array}$ & 1.00 & $0.90^{*}$ & $\begin{array}{c}(0.81 \\
1.00)\end{array}$ & 2358067 & 1.04 & $\begin{array}{c}(0.95 \\
1.15)\end{array}$ & 2989780 & 1.08 & $\begin{array}{c}(0.98 \\
1.18)\end{array}$ & 3881857 \\
\hline $\begin{array}{l}\text { Suspected } \\
\text { Develop- } \\
\text { mental } \\
\text { toxicants (94) }\end{array}$ & 1.00 & 1.04 & $\begin{array}{c}(0.94, \\
1.15)\end{array}$ & 2249010 & 0.92 & $\begin{array}{c}(0.84 \\
1.02)\end{array}$ & 3073401 & $1.16^{* * *}$ & $\begin{array}{c}(1.06 \\
1.27)\end{array}$ & 4435056 \\
\hline $\begin{array}{l}\text { Suspected } \\
\text { Endocrine } \\
\text { toxicants (64) }\end{array}$ & 1.00 & 0.92 & $\begin{array}{c}(0.83 \\
1.02)\end{array}$ & 2208012 & 0.95 & $\begin{array}{c}(0.87 \\
1.04)\end{array}$ & 3074432 & $1.15^{\text {*** }}$ & $\begin{array}{l}(1.06, \\
1.25)\end{array}$ & 4151693 \\
\hline $\begin{array}{l}\text { Suspected } \\
\text { Immuno- } \\
\text { toxicants (96) }\end{array}$ & 1.00 & $0.74^{* * * *}$ & $\begin{array}{c}(0.67 \\
0.82)\end{array}$ & 2319209 & 0.96 & $\begin{array}{c}(0.87 \\
1.04)\end{array}$ & 3165315 & $1.10^{*}$ & $\begin{array}{c}(1.02 \\
1.20)\end{array}$ & 4769708 \\
\hline
\end{tabular}




\begin{tabular}{|c|c|c|c|c|c|c|c|c|c|c|}
\hline \multicolumn{11}{|c|}{$\begin{array}{l}\text { Table 11: Odds Ratios(OR) and 95\% Confidence Interval (Cl) by Quartile: County Level Emissions and Total Self- } \\
\text { Reported MS cases }\end{array}$} \\
\hline $\begin{array}{l}\text { Variable (\# of } \\
\text { counties in } \\
\text { analysis for } \\
\text { each } \\
\text { variable }^{b} \text { ) }\end{array}$ & $\begin{array}{l}\text { OR for } \\
\text { lowest } \\
\text { quartile } \\
\text { (refer- } \\
\text { ence) }\end{array}$ & $\begin{array}{l}\text { OR for } \\
\text { second } \\
\text { quartile }\end{array}$ & $\begin{array}{l}95 \% \mathrm{Cl}^{\mathrm{a}} \\
\text { of the } \\
\text { second } \\
\text { quartile } \\
\text { OR }\end{array}$ & $\begin{array}{l}\text { N } \\
\text { (Number } \\
\text { of people } \\
\text { used for } \\
\text { the OR) }\end{array}$ & $\begin{array}{l}\text { OR for } \\
\text { third } \\
\text { quartile }\end{array}$ & $\begin{array}{l}95 \% \\
\mathrm{Cl}^{\mathrm{a}} \text { of } \\
\text { the } \\
\text { third } \\
\text { quartile } \\
\text { OR }\end{array}$ & $\begin{array}{l}\mathrm{N} \\
\text { (Number } \\
\text { of } \\
\text { people } \\
\text { used for } \\
\text { the OR) }\end{array}$ & $\begin{array}{l}\text { OR for } \\
\text { highest } \\
\text { quartile }\end{array}$ & $\begin{array}{l}95 \% \\
\mathrm{Cl}^{\mathrm{a}} \text { of } \\
\text { the } \\
\text { highest } \\
\text { quartile } \\
\text { OR }\end{array}$ & $\begin{array}{l}\mathrm{N} \\
\text { (Number } \\
\text { of } \\
\text { people } \\
\text { used for } \\
\text { the OR) }\end{array}$ \\
\hline $\begin{array}{l}\text { Suspected } \\
\text { Kidney } \\
\text { toxicants (100) }\end{array}$ & 1.00 & 1.03 & $\begin{array}{l}(0.91, \\
1.15)\end{array}$ & 1986463 & 1.07 & $\begin{array}{c}(0.96, \\
1.19)\end{array}$ & 3024089 & $1.26^{\star * * *}$ & $\begin{array}{l}(1.15, \\
1.39)\end{array}$ & 4653514 \\
\hline $\begin{array}{l}\text { Suspected } \\
\text { Gastro- } \\
\text { intestinal or } \\
\text { liver toxicants } \\
(107)\end{array}$ & 1.00 & $1.20^{* *}$ & $\begin{array}{c}(1.08, \\
1.35)\end{array}$ & 2096331 & 1.04 & $\begin{array}{l}(0.93 \\
1.15)\end{array}$ & 3101108 & $1.34^{* * * *}$ & $\begin{array}{l}(1.21 \\
1.47)\end{array}$ & 4699751 \\
\hline $\begin{array}{l}\text { Suspected } \\
\text { Musco- } \\
\text { skeletal } \\
\text { toxicants (32) }\end{array}$ & 1.00 & 1.09 & $\begin{array}{l}(0.99, \\
1.19)\end{array}$ & 2601356 & 0.96 & $\begin{array}{l}(0.87, \\
1.07)\end{array}$ & 2387914 & $1.29^{\star \star \star \star *}$ & $\begin{array}{l}(1.18, \\
1.41)\end{array}$ & 2617585 \\
\hline $\begin{array}{l}\text { Suspected } \\
\text { Neuro- } \\
\text { toxicants (104) }\end{array}$ & 1.00 & 1.05 & $\begin{array}{c}(0.95, \\
1.15)\end{array}$ & 2766274 & $0.86^{* *}$ & $\begin{array}{l}(0.78, \\
0.95)\end{array}$ & 2611959 & $1.16^{* * *}$ & $\begin{array}{r}(1.06, \\
1.26)\end{array}$ & 4723348 \\
\hline
\end{tabular}




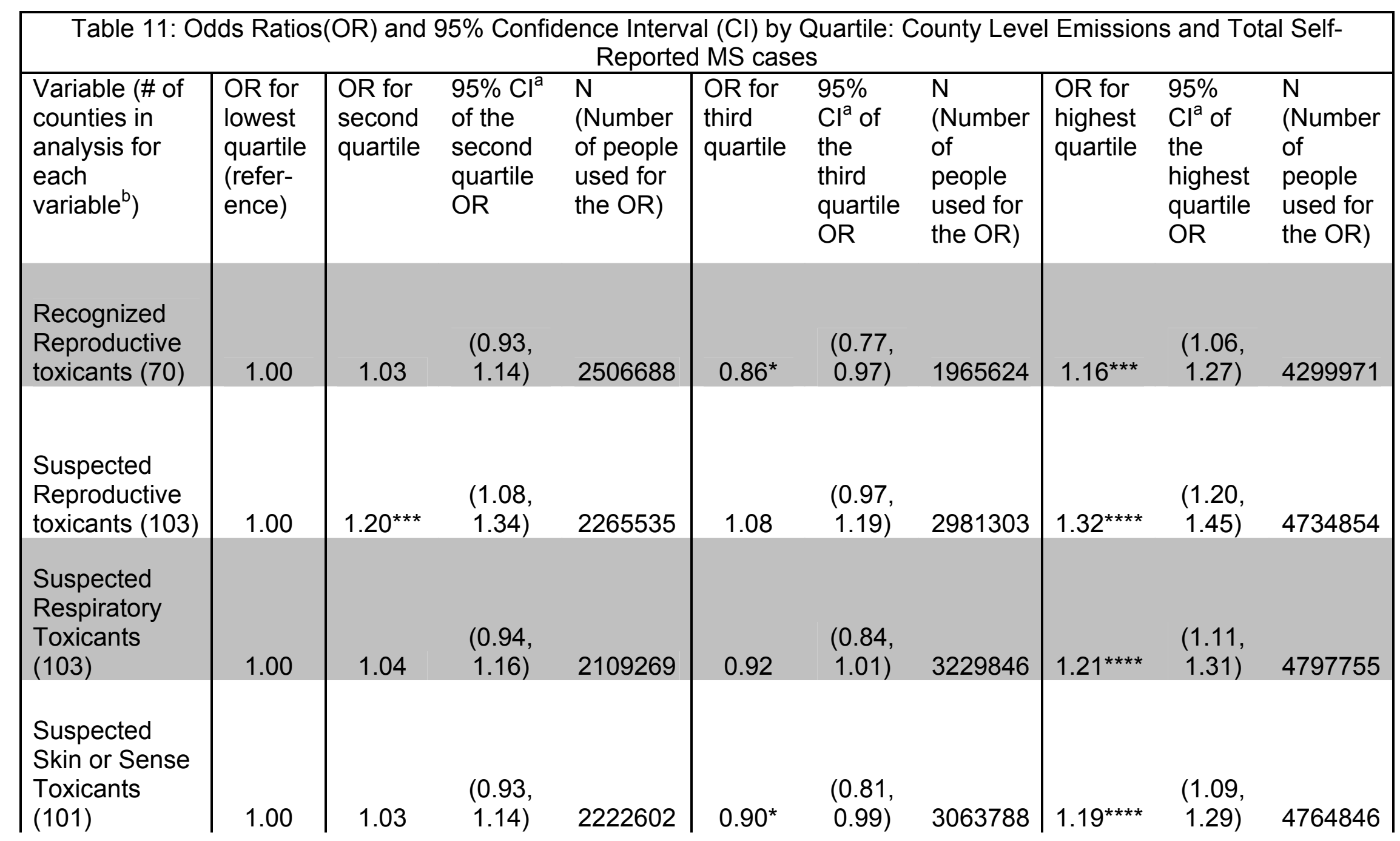




\begin{tabular}{|c|c|c|c|c|c|c|c|c|c|c|}
\hline $\begin{array}{l}\text { Variable (\# of } \\
\text { counties in } \\
\text { analysis for } \\
\text { each } \\
\text { variable }^{\text {b }} \text { ) }\end{array}$ & $\begin{array}{l}\text { OR for } \\
\text { lowest } \\
\text { quartile } \\
\text { (refer- } \\
\text { ence) }\end{array}$ & $\begin{array}{l}\text { OR for } \\
\text { second } \\
\text { quartile }\end{array}$ & $\begin{array}{l}95 \% \mathrm{Cl}^{\mathrm{a}} \\
\text { of the } \\
\text { second } \\
\text { quartile } \\
\text { OR }\end{array}$ & $\begin{array}{l}\mathrm{N} \\
\text { (Number } \\
\text { of people } \\
\text { used for } \\
\text { the OR) }\end{array}$ & $\begin{array}{l}\text { OR for } \\
\text { third } \\
\text { quartile }\end{array}$ & $\begin{array}{l}95 \% \\
\mathrm{Cl}^{\mathrm{a}} \text { of } \\
\text { the } \\
\text { third } \\
\text { quartile } \\
\text { OR }\end{array}$ & $\begin{array}{l}\mathrm{N} \\
\text { (Number } \\
\text { of } \\
\text { people } \\
\text { used for } \\
\text { the OR) }\end{array}$ & $\begin{array}{l}\text { OR for } \\
\text { highest } \\
\text { quartile }\end{array}$ & $\begin{array}{l}95 \% \\
\mathrm{Cl}^{\mathrm{a}} \text { of } \\
\text { the } \\
\text { highest } \\
\text { quartile } \\
\text { OR }\end{array}$ & $\begin{array}{l}\mathrm{N} \\
\text { (Number } \\
\text { of } \\
\text { people } \\
\text { used for } \\
\text { the OR) }\end{array}$ \\
\hline $\begin{array}{l}\text { Acetaldehyde } \\
\text { (14) }\end{array}$ & 1.00 & 0.75 & $\begin{array}{l}(0.55, \\
1.03)\end{array}$ & 277007 & 0.88 & $\begin{array}{l}(0.72 \\
1.09)\end{array}$ & 692052 & 0.91 & $\begin{array}{l}(0.73 \\
1.14)\end{array}$ & 513424 \\
\hline Ammonia (39) & 1.00 & 0.91 & $\begin{array}{c}(0.78, \\
1.05)\end{array}$ & 1684506 & $1.16^{* *}$ & $\begin{array}{l}(1.05 \\
1.27)\end{array}$ & 2564465 & $1.15^{\star *}$ & $\begin{array}{l}(1.06, \\
1.25)\end{array}$ & 3195643 \\
\hline $\begin{array}{l}\text { Formaldehyde } \\
\text { (27) }\end{array}$ & 1.00 & $1.45^{\star \star}$ & $\begin{array}{l}(1.14, \\
1.84)\end{array}$ & 472234 & $1.32^{* *}$ & $\begin{array}{l}(1.08, \\
1.61)\end{array}$ & 999745 & $1.53^{* * * *}$ & $\begin{array}{l}(1.26 \\
1.84)\end{array}$ & 1410500 \\
\hline $\begin{array}{l}\text { Lead/ lead } \\
\text { compounds } \\
(49)\end{array}$ & 1.00 & 0.92 & $\begin{array}{l}(0.81, \\
1.03)\end{array}$ & 1777914 & $0.83^{* *}$ & $\begin{array}{l}(0.74, \\
0.93)\end{array}$ & 1947538 & $1.14^{\star \star}$ & $\begin{array}{l}(1.04, \\
1.25)\end{array}$ & 2454203 \\
\hline $\begin{array}{l}\text { Manganese } \\
\text { compounds } \\
\text { (30) }\end{array}$ & 1.00 & 1 & $\begin{array}{l}(0.87, \\
1.16)\end{array}$ & 1819989 & $1.32^{* * *}$ & $\begin{array}{l}(1.14, \\
1.53)\end{array}$ & 1313616 & 0.96 & $\begin{array}{l}(0.82 \\
1.14)\end{array}$ & 1009772 \\
\hline Methanol (34) & 1.00 & 1.14 & $\begin{array}{r}(0.99, \\
1.31) \\
\end{array}$ & 1642066 & 1.12 & $\begin{array}{r}(0.97 \\
1.30) \\
\end{array}$ & 1334797 & 1.05 & $\begin{array}{l}(0.91 \\
1.21) \\
\end{array}$ & 1336137 \\
\hline
\end{tabular}




\begin{tabular}{|l|l|lll|lll|ll|}
\hline \multicolumn{7}{|c|}{ Table 11: Odds Ratios(OR) and 95\% Confidence Interval (CI) by Quartile: County Level Emissions and Total Self- } \\
Reported MS cases
\end{tabular}


Table 12 showed small to modest increases in the odds ratios for female MS self-reported cases, and tended to increase from the second to the fourth quartiles of county level emissions in pounds to outdoor air recognized developmental toxicants, suspected endocrine toxicants, suspected immunotoxicants, suspected kidney toxicants and ammonia. Also, there seemed to be lower odds ratios for recognized carcinogens; the values were similar across quartiles. 


\begin{tabular}{|c|c|c|c|c|c|c|c|c|c|c|}
\hline $\begin{array}{l}\text { Variable (\# of } \\
\text { counties in } \\
\left.\text { analysis }^{\text {b }}\right)\end{array}$ & $\begin{array}{l}\text { OR for } \\
\text { lowest } \\
\text { quartile } \\
\text { (refer- } \\
\text { ence) }\end{array}$ & $\begin{array}{l}\text { OR for } \\
\text { second } \\
\text { quartile }\end{array}$ & $\begin{array}{l}95 \% \mathrm{Cl}^{\mathrm{a}} \\
\text { of the } \\
\text { second } \\
\text { quartile' } \\
\text { s OR }\end{array}$ & $\begin{array}{l}\mathrm{N} \\
\text { (Number } \\
\text { of } \\
\text { people } \\
\text { used for } \\
\text { the OR) }\end{array}$ & $\begin{array}{l}\text { OR for } \\
\text { third } \\
\text { quartile }\end{array}$ & $\begin{array}{l}95 \% \\
\mathrm{Cl}^{a} \text { of } \\
\text { the } \\
\text { third } \\
\text { quartile' } \\
\text { s OR }\end{array}$ & $\begin{array}{l}\mathrm{N} \\
\text { (Number } \\
\text { of } \\
\text { people } \\
\text { used for } \\
\text { the OR) }\end{array}$ & $\begin{array}{l}\text { OR for } \\
\text { highest } \\
\text { quartile }\end{array}$ & $\begin{array}{l}95 \% \\
\mathrm{Cl}^{\mathrm{a}} \text { of } \\
\text { the } \\
\text { highest } \\
\text { quartil } \\
\text { e's OR }\end{array}$ & $\begin{array}{l}\mathrm{N} \\
\text { (Number } \\
\text { of } \\
\text { people } \\
\text { used for } \\
\text { the OR) }\end{array}$ \\
\hline $\begin{array}{l}\text { Recognized } \\
\text { Carcinogens } \\
\text { (83) }\end{array}$ & 1.00 & $0.86^{* *}$ & $\begin{array}{c}(0.77 \\
0.96)\end{array}$ & 1345737 & $0.89^{*}$ & $\begin{array}{l}(0.81 \\
0.98)\end{array}$ & 2004536 & $0.85^{\star *}$ & $\begin{array}{l}(0.77 \\
0.94)\end{array}$ & 1626595 \\
\hline $\begin{array}{l}\text { Suspected } \\
\text { Carcinogens } \\
(63)\end{array}$ & 1.00 & $1.14^{*}$ & $\begin{array}{r}(1.02, \\
1.27)\end{array}$ & 1428998 & 0.92 & $\begin{array}{c}(0.81 \\
1.05)\end{array}$ & 1080212 & $1.12^{*}$ & $\begin{array}{l}(1.01 \\
1.24)\end{array}$ & 2155182 \\
\hline $\begin{array}{l}\text { Suspected } \\
\text { Cardio- } \\
\text { vascular or } \\
\text { Blood } \\
\text { Toxicants (99) }\end{array}$ & 1.00 & 1.02 & $\begin{array}{c}(0.92, \\
1.21)\end{array}$ & 908939 & 1.04 & $\begin{array}{c}(0.92 \\
1.18)\end{array}$ & 1499244 & $1.16^{* *}$ & $\begin{array}{c}(1.04, \\
1.31)\end{array}$ & 2457076 \\
\hline $\begin{array}{l}\text { Recognized } \\
\text { Develop- } \\
\text { mental } \\
\text { toxicants (79) }\end{array}$ & 1.00 & 0.92 & $\begin{array}{c}(0.81, \\
1.04)\end{array}$ & 1181017 & 1.01 & $\begin{array}{c}(0.91 \\
1.14)\end{array}$ & 1513394 & 1.04 & $\begin{array}{l}(0.93 \\
1.16)\end{array}$ & 1979912 \\
\hline $\begin{array}{l}\text { Suspected } \\
\text { Develop- } \\
\text { mental } \\
\text { toxicants (94) }\end{array}$ & 1.00 & 1.04 & $\begin{array}{c}(0.92 \\
1.17)\end{array}$ & 1140228 & 0.94 & $\begin{array}{c}(0.84, \\
1.06)\end{array}$ & 1544766 & 1.12 & $\begin{array}{l}(1.01 \\
1.24)\end{array}$ & 2255240 \\
\hline
\end{tabular}




\begin{tabular}{|c|c|c|c|c|c|c|c|c|c|c|}
\hline \multicolumn{11}{|c|}{$\begin{array}{c}\text { Table 12: Odds Ratios(OR) and 95\% Confidence Interval }(\mathrm{Cl}) \text { by Quartile: County Level Emissions and Female Self- } \\
\text { Reported } \mathrm{MS} \text { cases }\end{array}$} \\
\hline $\begin{array}{l}\text { Variable (\# of } \\
\text { counties in } \\
\text { analysis }^{b} \text { ) }\end{array}$ & $\begin{array}{l}\text { OR for } \\
\text { lowest } \\
\text { quartile } \\
\text { (refer- } \\
\text { ence) }\end{array}$ & $\begin{array}{l}\text { OR for } \\
\text { second } \\
\text { quartile }\end{array}$ & $\begin{array}{l}95 \% \mathrm{Cl}^{\mathrm{a}} \\
\text { of the } \\
\text { second } \\
\text { quartile' } \\
\text { s OR }\end{array}$ & $\begin{array}{l}\mathrm{N} \\
\text { (Number } \\
\text { of } \\
\text { people } \\
\text { used for } \\
\text { the OR) }\end{array}$ & $\begin{array}{l}\text { OR for } \\
\text { third } \\
\text { quartile }\end{array}$ & $\begin{array}{l}95 \% \\
\mathrm{Cl}^{\mathrm{a}} \text { of } \\
\text { the } \\
\text { third } \\
\text { quartile' } \\
\text { s OR }\end{array}$ & $\begin{array}{l}\mathrm{N} \\
\text { (Number } \\
\text { of } \\
\text { people } \\
\text { used for } \\
\text { the OR) }\end{array}$ & $\begin{array}{l}\text { OR for } \\
\text { highest } \\
\text { quartile }\end{array}$ & $\begin{array}{l}95 \% \\
\mathrm{Cl}^{\mathrm{a}} \text { of } \\
\text { the } \\
\text { highest } \\
\text { quartil } \\
\text { e's OR }\end{array}$ & $\begin{array}{l}\mathrm{N} \\
\text { (Number } \\
\text { of } \\
\text { people } \\
\text { used for } \\
\text { the OR) }\end{array}$ \\
\hline $\begin{array}{l}\text { Suspected } \\
\text { Endocrine } \\
\text { toxicants (64) }\end{array}$ & 1.00 & 0.94 & $\begin{array}{c}(0.83 \\
1.07)\end{array}$ & 1126196 & 1.01 & $\begin{array}{c}(0.90 \\
1.12)\end{array}$ & 1551054 & $1.14^{* *}$ & $\begin{array}{c}(1.04, \\
1.26)\end{array}$ & 2109476 \\
\hline $\begin{array}{l}\text { Suspected } \\
\text { Immuno- } \\
\text { toxicants (96) }\end{array}$ & 1.00 & $0.72^{\star * \star *}$ & $\begin{array}{c}(0.64, \\
0.82)\end{array}$ & 1175080 & 0.96 & $\begin{array}{c}(0.86 \\
1.06)\end{array}$ & 1584123 & 1.07 & $\begin{array}{c}(0.97 \\
1.17)\end{array}$ & 2423900 \\
\hline $\begin{array}{l}\text { Suspected } \\
\text { Kidney } \\
\text { toxicants (100) }\end{array}$ & 1.00 & 1.04 & $\begin{array}{c}(0.90 \\
1.19)\end{array}$ & 1006583 & 1.10 & $\begin{array}{c}(0.97 \\
1.24)\end{array}$ & 1516143 & $1.24^{* * *}$ & $\begin{array}{c}(1.10 \\
1.39)\end{array}$ & 2366472 \\
\hline $\begin{array}{l}\text { Suspected } \\
\text { Gastro- } \\
\text { intestinal or } \\
\text { liver toxicants } \\
(107)\end{array}$ & 1.00 & $1.15^{*}$ & $\begin{array}{c}(1.01 \\
1.31)\end{array}$ & 1056961 & 1.05 & $\begin{array}{c}(0.93 \\
1.19)\end{array}$ & 1563048 & $1.28^{* * * *}$ & $\begin{array}{c}(1.15 \\
1.44)\end{array}$ & 2390813 \\
\hline $\begin{array}{l}\text { Suspected } \\
\text { Musco-skeletal } \\
\text { toxicants (32) }\end{array}$ & 1.00 & 1.03 & $\begin{array}{c}(0.92 \\
1.15)\end{array}$ & 1311624 & 0.96 & $\begin{array}{c}(0.85 \\
1.09)\end{array}$ & 1214744 & $1.29 * * * *$ & $\begin{array}{c}(1.16 \\
1.43)\end{array}$ & 1313325 \\
\hline $\begin{array}{l}\text { Suspected } \\
\text { Neuro- } \\
\text { toxicants (104) }\end{array}$ & 1.00 & 1.07 & $\begin{array}{c}(0.95 \\
1.20)\end{array}$ & 1385840 & 0.89 & $\begin{array}{r}(0.79 \\
1.01)\end{array}$ & 1323064 & $1.14^{*}$ & $\begin{array}{c}(1.03 \\
1.26)\end{array}$ & 2398195 \\
\hline
\end{tabular}




\begin{tabular}{|c|c|c|c|c|c|c|c|c|c|c|}
\hline \multicolumn{11}{|c|}{$\begin{array}{c}\text { Table 12: Odds Ratios(OR) and 95\% Confidence Interval (Cl) by Quartile: County Level Emissions and Female Self- } \\
\text { Reported MS cases }\end{array}$} \\
\hline $\begin{array}{l}\text { Variable (\# of } \\
\text { counties in } \\
\left.\text { analysis }^{\text {b }}\right)\end{array}$ & $\begin{array}{l}\text { OR for } \\
\text { lowest } \\
\text { quartile } \\
\text { (refer- } \\
\text { ence) }\end{array}$ & $\begin{array}{l}\text { OR for } \\
\text { second } \\
\text { quartile }\end{array}$ & $\begin{array}{l}95 \% \mathrm{Cl}^{\mathrm{a}} \\
\text { of the } \\
\text { second } \\
\text { quartile' } \\
\text { s OR }\end{array}$ & $\begin{array}{l}\mathrm{N} \\
\text { (Number } \\
\text { of } \\
\text { people } \\
\text { used for } \\
\text { the OR) }\end{array}$ & $\begin{array}{l}\text { OR for } \\
\text { third } \\
\text { quartile }\end{array}$ & $\begin{array}{l}95 \% \\
\mathrm{Cl}^{\mathrm{a}} \text { of } \\
\text { the } \\
\text { third } \\
\text { quartile' } \\
\text { s OR }\end{array}$ & $\begin{array}{l}\mathrm{N} \\
\text { (Number } \\
\text { of } \\
\text { people } \\
\text { used for } \\
\text { the OR) }\end{array}$ & $\begin{array}{l}\text { OR for } \\
\text { highest } \\
\text { quartile }\end{array}$ & $\begin{array}{l}95 \% \\
\mathrm{Cl}^{\mathrm{a}} \text { of } \\
\text { the } \\
\text { highest } \\
\text { quartil } \\
\text { e's OR }\end{array}$ & $\begin{array}{l}\mathrm{N} \\
\text { (Number } \\
\text { of } \\
\text { people } \\
\text { used for } \\
\text { the OR) }\end{array}$ \\
\hline $\begin{array}{l}\text { Recognized } \\
\text { Reproductive } \\
\text { toxicants (70) }\end{array}$ & 1.00 & 1.05 & $\begin{array}{l}(0.93 \\
1.18)\end{array}$ & 1257874 & 0.88 & $\begin{array}{c}(0.77, \\
1.01)\end{array}$ & 993398 & $1.13^{*}$ & $\begin{array}{r}(1.01 \\
1.25)\end{array}$ & 2182681 \\
\hline $\begin{array}{l}\text { Suspected } \\
\text { Reproductive } \\
\text { toxicants (103) }\end{array}$ & 1.00 & $1.15^{\star}$ & $\begin{array}{c}(1.01 \\
1.31)\end{array}$ & 1144559 & 1.09 & $\begin{array}{c}(0.97 \\
1.23)\end{array}$ & 1498011 & $1.25^{\star * * *}$ & $\begin{array}{l}(1.12, \\
1.40)\end{array}$ & 2408274 \\
\hline $\begin{array}{l}\text { Suspected } \\
\text { Respiratory } \\
\text { Toxicants } \\
\text { (103) }\end{array}$ & 1.00 & 1.05 & $\begin{array}{r}(0.93, \\
1.19)\end{array}$ & 1065348 & 0.95 & $\begin{array}{l}(0.85 \\
1.06)\end{array}$ & 1624733 & $1.19^{* * *}$ & $\begin{array}{l}(1.07, \\
1.32)\end{array}$ & 2438482 \\
\hline $\begin{array}{l}\text { Suspected } \\
\text { Skin or Sense } \\
\text { Toxicants } \\
\text { (101) }\end{array}$ & 1.00 & 1.03 & $\begin{array}{l}(0.91 \\
1.16)\end{array}$ & 1124204 & 0.94 & $\begin{array}{c}(0.84 \\
1.05)\end{array}$ & 1538373 & $1.18^{*}$ & $\begin{array}{l}(1.06 \\
1.30)\end{array}$ & 2421997 \\
\hline $\begin{array}{l}\text { Acetaldehyde } \\
\text { (14) }\end{array}$ & 1.00 & 0.9 & $\begin{array}{l}(0.62 \\
1.30)\end{array}$ & 138622 & 0.89 & $\begin{array}{l}(0.69 \\
1.15)\end{array}$ & 358164 & 1.08 & $\begin{array}{l}(0.83 \\
1.40)\end{array}$ & 262337 \\
\hline Ammonia (39) & 1.00 & 0.91 & $\begin{array}{l}(0.76 \\
1.08)\end{array}$ & 848900 & $1.13^{*}$ & $\begin{array}{l}(1.01 \\
1.26)\end{array}$ & 1289724 & $1.11^{*}$ & $\begin{array}{l}(1.00 \\
1.23)\end{array}$ & 1621452 \\
\hline
\end{tabular}




\begin{tabular}{|c|c|c|c|c|c|c|c|c|c|c|}
\hline \multicolumn{11}{|c|}{$\begin{array}{c}\text { Table 12: Odds Ratios(OR) and 95\% Confidence Interval }(\mathrm{Cl}) \text { by Quartile: County Level Emissions and Female Self- } \\
\text { Reported MS cases }\end{array}$} \\
\hline $\begin{array}{l}\text { Variable (\# of } \\
\text { counties in } \\
\text { analysis }^{\mathrm{b}} \text { ) }\end{array}$ & $\begin{array}{l}\text { OR for } \\
\text { lowest } \\
\text { quartile } \\
\text { (refer- } \\
\text { ence) }\end{array}$ & $\begin{array}{l}\text { OR for } \\
\text { second } \\
\text { quartile }\end{array}$ & $\begin{array}{l}95 \% \mathrm{Cl}^{\mathrm{a}} \\
\text { of the } \\
\text { second } \\
\text { quartile' } \\
\text { s OR }\end{array}$ & $\begin{array}{l}\mathrm{N} \\
\text { (Number } \\
\text { of } \\
\text { people } \\
\text { used for } \\
\text { the OR) }\end{array}$ & $\begin{array}{l}\text { OR for } \\
\text { third } \\
\text { quartile }\end{array}$ & $\begin{array}{l}95 \% \\
\mathrm{Cl}^{\mathrm{a}} \text { of } \\
\text { the } \\
\text { third } \\
\text { quartile' } \\
\mathrm{s} \text { OR }\end{array}$ & $\begin{array}{l}\mathrm{N} \\
\text { (Number } \\
\text { of } \\
\text { people } \\
\text { used for } \\
\text { the OR) }\end{array}$ & $\begin{array}{l}\text { OR for } \\
\text { highest } \\
\text { quartile }\end{array}$ & $\begin{array}{l}95 \% \\
\mathrm{Cl}^{\mathrm{a}} \text { of } \\
\text { the } \\
\text { highest } \\
\text { quartil } \\
\text { e's OR }\end{array}$ & $\begin{array}{l}\mathrm{N} \\
\text { (Number } \\
\text { of } \\
\text { people } \\
\text { used for } \\
\text { the OR) }\end{array}$ \\
\hline $\begin{array}{l}\text { Formaldehyde } \\
\text { (27) }\end{array}$ & 1.00 & $1.42^{* *}$ & $\begin{array}{l}(1.08 \\
1.87)\end{array}$ & 238691 & 1.23 & $\begin{array}{r}(0.98 \\
1.55)\end{array}$ & 512801 & $1.34^{* *}$ & $\begin{array}{l}(1.08 \\
1.67)\end{array}$ & 720232 \\
\hline $\begin{array}{l}\text { Lead/ lead } \\
\text { compounds } \\
(49)\end{array}$ & 1.00 & 0.93 & $\begin{array}{r}(0.81 \\
1.07)\end{array}$ & 891840 & $0.81^{*}$ & $\begin{array}{l}(0.71 \\
0.93)\end{array}$ & 985396 & $1.15^{*}$ & $\begin{array}{r}(1.03, \\
1.28)\end{array}$ & 1226351 \\
\hline $\begin{array}{l}\text { Manganese } \\
\text { compounds } \\
(30)\end{array}$ & 1.00 & 1.03 & $\begin{array}{r}(0.87 \\
1.23)\end{array}$ & 919813 & $1.34^{* * *}$ & $\begin{array}{l}(1.12 \\
1.60)\end{array}$ & 662482 & 1.02 & $\begin{array}{l}(0.84 \\
1.24)\end{array}$ & 515580 \\
\hline Methanol (34) & 1.00 & 1.13 & $\begin{array}{r}(0.96 \\
1.34) \\
\end{array}$ & 837831 & 1.08 & $\begin{array}{l}(0.91 \\
1.28) \\
\end{array}$ & 681676 & 1.07 & $\begin{array}{r}(0.90 \\
1.28) \\
\end{array}$ & 689674 \\
\hline \multicolumn{11}{|c|}{$\begin{array}{l}\text { The measurements for toxicants and selected produced compounds were reported in pounds for the year } 2002 . \\
\text { a } 95 \% \mathrm{Cl} \text { is calculated using the case-control study estimation model. } \\
\text { b Every county that had information concerning the respective variable was included. The total number of counties in GA } \\
\text { is } 159 \text { at the time of this study. } \\
{ }^{*} \text { Values are significant at the } 0.05 \text { level using a Chi-squared test for } 2 \times 2 \text { contingency tables. } \\
{ }^{* * V a l u e s ~ a r e ~ s i g n i f i c a n t ~ a t ~ t h e ~} 0.01 \text { level using a Chi-squared test for } 2 \times 2 \text { contingency tables. } \\
{ }^{* * * V a l u e s ~ a r e ~ s i g n i f i c a n t ~ a t ~ t h e ~} 0.001 \text { level using a Chi-squared test for } 2 \times 2 \text { contingency tables. } \\
{ }^{* * * * V a l u e s ~ a r e ~ s i g n i f i c a n t ~ a t ~ t h e ~} 0.0001 \text { level using a Chi-squared test for } 2 \times 2 \text { contingency tables. }\end{array}$} \\
\hline
\end{tabular}


Table 13 showed odds ratios tended to increase for male MS self-reported from the second to the fourth quartiles of county level emissions in pounds of outdoor air for recognized developmental toxicants, suspected endocrine toxicants, suspected immunotoxicants, suspected kidney toxicants, ammonia and formaldehyde. It is important to note only the counties that reported values for the variable of interest were included for each variable. 


\begin{tabular}{|c|c|c|c|c|c|c|c|c|c|c|}
\hline \multicolumn{11}{|c|}{$\begin{array}{c}\text { Table 13: Odds Ratios(OR) and 95\% Confidence Interval }(\mathrm{Cl}) \text { by Quartile: County Level Emissions and Male Self- } \\
\text { Reported MS cases }\end{array}$} \\
\hline $\begin{array}{l}\text { Variable (\# of } \\
\text { counties in } \\
\left.\text { analysis }^{\text {b }}\right)\end{array}$ & $\begin{array}{l}\text { OR for } \\
\text { lowest } \\
\text { quartile }\end{array}$ & $\begin{array}{l}\text { OR for } \\
\text { second } \\
\text { quartile }\end{array}$ & $\begin{array}{l}95 \% \mathrm{Cl}^{\mathrm{a}} \\
\text { of the } \\
\text { second } \\
\text { quartile } \\
\text { OR }\end{array}$ & $\begin{array}{l}\mathrm{N} \\
\text { (Number } \\
\text { of people } \\
\text { used for } \\
\text { the OR) }\end{array}$ & $\begin{array}{l}\text { OR for } \\
\text { third } \\
\text { quartile }\end{array}$ & $\begin{array}{l}95 \% \\
\mathrm{Cl}^{\mathrm{a}} \text { of } \\
\text { the } \\
\text { third } \\
\text { quartile } \\
\text { OR }\end{array}$ & $\begin{array}{l}\mathrm{N} \\
\text { (Number } \\
\text { of } \\
\text { people } \\
\text { used for } \\
\text { the OR) }\end{array}$ & $\begin{array}{l}\text { OR for } \\
\text { highest } \\
\text { quartile }\end{array}$ & $\begin{array}{l}95 \% \\
\mathrm{Cl}^{\mathrm{a}} \text { of } \\
\text { the } \\
\text { highest } \\
\text { quartile } \\
\text { OR }\end{array}$ & $\begin{array}{l}\mathrm{N} \\
\text { (Number } \\
\text { of } \\
\text { people } \\
\text { used for } \\
\text { the OR) }\end{array}$ \\
\hline $\begin{array}{l}\text { Suspected } \\
\text { Carcinogens } \\
\text { (63) }\end{array}$ & 1.00 & 1.19 & $\begin{array}{c}(0.97 \\
1.47)\end{array}$ & 1371767 & 0.88 & $\begin{array}{c}(0.69 \\
1.13)\end{array}$ & 1032001 & $1.31^{* *}$ & $\begin{array}{c}(1.08 \\
1.58)\end{array}$ & 2090183 \\
\hline $\begin{array}{l}\text { Suspected } \\
\text { Cardio- } \\
\text { vascular or } \\
\text { Blood } \\
\text { Toxicants (99) }\end{array}$ & 1.00 & 1.25 & $\begin{array}{c}(0.97 \\
1.61)\end{array}$ & 887363 & 1.08 & $\begin{array}{c}(0.85 \\
1.36)\end{array}$ & 1475807 & $1.32^{*}$ & $\begin{array}{c}(1.06, \\
1.64)\end{array}$ & 2386972 \\
\hline $\begin{array}{l}\text { Recognized } \\
\text { Develop- } \\
\text { mental } \\
\text { toxicants (79) }\end{array}$ & 1.00 & 0.95 & $\begin{array}{r}(0.75, \\
1.20)\end{array}$ & 1177051 & 1.20 & $\begin{array}{c}(0.97 \\
1.49)\end{array}$ & 1476386 & $1.25^{*}$ & $\begin{array}{r}(1.02, \\
1.53)\end{array}$ & 1901945 \\
\hline $\begin{array}{l}\text { Suspected } \\
\text { Develop- } \\
\text { mental } \\
\text { toxicants (94) }\end{array}$ & 1.00 & 1.05 & $\begin{array}{r}(0.83, \\
1.32)\end{array}$ & 1108782 & 0.90 & $\begin{array}{l}(0.72, \quad-1 \\
1.11)\end{array}$ & 1528635 & $1.31^{* *}$ & $\begin{array}{r}(1.09, \\
1.59)\end{array}$ & 2179816 \\
\hline
\end{tabular}




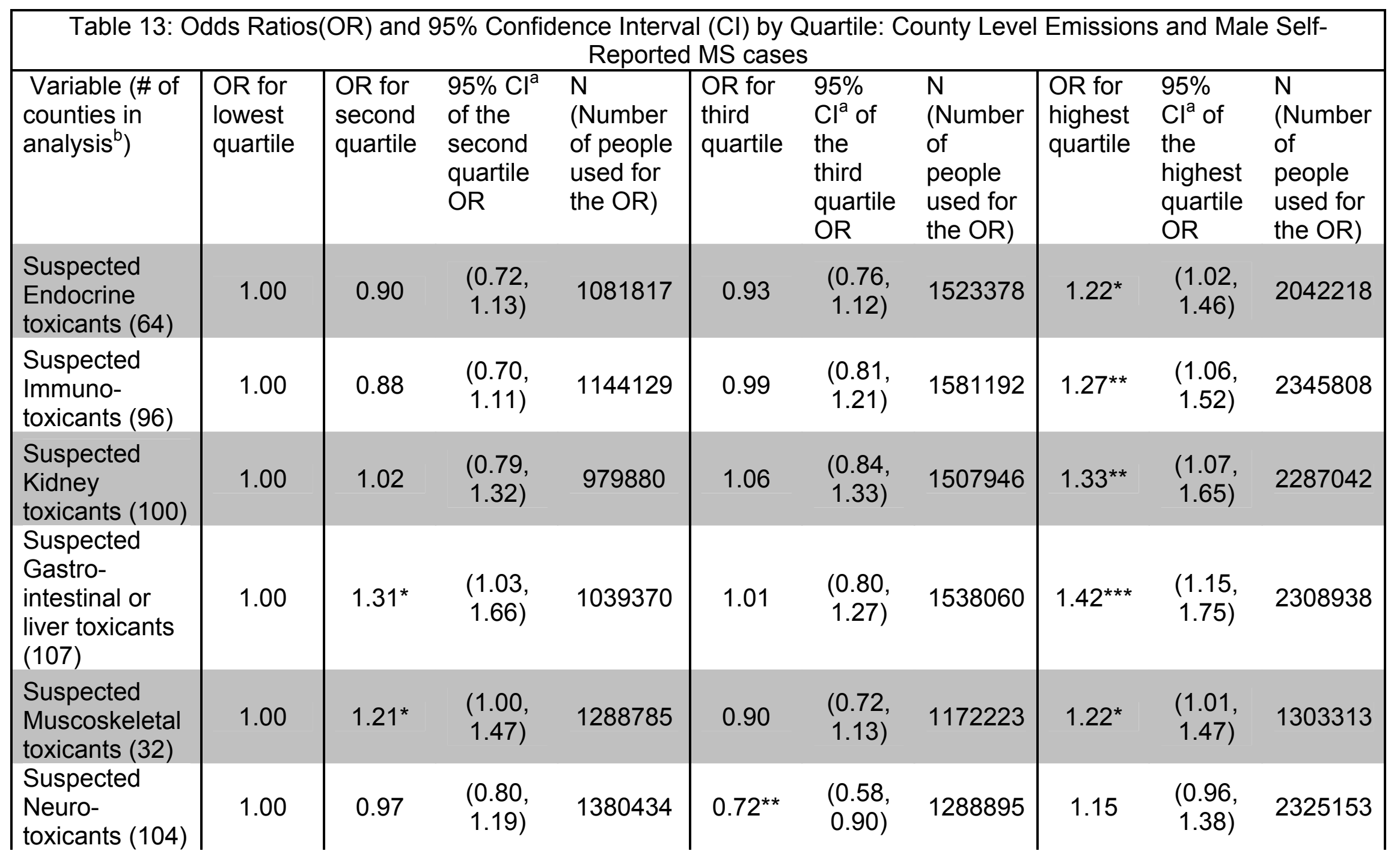




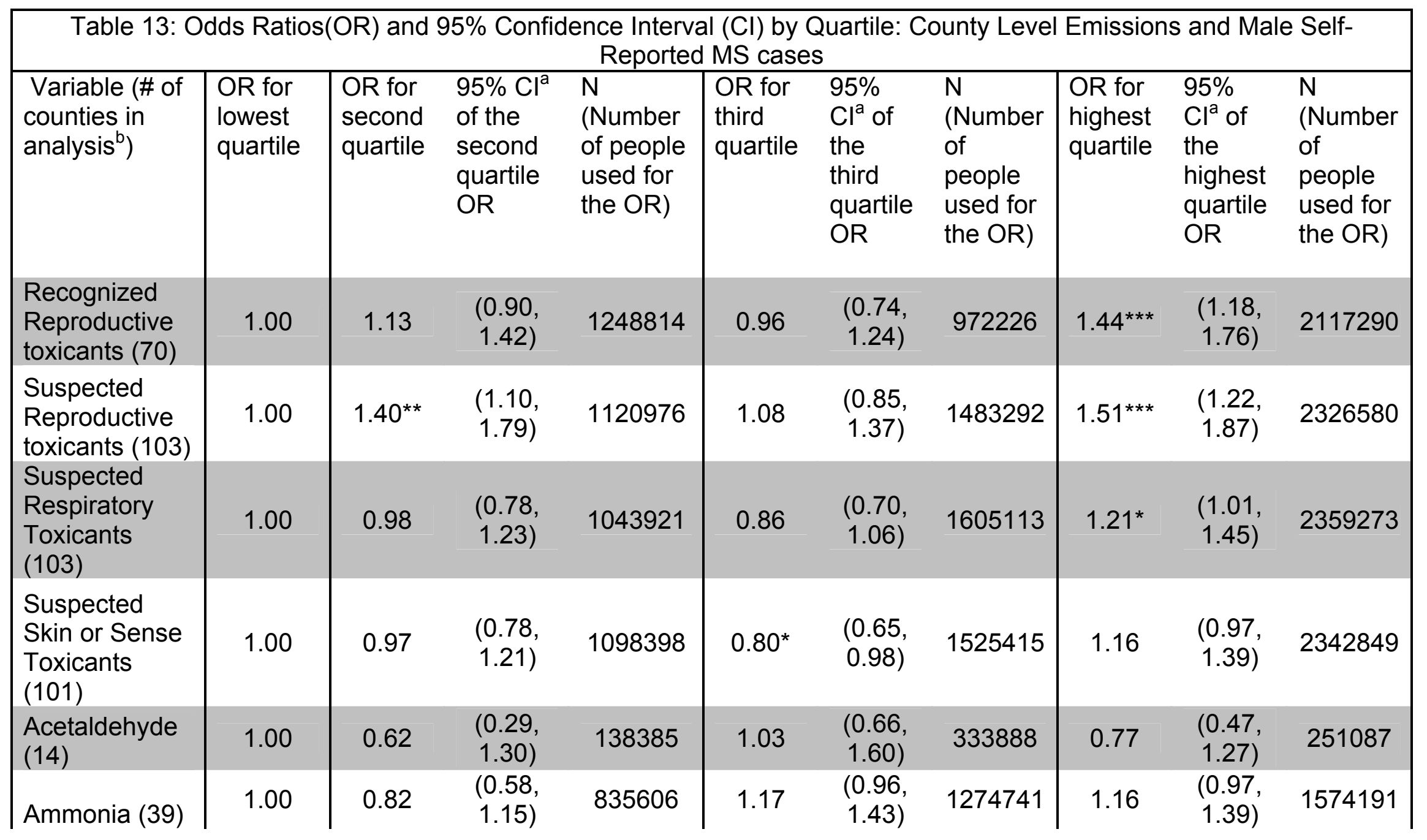




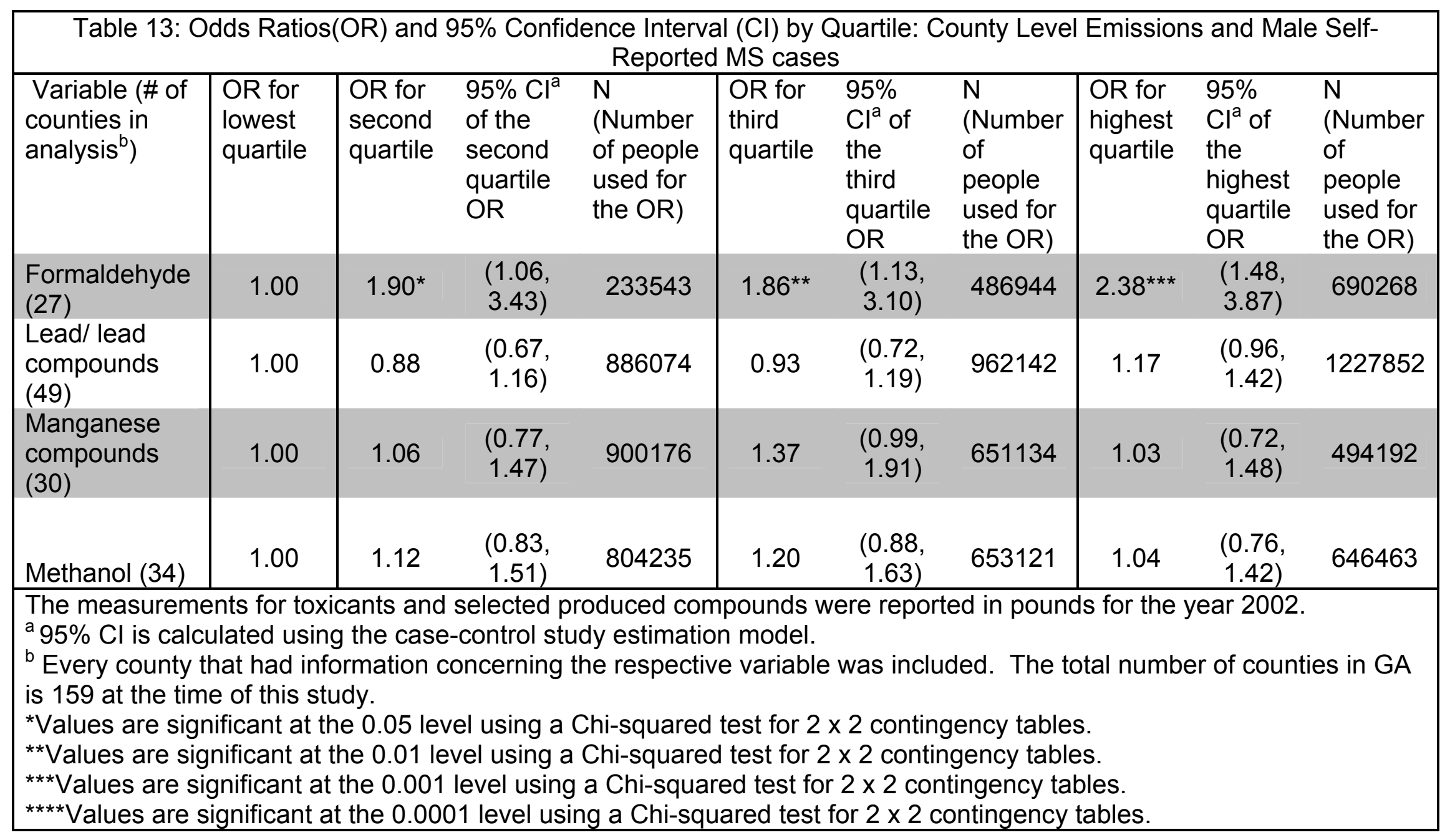


Table 14 shows increasing odds ratios for total MS self-reported cases with increasing emissions of selected criteria air pollutants to outdoor air for carbon monoxide (mobile sources), nitrogen oxides (mobile and areas sources), PM-2.5 (mobile sources), PM-10 (mobile sources), and volatile organic compounds (mobile sources). In addition, the odds ratios tended to increase from the second to the fourth quartile for nitrogen (all sources), PM-2.5 (area and all sources), PM-10 (area and all sources), sulfur dioxide (area and all sources), and volatile organic compounds (area sources). The majority of these findings were highly statistically significant. 


\begin{tabular}{|c|c|c|c|c|c|c|c|c|c|c|}
\hline \multicolumn{11}{|c|}{$\begin{array}{c}\text { Table 14: Odds Ratios(OR) and 95\% Confidence Interval }(\mathrm{Cl}) \text { by Quartile: Criteria Air Pollutants and Total Self- } \\
\text { Reported MS cases }\end{array}$} \\
\hline Variable & $\begin{array}{l}\text { OR for } \\
\text { lowest } \\
\text { quartile }\end{array}$ & $\begin{array}{l}\text { OR for } \\
\text { second } \\
\text { quartile }\end{array}$ & $\begin{array}{l}95 \% \mathrm{Cl}^{\mathrm{a}} \\
\text { of the } \\
\text { second } \\
\text { quartile } \\
\text { OR }\end{array}$ & $\begin{array}{l}\text { N } \\
\text { (Number } \\
\text { of } \\
\text { people } \\
\text { used for } \\
\text { the OR) }\end{array}$ & $\begin{array}{l}\text { OR for } \\
\text { third } \\
\text { quartile }\end{array}$ & $\begin{array}{l}95 \% \mathrm{Cl}^{\mathrm{a}} \\
\text { of the } \\
\text { third } \\
\text { quartile } \\
\text { OR }\end{array}$ & $\begin{array}{l}\text { N } \\
\text { (Number } \\
\text { of } \\
\text { people } \\
\text { used for } \\
\text { the OR) }\end{array}$ & $\begin{array}{l}\text { OR for } \\
\text { highest } \\
\text { quartile }\end{array}$ & $\begin{array}{l}95 \% \mathrm{Cl}^{\mathrm{a}} \\
\text { of the } \\
\text { fourth } \\
\text { quartile } \\
\text { OR }\end{array}$ & $\begin{array}{l}\mathrm{N} \text { (Number } \\
\text { of people } \\
\text { used for } \\
\text { the OR) }\end{array}$ \\
\hline $\begin{array}{l}\text { Carbon } \\
\text { Monoxide } \\
\text { (mobile) }\end{array}$ & 1.00 & $1.21^{*}$ & $\begin{array}{l}(1.00 \\
1.47)\end{array}$ & 1067078 & $1.26^{*}$ & $\begin{array}{l}(1.11 \\
1.42)\end{array}$ & 1546590 & $1.63^{* * * *}$ & $\begin{array}{r}(1.38, \\
1.92)\end{array}$ & 6946275 \\
\hline $\begin{array}{l}\text { Carbon } \\
\text { monoxide } \\
\text { (area) }\end{array}$ & 1.00 & $1.29^{* * * *}$ & $\begin{array}{r}(1.15, \\
1.44)\end{array}$ & 2906874 & $1.26^{* * * *}$ & $\begin{array}{r}(1.12, \\
1.42)\end{array}$ & 2366165 & $1.46^{* * * *}$ & $\begin{array}{r}(1.31 \\
1.62)\end{array}$ & 5166698 \\
\hline $\begin{array}{l}\text { Carbon } \\
\text { monoxide } \\
\text { (all) }\end{array}$ & 1.00 & $0.75^{* * * *}$ & $\begin{array}{l}(0.65, \\
0.86)\end{array}$ & 1343172 & $0.72^{* * * *}$ & $\begin{array}{l}(0.64, \\
0.82)\end{array}$ & 1915213 & 1.04 & $\begin{array}{l}(0.94 \\
1.15)\end{array}$ & 6850832 \\
\hline $\begin{array}{l}\text { Nitrogen } \\
\text { oxides } \\
\text { (mobile) }\end{array}$ & 1.00 & 1.01 & $\begin{array}{r}(0.85 \\
1.19)\end{array}$ & 1205793 & 1.04 & $\begin{array}{r}(0.89 \\
1.21)\end{array}$ & 1596924 & $1.40^{* * * *}$ & $\begin{array}{r}(1.22, \\
1.61)\end{array}$ & 6930996 \\
\hline $\begin{array}{l}\text { Nitrogen } \\
\text { oxides } \\
\text { (area) }\end{array}$ & 1.00 & 1.02 & $\begin{array}{r}(0.90 \\
1.15)\end{array}$ & 1849188 & 1.09 & $\begin{array}{c}(0.97 \\
1.22)\end{array}$ & 2364973 & $1.23^{* * * *}$ & $\begin{array}{l}(1.11, \\
1.36)\end{array}$ & 6178314 \\
\hline $\begin{array}{l}\text { Nitrogen } \\
\text { oxides } \\
\text { (all) }\end{array}$ & 1.00 & 0.94 & $\begin{array}{c}(0.79 \\
1.12)\end{array}$ & 1128444 & 0.94 & $\begin{array}{c}(0.80 \\
1.11)\end{array}$ & 1702089 & $1.43^{* * * *}$ & $\begin{array}{c}(1.23 \\
1.65)\end{array}$ & 6793742 \\
\hline $\begin{array}{l}\text { PM-2.5 } \\
\text { (mobile) }\end{array}$ & 1.00 & 1.21 & $\begin{array}{c}(0.99 \\
1.49)\end{array}$ & 993506 & $1.22^{*}$ & $\begin{array}{l}(1.00 \\
1.48)\end{array}$ & 1510700 & $1.75^{\star * * *}$ & $\begin{array}{l}(1.47 \\
2.10)\end{array}$ & 6998801 \\
\hline PM-2.5 & 1.00 & 0.94 & (0.85, & 2858242 & 1.01 & $(0.90$ & 2444023 & $1.16^{* *}$ & (1.05, & 5065518 \\
\hline
\end{tabular}




\begin{tabular}{|c|c|c|c|c|c|c|c|c|c|c|}
\hline \multicolumn{11}{|c|}{$\begin{array}{r}\text { Table 14: Odds Ratios(OR) and 95\% Confidence Interval }(\mathrm{Cl}) \text { by } \mathrm{Q} \\
\text { Reported MS cases }\end{array}$} \\
\hline Variable & $\begin{array}{l}\text { OR for } \\
\text { lowest } \\
\text { quartile }\end{array}$ & $\begin{array}{l}\text { OR for } \\
\text { second } \\
\text { quartile }\end{array}$ & $\begin{array}{l}95 \% \mathrm{Cl}^{\mathrm{a}} \\
\text { of the } \\
\text { second } \\
\text { quartile } \\
\text { OR }\end{array}$ & $\begin{array}{l}\mathrm{N} \\
\text { (Number } \\
\text { of } \\
\text { people } \\
\text { used for } \\
\text { the OR) }\end{array}$ & $\begin{array}{l}\text { OR for } \\
\text { third } \\
\text { quartile }\end{array}$ & $\begin{array}{l}95 \% \mathrm{Cl}^{\mathrm{a}} \\
\text { of the } \\
\text { third } \\
\text { quartile } \\
\text { OR }\end{array}$ & $\begin{array}{l}\mathrm{N} \\
\text { (Number } \\
\text { of } \\
\text { people } \\
\text { used for } \\
\text { the OR) }\end{array}$ & $\begin{array}{l}\text { OR for } \\
\text { highest } \\
\text { quartile }\end{array}$ & $\begin{array}{l}95 \% \mathrm{Cl}^{\mathrm{a}} \\
\text { of the } \\
\text { fourth } \\
\text { quartile } \\
\text { OR }\end{array}$ & $\begin{array}{l}\mathrm{N} \text { (Number } \\
\text { of people } \\
\text { used for } \\
\text { the OR) }\end{array}$ \\
\hline (area) & \multicolumn{4}{|c|}{ 1.05) } & \multicolumn{3}{|c|}{ 1.12) } & \multicolumn{3}{|c|}{ 1.28) } \\
\hline $\begin{array}{l}\text { PM-2.5 } \\
\text { (all) }\end{array}$ & 1.00 & 0.89 & $\begin{array}{l}(0.77 \\
1.03)\end{array}$ & 1384414 & 1.00 & $\begin{array}{l}(0.88 \\
1.13)\end{array}$ & 2425057 & $1.23^{* * *}$ & $\begin{array}{l}(1.09 \\
1.38)\end{array}$ & 6163914 \\
\hline $\begin{array}{l}\text { PM-10 } \\
\text { (mobile) }\end{array}$ & 1.00 & 1.00 & $\begin{array}{r}(0.84 \\
1.20)\end{array}$ & 1048779 & 1.06 & $\begin{array}{r}(0.90 \\
1.25)\end{array}$ & 1740213 & $1.47^{* * * *}$ & $\begin{array}{r}(1.27 \\
1.70)\end{array}$ & 6858117 \\
\hline $\begin{array}{l}\text { PM-10 } \\
\text { (area) }\end{array}$ & 1.00 & 0.93 & $\begin{array}{l}(0.83, \\
1.03)\end{array}$ & 2475108 & 0.93 & $\begin{array}{l}(0.84, \\
1.04)\end{array}$ & 2493041 & $1.12^{*}$ & $\begin{array}{c}(1.02 \\
1.24)\end{array}$ & 5468954 \\
\hline $\begin{array}{l}\text { PM-10 } \\
\text { (all) }\end{array}$ & 1.00 & 0.87 & $\begin{array}{l}(0.74 \\
1.01)\end{array}$ & 1172668 & $0.87^{*}$ & $\begin{array}{l}(0.76 \\
0.99)\end{array}$ & 2312006 & $1.20^{* *}$ & $\begin{array}{l}(1.06 \\
1.35)\end{array}$ & 6359593 \\
\hline $\begin{array}{l}\text { Sulfur } \\
\text { dioxide } \\
\text { (mobile) }\end{array}$ & 1.00 & 1.09 & $\begin{array}{l}(0.91 \\
1.30)\end{array}$ & 1077110 & 0.95 & $\begin{array}{l}(0.81 \\
1.13)\end{array}$ & 1598051 & $1.50^{* * * *}$ & $\begin{array}{c}(1.29 \\
1.74)\end{array}$ & 6960012 \\
\hline $\begin{array}{l}\text { Sulfur } \\
\text { dioxide } \\
\text { (area) }\end{array}$ & 1.00 & 0.93 & $\begin{array}{r}(0.79 \\
1.09)\end{array}$ & 1256009 & 0.94 & $\begin{array}{r}(0.81 \\
1.09)\end{array}$ & 1728222 & $1.43^{* * * *}$ & $\begin{array}{c}(1.27 \\
1.62)\end{array}$ & 6942742 \\
\hline $\begin{array}{l}\text { Sulfur } \\
\text { dioxide } \\
\text { (all) }\end{array}$ & 1.00 & 0.94 & $\begin{array}{l}(0.79 \\
1.12)\end{array}$ & 1191739 & 1.15 & $\begin{array}{l}(0.98 \\
1.34)\end{array}$ & 2034489 & $1.36^{* * * *}$ & $\begin{array}{c}(1.18 \\
1.57)\end{array}$ & 6396515 \\
\hline
\end{tabular}




\begin{tabular}{|c|c|c|c|c|c|c|c|c|c|c|}
\hline \multicolumn{11}{|c|}{$\begin{array}{c}\text { Table 14: Odds Ratios(OR) and 95\% Confidence Interval }(\mathrm{Cl}) \text { by Quartile: Criteria Air Pollutants and Total Self- } \\
\text { Reported MS cases }\end{array}$} \\
\hline Variable & $\begin{array}{l}\text { OR for } \\
\text { lowest } \\
\text { quartile }\end{array}$ & $\begin{array}{l}\text { OR for } \\
\text { second } \\
\text { quartile }\end{array}$ & $\begin{array}{l}95 \% \mathrm{Cl}^{\mathrm{a}} \\
\text { of the } \\
\text { second } \\
\text { quartile } \\
\text { OR }\end{array}$ & $\begin{array}{l}\text { N } \\
\text { (Number } \\
\text { of } \\
\text { people } \\
\text { used for } \\
\text { the OR) }\end{array}$ & $\begin{array}{l}\text { OR for } \\
\text { third } \\
\text { quartile }\end{array}$ & $\begin{array}{l}95 \% \mathrm{Cl}^{\mathrm{a}} \\
\text { of the } \\
\text { third } \\
\text { quartile } \\
\text { OR }\end{array}$ & $\begin{array}{l}\text { N } \\
\text { (Number } \\
\text { of } \\
\text { people } \\
\text { used for } \\
\text { the OR) }\end{array}$ & $\begin{array}{l}\text { OR for } \\
\text { highest } \\
\text { quartile }\end{array}$ & $\begin{array}{l}95 \% \mathrm{Cl}^{\mathrm{a}} \\
\text { of the } \\
\text { fourth } \\
\text { quartile } \\
\text { OR }\end{array}$ & $\begin{array}{l}\mathrm{N} \text { (Number } \\
\text { of people } \\
\text { used for } \\
\text { the OR) }\end{array}$ \\
\hline $\begin{array}{l}\text { VOCs } \\
\text { (mobile) }\end{array}$ & 1.00 & 1.09 & $\begin{array}{c}(0.91 \\
1.30)\end{array}$ & 1087960 & 1.14 & $\begin{array}{l}(0.96 \\
1.34)\end{array}$ & 1593661 & $1.48^{* * * *}$ & $\begin{array}{l}(1.27 \\
1.72)\end{array}$ & 6939764 \\
\hline $\begin{array}{l}\text { VOCs } \\
\text { (area) }\end{array}$ & 1.00 & $0.80^{*}$ & $\begin{array}{c}(0.68 \\
0.95)\end{array}$ & 1092424 & 0.94 & $\begin{array}{l}(0.81 \\
1.09)\end{array}$ & 1727586 & $1.25^{* * *}$ & $\begin{array}{l}(1.09 \\
1.42)\end{array}$ & 6888893 \\
\hline $\begin{array}{l}\text { VOCs } \\
\text { (all) }\end{array}$ & 1.00 & 1.10 & $\begin{array}{l}(0.92 \\
1.33)\end{array}$ & 1087682 & 1.09 & $\begin{array}{c}(0.92 \\
1.30)\end{array}$ & 1546984 & $1.54^{* * * *}$ & $\begin{array}{l}(1.32 \\
1.80)\end{array}$ & 6962477 \\
\hline \multicolumn{11}{|c|}{$\begin{array}{l}\text { Each variable under analysis included } 158 \text { of the } 159 \text { counties in GA. VOCs are volatile organic compounds, and PM } \\
\text { is particulate matter. Also, the selected air pollutants were reported as emissions in tons, in } 1999 . \\
\text { a } 95 \% \mathrm{Cl} \text { is calculated using the case-control study estimation model } \\
{ }^{*} \text { Values are significant at the } 0.05 \text { level using a Chi-squared test for } 2 \times 2 \text { contingency tables } \\
{ }^{* * V a l u e s ~ a r e ~ s i g n i f i c a n t ~ a t ~ t h e ~} 0.01 \text { level using a Chi-squared test for } 2 \times 2 \text { contingency tables } \\
{ }^{* * * V a l u e s} \text { are significant at the } 0.001 \text { level using a Chi-squared test for } 2 \times 2 \text { contingency tables } \\
* * * \text { Values are significant at the } 0.0001 \text { level using a Chi-squared test for } 2 \times 2 \text { contingency tables }\end{array}$} \\
\hline
\end{tabular}


Table 15 shows increasing odds ratios for female MS self-reported cases with increasing emissions of selected criteria air pollutants to outdoor air for carbon monoxide (mobile and area sources), nitrogen oxides (areas sources), and PM-2.5 (mobile sources). In addition, the odds ratios tended to increase as we go from the second to the fourth quartile for nitrogen oxides (mobile and all sources), PM-2.5 (area and all sources), PM-10 (mobile, area and all sources), sulfur dioxide (area and all sources), and volatile organic compounds (mobile and area sources). The majority of the findings were highly statistically significant. 


\begin{tabular}{|c|c|c|c|c|c|c|c|c|c|c|}
\hline Variable & $\begin{array}{l}\text { OR for } \\
\text { lowest } \\
\text { quartile }\end{array}$ & $\begin{array}{l}\text { OR for } \\
\text { second } \\
\text { quartile }\end{array}$ & $\begin{array}{l}95 \% \\
\mathrm{Cl}^{\mathrm{a}} \text { of } \\
\text { the } \\
\text { second } \\
\text { quartile } \\
\text { OR }\end{array}$ & $\begin{array}{l}\mathrm{N} \\
\text { (Number } \\
\text { of } \\
\text { people } \\
\text { used for } \\
\text { the OR) }\end{array}$ & $\begin{array}{l}\text { OR for } \\
\text { third } \\
\text { quartile }\end{array}$ & $\begin{array}{l}95 \% \mathrm{Cl}^{\mathrm{a}} \\
\text { of the } \\
\text { third } \\
\text { quartile's } \\
\text { OR }\end{array}$ & $\begin{array}{l}\mathrm{N} \\
\text { (Number } \\
\text { of } \\
\text { people } \\
\text { used for } \\
\text { the OR) }\end{array}$ & $\begin{array}{l}\text { OR for } \\
\text { highest } \\
\text { quartile }\end{array}$ & $\begin{array}{l}95 \% \mathrm{Cl}^{\mathrm{a}} \\
\text { of the } \\
\text { fourth } \\
\text { quartile's } \\
\text { OR }\end{array}$ & $\begin{array}{l}\mathrm{N} \text { (Number } \\
\text { of people } \\
\text { used for } \\
\text { the OR) }\end{array}$ \\
\hline $\begin{array}{l}\text { Carbon } \\
\text { Monoxide } \\
\text { (mobile) }\end{array}$ & 1.00 & 1.13 & $\begin{array}{c}(0.90 \\
1.41)\end{array}$ & 535442 & 1.23 & $\begin{array}{c}(0.99 \\
1.51)\end{array}$ & 776385 & $1.55^{\star * * *}$ & $\begin{array}{c}(1.28 \\
1.88)\end{array}$ & 3515655 \\
\hline $\begin{array}{l}\text { Carbon } \\
\text { monoxide } \\
\text { (area) }\end{array}$ & 1.00 & $1.26^{* * *}$ & $\begin{array}{c}(1.10 \\
1.44)\end{array}$ & 1478302 & $1.27^{* * *}$ & $\begin{array}{c}(1.10 \\
1.46)\end{array}$ & 1192659 & $1.44^{* * * *}$ & $\begin{array}{c}(1.27 \\
1.63)\end{array}$ & 2604139 \\
\hline $\begin{array}{l}\text { Carbon } \\
\text { monoxide } \\
\text { (all) }\end{array}$ & 1.00 & $0.76^{\star * *}$ & $\begin{array}{l}(0.64 \\
0.89)\end{array}$ & 676178 & $0.72^{* * * *}$ & $\begin{array}{c}(0.62, \\
0.83)\end{array}$ & 965122 & 1.04 & $\begin{array}{c}(0.92 \\
1.17)\end{array}$ & 3469210 \\
\hline $\begin{array}{l}\text { Nitrogen } \\
\text { oxides } \\
\text { (mobile) }\end{array}$ & 1.00 & 0.98 & $\begin{array}{c}(0.81 \\
1.19)\end{array}$ & 604846 & 1.01 & $\begin{array}{c}(0.84, \\
1.21)\end{array}$ & 803584 & $1.34^{* * *}$ & $\begin{array}{c}(1.15) \\
1.58)\end{array}$ & 3508701 \\
\hline $\begin{array}{l}\text { Nitrogen } \\
\text { oxides } \\
\text { (area) }\end{array}$ & 1.00 & 1.02 & $\begin{array}{c}(0.88 \\
1.18)\end{array}$ & 931641 & 1.08 & $\begin{array}{c}(0.95 \\
1.24)\end{array}$ & 1198135 & $1.23^{* * *}$ & $\begin{array}{c}(1.10 \\
1.39)\end{array}$ & 3128221 \\
\hline $\begin{array}{l}\text { Nitrogen } \\
\text { oxides } \\
\text { (all) }\end{array}$ & 1.00 & 0.87 & $\begin{array}{c}(0.71 \\
1.07)\end{array}$ & 565409 & 0.90 & $\begin{array}{c}(0.75 \\
1.09)\end{array}$ & 858482 & $1.35^{* * *}$ & $\begin{array}{c}(1.14, \\
1.60)\end{array}$ & 3439471 \\
\hline $\begin{array}{l}\text { PM-2.5 } \\
\text { (mobile) }\end{array}$ & 1.00 & 1.13 & $\begin{array}{c}(0.88, \\
1.44)\end{array}$ & 498241 & 1.19 & $\begin{array}{l}(0.95 \\
1.49)\end{array}$ & 760421 & $1.68^{* * * *}$ & $\begin{array}{l}(1.37 \\
2.07)\end{array}$ & 3543774 \\
\hline
\end{tabular}




\begin{tabular}{|c|c|c|c|c|c|c|c|c|c|c|}
\hline \multicolumn{11}{|c|}{$\begin{array}{c}\text { Table 15: Odds Ratios(OR) and 95\% Confidence Interval }(\mathrm{Cl}) \text { by Quartile: Criteria Air Pollutants and Female Self- } \\
\text { Reported } \mathrm{MS} \text { cases }\end{array}$} \\
\hline Variable & $\begin{array}{l}\text { OR for } \\
\text { lowest } \\
\text { quartile }\end{array}$ & $\begin{array}{l}\text { OR for } \\
\text { second } \\
\text { quartile }\end{array}$ & $\begin{array}{l}95 \% \\
\mathrm{Cl}^{\mathrm{a}} \text { of } \\
\text { the } \\
\text { second } \\
\text { quartile } \\
\text { OR }\end{array}$ & $\begin{array}{l}\mathrm{N} \\
\text { (Number } \\
\text { of } \\
\text { people } \\
\text { used for } \\
\text { the OR) }\end{array}$ & $\begin{array}{l}\text { OR for } \\
\text { third } \\
\text { quartile }\end{array}$ & $\begin{array}{l}95 \% \mathrm{Cl}^{\mathrm{a}} \\
\text { of the } \\
\text { third } \\
\text { quartile's } \\
\text { OR }\end{array}$ & $\begin{array}{l}\mathrm{N} \\
\text { (Number } \\
\text { of } \\
\text { people } \\
\text { used for } \\
\text { the OR) }\end{array}$ & $\begin{array}{l}\text { OR for } \\
\text { highest } \\
\text { quartile }\end{array}$ & $\begin{array}{l}95 \% \mathrm{Cl}^{\mathrm{a}} \\
\text { of the } \\
\text { fourth } \\
\text { quartile's } \\
\text { OR }\end{array}$ & $\begin{array}{l}\mathrm{N} \text { (Number } \\
\text { of people } \\
\text { used for } \\
\text { the OR) }\end{array}$ \\
\hline $\begin{array}{l}\text { PM-2.5 } \\
\text { (area) }\end{array}$ & 1.00 & 0.90 & $\begin{array}{l}(0.80 \\
1.03)\end{array}$ & 1453576 & 1.02 & $\begin{array}{l}(0.90 \\
1.16)\end{array}$ & 1233432 & $1.14^{*}$ & $\begin{array}{l}(1.02, \\
1.28)\end{array}$ & 2550552 \\
\hline $\begin{array}{l}\text { PM-2.5 } \\
\text { (all) }\end{array}$ & 1.00 & $0.84^{*}$ & $\begin{array}{l}(0.71 \\
1.00)\end{array}$ & 695928 & 0.95 & $\begin{array}{l}(0.82, \\
1.10)\end{array}$ & 1229098 & $1.18^{*}$ & $\begin{array}{l}(1.03, \\
1.34)\end{array}$ & 3114398 \\
\hline $\begin{array}{l}\text { PM-10 } \\
\text { (mobile) }\end{array}$ & 1.00 & 0.97 & $\begin{array}{l}(0.78, \\
1.20)\end{array}$ & 527312 & 1.07 & $\begin{array}{l}(0.89) \\
1.30)\end{array}$ & 878612 & $1.46^{* * * *}$ & $\begin{array}{l}(1.23 \\
1.74)\end{array}$ & 3469741 \\
\hline $\begin{array}{l}\text { PM-10 } \\
\text { (area) }\end{array}$ & 1.00 & 0.90 & $\begin{array}{l}(0.79 \\
1.02)\end{array}$ & 1256057 & 0.95 & $\begin{array}{l}(0.84, \\
1.08)\end{array}$ & 1257146 & $1.12^{*}$ & $\begin{array}{l}(1.00 \\
1.25)\end{array}$ & 2758341 \\
\hline $\begin{array}{l}\text { PM-10 } \\
\text { (all) }\end{array}$ & 1.00 & 0.89 & $\begin{array}{l}(0.74, \\
1.07)\end{array}$ & 588260 & 0.88 & $\begin{array}{l}(0.76) \\
1.04)\end{array}$ & 1172605 & $1.23^{* *}$ & $\begin{array}{l}(1.06 \\
1.42)\end{array}$ & 3211310 \\
\hline $\begin{array}{l}\text { Sulfur } \\
\text { dioxide } \\
\text { (mobile) }\end{array}$ & 1.00 & 1.06 & $\begin{array}{l}(0.87 \\
1.33)\end{array}$ & 542359 & 0.95 & $\begin{array}{c}(0.77, \\
1.16)\end{array}$ & 800885 & $1.48^{* * * *}$ & $\begin{array}{l}(1.24, \\
1.77)\end{array}$ & 3521391 \\
\hline $\begin{array}{l}\text { Sulfur } \\
\text { dioxide } \\
\text { (area) }\end{array}$ & 1.00 & 0.95 & $\begin{array}{c}(0.79 \\
1.16)\end{array}$ & 633212 & 1.00 & $\begin{array}{c}(0.84, \\
1.19)\end{array}$ & 870761 & $1.47^{* * * *}$ & $\begin{array}{l}(1.26) \\
1.70)\end{array}$ & 3518047 \\
\hline $\begin{array}{l}\text { Sulfur } \\
\text { dioxide } \\
\text { (all) }\end{array}$ & 1.00 & 0.93 & $\begin{array}{c}(0.76 \\
1.15)\end{array}$ & 597066 & 1.10 & $\begin{array}{l}(0.92 \\
1.32)\end{array}$ & 1027098 & $1.31^{* *}$ & $\begin{array}{c}(1.11, \\
1.56)\end{array}$ & 3238501 \\
\hline
\end{tabular}




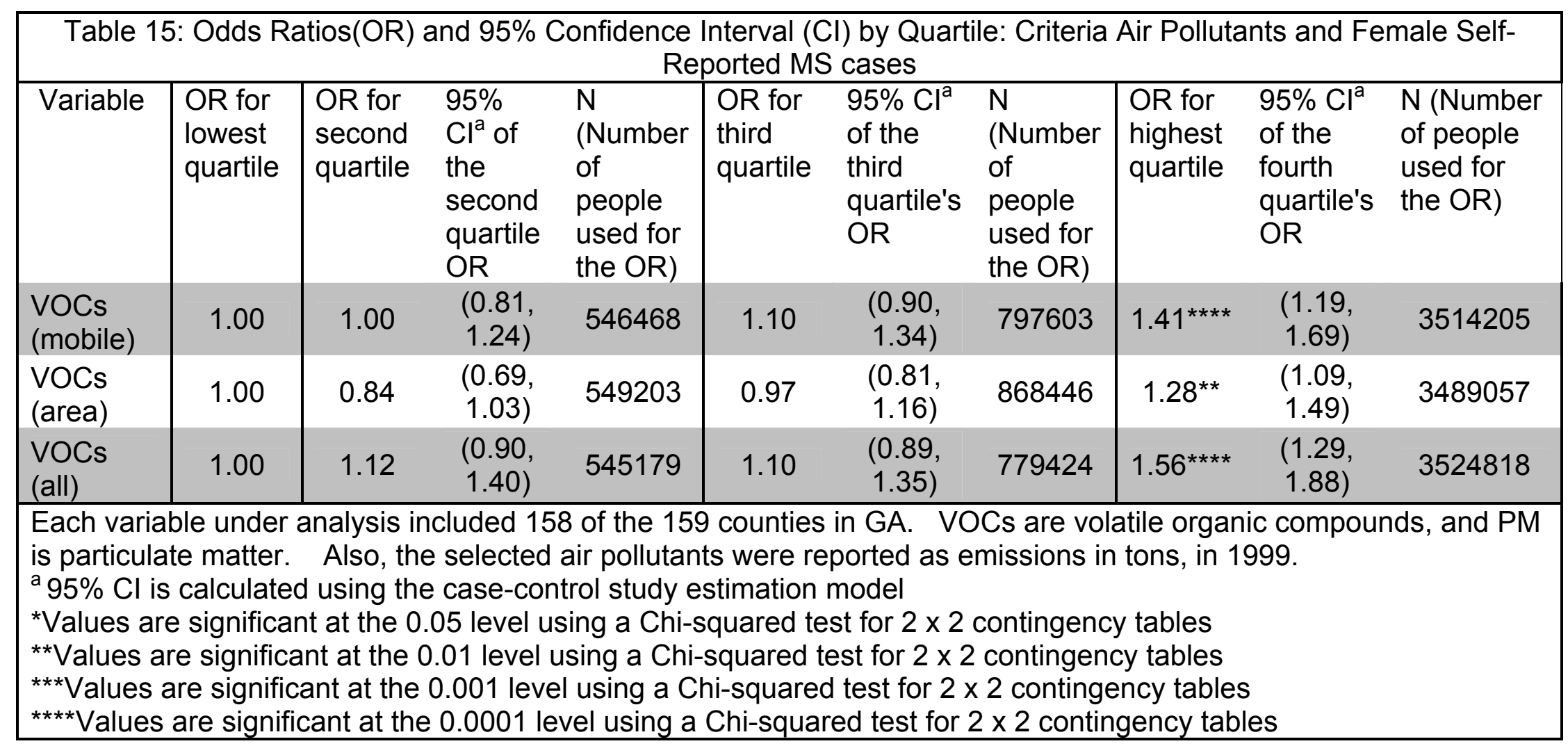


Table 16 shows increasing odds ratios for male MS self-reported cases with increasing emissions of selected criteria air pollutants to outdoor air for PM-2.5 (all sources), sulfur dioxide (all sources), and volatile organic compounds (all sources). In addition, the odds ratios tended to increase from the second to the fourth quartile for nitrogen oxides (mobile and areas sources) and volatile organic compounds (area sources). 


\begin{tabular}{|c|c|c|c|c|c|c|c|c|c|c|}
\hline \multicolumn{11}{|c|}{$\begin{array}{c}\text { Table 16: Odds Ratios(OR) and 95\% Confidence Interval }(\mathrm{Cl}) \text { by Quartile: Criteria Air Pollutants and Male Self- } \\
\text { Reported MS cases }\end{array}$} \\
\hline Variable & $\begin{array}{l}\text { OR for } \\
\text { lowest } \\
\text { quartile }\end{array}$ & $\begin{array}{l}\text { OR for } \\
\text { second } \\
\text { quartile }\end{array}$ & $\begin{array}{l}95 \% \mathrm{Cl}^{\mathrm{a}} \\
\text { of the } \\
\text { second } \\
\text { quartile's } \\
\text { OR }\end{array}$ & $\begin{array}{l}\mathrm{N} \\
\text { (Number } \\
\text { of } \\
\text { people } \\
\text { used for } \\
\text { the OR) }\end{array}$ & $\begin{array}{l}\text { OR for } \\
\text { third } \\
\text { quartile }\end{array}$ & $\begin{array}{l}95 \% \mathrm{Cl}^{\mathrm{a}} \\
\text { of the } \\
\text { third } \\
\text { quartile's } \\
\text { OR }\end{array}$ & $\begin{array}{l}\text { N } \\
\text { (Number } \\
\text { of } \\
\text { people } \\
\text { used for } \\
\text { the OR) }\end{array}$ & $\begin{array}{l}\text { OR for } \\
\text { highest } \\
\text { quartile }\end{array}$ & $\begin{array}{l}95 \% \mathrm{Cl}^{\mathrm{a}} \\
\text { of the } \\
\text { fourth } \\
\text { quartile's } \\
\text { OR }\end{array}$ & $\begin{array}{l}\mathrm{N} \text { (Number } \\
\text { of people } \\
\text { used for } \\
\text { the OR) }\end{array}$ \\
\hline $\begin{array}{l}\text { Carbon } \\
\text { Monoxide } \\
\text { (mobile) }\end{array}$ & 1.00 & 1.51 & $\begin{array}{l}(0.98 \\
2.35)\end{array}$ & 531636 & 1.45 & $\begin{array}{l}(0.96) \\
2.20)\end{array}$ & 770204 & $1.93^{* * *}$ & $\begin{array}{l}(1.32, \\
2.85)\end{array}$ & 3430620 \\
\hline $\begin{array}{l}\text { Carbon } \\
\text { monoxide } \\
\text { (area) }\end{array}$ & 1.00 & $1.37^{*}$ & $\begin{array}{l}(1.07, \\
1.75)\end{array}$ & 1428572 & 1.21 & $\begin{array}{l}(0.93 \\
1.56)\end{array}$ & 1173506 & $1.51^{* * *}$ & $\begin{array}{l}(1.21, \\
1.91)\end{array}$ & 2562559 \\
\hline $\begin{array}{l}\text { Carbon } \\
\text { monoxide } \\
\text { (all) }\end{array}$ & 1.00 & 0.76 & $\begin{array}{l}(0.56) \\
1.03)\end{array}$ & 666994 & $0.73^{*}$ & $\begin{array}{l}(0.56 \\
0.96)\end{array}$ & 950091 & 1.07 & $\begin{array}{l}(0.86) \\
1.33)\end{array}$ & 3381622 \\
\hline $\begin{array}{l}\text { Nitrogen } \\
\text { oxides } \\
\text { (mobile) }\end{array}$ & 1.00 & 0.94 & $\begin{array}{l}(0.65 \\
1.36)\end{array}$ & 600947 & 1.10 & $\begin{array}{l}(0.79 \\
1.55)\end{array}$ & 793340 & $1.47^{* *}$ & $\begin{array}{l}(1.09 \\
1.99)\end{array}$ & 3422295 \\
\hline $\begin{array}{l}\text { Nitrogen } \\
\text { oxides } \\
\text { (area) }\end{array}$ & 1.00 & 0.99 & $\begin{array}{l}(0.76 \\
1.29)\end{array}$ & 917547 & 1.09 & $\begin{array}{l}(0.85 \\
1.39)\end{array}$ & 1166838 & $1.24^{*}$ & $\begin{array}{l}(1.00 \\
1.54)\end{array}$ & 3050093 \\
\hline $\begin{array}{l}\text { Nitrogen } \\
\text { oxides } \\
\text { (all) }\end{array}$ & 1.00 & 1.15 & $\begin{array}{l}(0.77, \\
1.74)\end{array}$ & 563035 & 1.14 & $\begin{array}{l}(0.78, \\
1.67)\end{array}$ & 843607 & $1.74^{* * *}$ & $\begin{array}{l}(1.23, \\
2.46)\end{array}$ & 3354271 \\
\hline $\begin{array}{l}\text { PM-2.5 } \\
\text { (mobile) }\end{array}$ & 1.00 & 1.28 & $\begin{array}{l}(0.82, \\
2.02)\end{array}$ & 495265 & 1.24 & $\begin{array}{l}(0.81 \\
1.90)\end{array}$ & 750279 & $1.84^{* *}$ & $\begin{array}{l}(1.25, \\
2.73)\end{array}$ & 3455027 \\
\hline
\end{tabular}




\begin{tabular}{|c|c|c|c|c|c|c|c|c|c|c|}
\hline \multicolumn{11}{|c|}{$\begin{array}{c}\text { Table 16: Odds Ratios(OR) and 95\% Confidence Interval }(\mathrm{Cl}) \text { by Quartile: Criteria Air Pollutants and Male Self- } \\
\text { Reported MS cases }\end{array}$} \\
\hline Variable & $\begin{array}{l}\text { OR for } \\
\text { lowest } \\
\text { quartile }\end{array}$ & $\begin{array}{l}\text { OR for } \\
\text { second } \\
\text { quartile }\end{array}$ & $\begin{array}{l}95 \% \mathrm{Cl}^{\mathrm{a}} \\
\text { of the } \\
\text { second } \\
\text { quartile's } \\
\text { OR }\end{array}$ & $\begin{array}{l}\text { N } \\
\text { (Number } \\
\text { of } \\
\text { people } \\
\text { used for } \\
\text { the OR) }\end{array}$ & $\begin{array}{l}\text { OR for } \\
\text { third } \\
\text { quartile }\end{array}$ & $\begin{array}{l}95 \% \mathrm{Cl}^{\mathrm{a}} \\
\text { of the } \\
\text { third } \\
\text { quartile's } \\
\text { OR }\end{array}$ & $\begin{array}{l}\mathrm{N} \\
\text { (Number } \\
\text { of } \\
\text { people } \\
\text { used for } \\
\text { the OR) }\end{array}$ & $\begin{array}{l}\text { OR for } \\
\text { highest } \\
\text { quartile }\end{array}$ & $\begin{array}{l}95 \% \mathrm{Cl}^{\mathrm{a}} \\
\text { of the } \\
\text { fourth } \\
\text { quartile's } \\
\text { OR }\end{array}$ & $\begin{array}{l}\mathrm{N} \text { (Number } \\
\text { of people } \\
\text { used for } \\
\text { the OR) }\end{array}$ \\
\hline $\begin{array}{l}\text { PM-2.5 } \\
\text { (area) }\end{array}$ & 1.00 & 1.04 & $\begin{array}{r}(0.83 \\
1.32)\end{array}$ & 1404666 & 0.96 & $\begin{array}{r}(0.75 \\
1.22)\end{array}$ & 1210591 & $1.24^{*}$ & $\begin{array}{l}(1.00, \\
1.54)\end{array}$ & 2514966 \\
\hline $\begin{array}{l}\text { PM-2.5 } \\
\text { (all ) }\end{array}$ & 1.00 & 1.16 & $\begin{array}{c}(0.84, \\
1.61)\end{array}$ & 688486 & 1.22 & $\begin{array}{l}(0.91 \\
1.63)\end{array}$ & 1195959 & $1.51^{* *}$ & $\begin{array}{c}(1.16, \\
1.98)\end{array}$ & 3049516 \\
\hline $\begin{array}{l}\text { PM-10 } \\
\text { (mobile) }\end{array}$ & 1.00 & 0.96 & $\begin{array}{l}(0.65 \\
1.41)\end{array}$ & 521467 & 0.95 & $\begin{array}{c}(0.719 \\
1.248)\end{array}$ & 861601 & $1.415^{*}$ & $\begin{array}{c}(1.121 \\
1.785)\end{array}$ & 3388376 \\
\hline $\begin{array}{l}\text { PM-10 } \\
\text { (area) }\end{array}$ & 1.00 & 1.04 & $\begin{array}{r}(0.83 \\
1.32)\end{array}$ & 1219051 & 0.92 & $\begin{array}{r}(0.72 \\
1.16)\end{array}$ & 1235895 & 1.18 & $\begin{array}{l}(0.96 \\
1.45)\end{array}$ & 2710613 \\
\hline $\begin{array}{l}\text { PM-10 } \\
\text { (all) }\end{array}$ & 1.00 & 0.88 & $\begin{array}{r}(0.63, \\
1.22)\end{array}$ & 584408 & 0.86 & $\begin{array}{c}(0.65 \\
1.13)\end{array}$ & 1139401 & 1.18 & $\begin{array}{c}(0.92, \\
1.53)\end{array}$ & 3148283 \\
\hline $\begin{array}{l}\text { Sulfur } \\
\text { Dioxide } \\
\text { (mobile) }\end{array}$ & 1.00 & 1.23 & $\begin{array}{c}(0.83 \\
1.85)\end{array}$ & 534750 & 1.13 & $\begin{array}{c}(0.77, \\
1.65)\end{array}$ & 797166 & $1.72^{\star *}$ & $\begin{array}{l}(1.22, \\
2.42)\end{array}$ & 3438621 \\
\hline $\begin{array}{l}\text { Sulfur } \\
\text { Dioxide } \\
\text { (area) }\end{array}$ & 1.00 & 0.81 & $\begin{array}{c}(0.58 \\
1.13)\end{array}$ & 622797 & 0.74 & $\begin{array}{c}(0.54 \\
1.00)\end{array}$ & 857461 & $1.29^{*}$ & $\begin{array}{c}(1.00 \\
1.66)\end{array}$ & 3424695 \\
\hline $\begin{array}{l}\text { Sulfur } \\
\text { Dioxide } \\
\text { (all) }\end{array}$ & 1.00 & 1.05 & $\begin{array}{c}(0.71 \\
1.55)\end{array}$ & 594673 & 1.32 & $\begin{array}{c}(0.93 \\
1.88)\end{array}$ & 1007391 & $1.56^{* *}$ & $\begin{array}{l}(1.12, \\
2.18)\end{array}$ & 3158014 \\
\hline
\end{tabular}




\begin{tabular}{|c|c|c|c|c|c|c|c|c|c|c|}
\hline \multicolumn{11}{|c|}{$\begin{array}{c}\text { Table 16: Odds Ratios(OR) and 95\% Confidence Interval }(\mathrm{Cl}) \text { by Quartile: Criteria Air Pollutants and Male Self- } \\
\text { Reported MS cases }\end{array}$} \\
\hline Variable & $\begin{array}{l}\text { OR for } \\
\text { lowest } \\
\text { quartile }\end{array}$ & $\begin{array}{l}\text { OR for } \\
\text { second } \\
\text { quartile }\end{array}$ & $\begin{array}{l}95 \% \mathrm{Cl}^{\mathrm{a}} \\
\text { of the } \\
\text { second } \\
\text { quartile's } \\
\text { OR }\end{array}$ & $\begin{array}{l}\text { N } \\
\text { (Number } \\
\text { of } \\
\text { people } \\
\text { used for } \\
\text { the OR) }\end{array}$ & $\begin{array}{l}\text { OR for } \\
\text { third } \\
\text { quartile }\end{array}$ & $\begin{array}{l}95 \% \mathrm{Cl}^{\mathrm{a}} \\
\text { of the } \\
\text { third } \\
\text { quartile's } \\
\text { OR }\end{array}$ & $\begin{array}{l}\text { N } \\
\text { (Number } \\
\text { of } \\
\text { people } \\
\text { used for } \\
\text { the OR) }\end{array}$ & $\begin{array}{l}\text { OR for } \\
\text { highest } \\
\text { quartile }\end{array}$ & $\begin{array}{l}95 \% \mathrm{Cl}^{\mathrm{a}} \\
\text { of the } \\
\text { fourth } \\
\text { quartile's } \\
\text { OR }\end{array}$ & $\begin{array}{l}\mathrm{N} \text { (Number } \\
\text { of people } \\
\text { used for } \\
\text { the OR) }\end{array}$ \\
\hline $\begin{array}{l}\text { VOCs } \\
\text { (mobile) }\end{array}$ & 1.00 & $1.51^{*}$ & $\begin{array}{l}(1.00, \\
2.27)\end{array}$ & 541492 & 1.35 & $\begin{array}{r}(0.92, \\
1.99)\end{array}$ & 796058 & $1.79 * * *$ & $\begin{array}{l}(1.26, \\
2.56)\end{array}$ & 3425559 \\
\hline $\begin{array}{l}\text { VOCs } \\
\text { (area) }\end{array}$ & 1.00 & $0.68^{*}$ & $\begin{array}{c}(0.48 \\
0.98)\end{array}$ & 543221 & 0.82 & $\begin{array}{c}(0.60 \\
1.11)\end{array}$ & 859140 & 1.14 & $\begin{array}{c}(0.87 \\
1.49)\end{array}$ & 3399836 \\
\hline $\begin{array}{l}\text { VOCs } \\
\text { (all) }\end{array}$ & 1.00 & 1.03 & $\begin{array}{r}(0.69 \\
1.53)\end{array}$ & 542503 & 1.10 & $\begin{array}{r}(0.76 \\
1.59)\end{array}$ & 767560 & $1.51^{*}$ & $\begin{array}{l}(1.09, \\
2.11)\end{array}$ & 3437659 \\
\hline \multicolumn{11}{|c|}{$\begin{array}{l}\text { Each variable under analysis included } 158 \text { of the } 159 \text { counties in GA. VOCs are volatile organic compounds, and PM } \\
\text { is particulate matter. Also, the selected air pollutants were reported as emissions in tons, in } 1999 . \\
\text { a } 95 \% \mathrm{Cl} \text { is calculated using the case-control study estimation model } \\
{ }^{*} \text { Values are significant at the } 0.05 \text { level using a Chi-squared test for } 2 \times 2 \text { contingency tables } \\
{ }^{* *} \text { Values are significant at the } 0.01 \text { level using a Chi-squared test for } 2 \times 2 \text { contingency tables } \\
{ }^{* * *} \text { Values are significant at the } 0.001 \text { level using a Chi-squared test for } 2 \times 2 \text { contingency tables } \\
{ }^{* * *} \text { Values are significant at the } 0.0001 \text { level using a Chi-squared test for } 2 \times 2 \text { contingency tables }\end{array}$} \\
\hline
\end{tabular}




\section{Discussion and Conclusions}

\section{Summary of Figures and Tables}

Again, the purpose of this research was to determine the distribution of MS in GA and also to examine the potential relationships between environmental air pollutants and the distribution of MS in GA. From the geographic distribution of MS, we observed the bulk of the total and female self-reported MS prevalence rates seem to center around Atlanta, the largest city in GA. Also, we found the best predictive model for females with MS includes both per-capita income, a characteristic seen in studies done by Mayer and others (Mayer 1981), and PM-10. Males only had per-capita income in their predictive model. In addition, per-capita income seemed to have a positive influence on the total and female rates in the model, while the PM-10 seemed to have a negative influence on these rates in the model. It is important to note this multivariate model only included U.S. census and NEI source emissions data, not TRI source emissions data, because NEI had data for 158 of 159 GA counties. The TRI included data for between 32 and 107 counties, because emissions (total, to specific environmental media, and in processes or waste transported off site) must only be reported by sources to U.S. EPA over certain threshold levels. If nothing in a county emitted enough to be required to report a specific pollutant to TRI, then that county did not have any information on that specific pollutant.

The odds ratios (ORs) of all three population strata (total, female, and male) increased consistently with increases in the total population, male population, and per capita income. Nonconsistent increases were observed for source emissions of developmental toxicants, suspected endocrine toxicants, suspected immunotoxicants, and suspected kidney toxicants. The three population strata had lower ORs for people living in the same house in subsequent census collection years. 
For source emissions of criteria air pollutants, the ORs for total and female rates increased with increases of carbon monoxide (mobile sources), nitrogen oxides (areas sources), PM-2.5 (mobile sources), PM-10 (mobile sources), and volatile organic compounds (mobile sources). In addition, the ORs increased as we go from the second to the fourth quartile for nitrogen (all sources), PM-2.5 (area and all sources), PM-10 (area and all sources), sulfur dioxide (area and all sources), and volatile organic compounds (area sources). Also, male ORs increased with increasing emissions of PM-2.5 (all sources), sulfur dioxide (all sources), and volatile organic compounds (all sources). Furthermore, the ORs increased from the second to the fourth quartile for nitrogen oxides (mobile and areas sources) and volatile organic compounds (area sources).

Lastly, table 8 showed the percent black and percent white show significantly strong but varying ORs. U.S. Census data does not differentiate Hispanics from the percent black or percent white groups, thus this may partially explain the large jumps in ORs. This may support the need for Census data with percent white and percent black that do not include Hispanic populations.

\section{Discussion}

Prevalence rates help to control for differences in population distribution. Thus, because of the greater prevalence of MS around the largest metropolitan statistical area in GA, Atlanta, and the increasing MS ORs when organized by people per square mile, this study’s results suggested a possible role of urban environmental factors in the MS distribution in GA. This coincides with previous studies that suggested that MS rates were positively correlated with per capita income, physicians per capita, steel consumption, and several other characteristics which may increase in cities (Mayer 1981) as well as increased air pollution and other environmental 
factors (Oikonen et al, 2003). While this relationship was somewhat weak for the self-reported male prevalence rates, it was stronger for the female prevalence rates.

These differences in the distribution and the models used could be due to several reasons. The majority of MS cases in GA were female. This study has a female to male self-reported case ratio of 3.20 similar to studies conducted by Keegan et al. (2002) and Williamson et al. (Williamson 2007). Thus, in the NMSS-GA data, females were more likely to self-report being diagnosed with MS, females were more likely to become a member, or a combination of both of these characteristics. Thus, the prevalence in females will include a greater number of cases, and thus there may be less internal error in the female prevalence rates than in the male prevalence rates. This could lead to more significant statistics for the females than for the males. Also, there were biochemical gender difference in the mouse model for MS (Spach and Hayes 2005), thus there may also be biochemical gender differences between human MS patients. In addition, while per-capita income has been seen in some studies as associated with MS (Mayer 1981, Catanzaro et al 1992), PM-10 has never before been shown to be associated with MS prevalence rates; however, PM-10 has been shown to be associated with MS relapse in one study conducted in Finland (Oikonen et al. 2003).

Our present study found that self-reported MS prevalence from the National Multiple Sclerosis Society's Georgia Chapter (NMSS-GA) is also related strongly to PM-10 and MS may be positively associated with developmental toxicants, suspected endocrine toxicants, suspected immunotoxicants, suspected kidney toxicants, carbon monoxide (mobile sources), nitrogen oxides (areas and all sources), PM-2.5 (mobile, area, and all sources), PM-10 (mobile, are and all sources), and sulfur dioxide (area and all sources), and volatile organic compounds (area sources). 
Biochemically, inhaled particulates like PM-10 can affect a number of host defenses, including the development of specific immune responses such as cell-mediated immunity, the principal part of the immune system implicated in MS. Also, immune stimulation by particulates has also led to increased T-cell activity and immunoglobulin E (IgE) formation. (Bom 2007)

There is a clear relationship, based on many studies published over recent decades, between PM-10 and cardiovascular deaths and respiratory morbidity like asthma symptoms with measured increased outdoor air concentrations of PM-10. Thus, PM-10 may affect not only the cardiovascular and respiratory systems, but also the immune system. Furthermore the immune stimulation and IgE formation could lead to inflammation that is found in MS patients.

In addition to the inflammatory role of PM-10 in MS, heavy metals in particulate matter have been believed to have a relationship with MS clusters (Ingalls 1986; Landrigan et al. 1975). Using odds ratios, we found a significant relationship between lead compounds and female or total MS rates, although this relationship was not seen with males. Nevertheless, this study showed a stronger relationship with particulate matter than the relationship with heavy metals.

The implications of this research are far-reaching. Self-reported MS prevalence was highly associated with PM-10, at the county level, and PM-10 and per-capita income are best associated with MS in our model. Still, the research of environmental air pollutants and MS is sparse, thus additional research is needed to confirm this and the previous study (Oikonen et al. 2003) with richer outcome and exposure data.

\section{Advantages of This Study's Methods}

This study was conducted using county level data for several reasons. First, county level data allowed a more intense study of how regional emissions may be associated with regional rates of disease. Also, county level data may allow this study to be repeated in states with 
similar data. State emissions data may prove difficult to compare to this study because the distribution of emissions are too large to ensure comparability; however, county level emissions may be specific enough to accomplish this comparison. For example, previous research suggested different latitudes (Mayer 1981; Rosati 2001) made it difficult to compare data with other states further north or south. This study’s methodology therefore helped ensure we could compare data from one county to another, instead of comparing GA data with states that have higher or lower MS prevalence because of the effect of sunlight. While this study may have been done at an even smaller level, it was kept at the county level to help ensure continued confidentiality of members of the NMSS-GA.

Also, this study was done using the NMSS-GA member list. To date, a nationwide (beyond NMSS) MS registry has not been created; thus, these data may be from the most accurate database available throughout the country. The NMSS-GA data are also a good source of data, because it is from a national database, and thus the information may be comparable to other NMSS chapter databases throughout the country.

\section{Limitations of This Study's Methods}

There are several limitations to this study. First of all, the cases are self-reported from the member's list of the NMSS. While cases were asked to write the date of their MS diagnosis, this information could be fabricated. In addition, there is a small fee to register for the NMSS list. Therefore there is a strong possibility there may be under-reporting and non-differential bias due to information error in our results. Along with these limitations, there may also be relatively more underreporting in males, given generally males are less likely to seek medical care. Still, the NMSS-GA estimated that its list included approximately 75\% of the total MS cases in GA. 
Also, these data are cross-sectional, although they represented a cumulative prevalence of self-reported MS cases in GA. Therefore, only an estimate of true risk (OR) can be use, and casual inferences cannot be made. Georgia may have different laws, demographics, and other differences from other states. Thus, because this study uses data from GA only, the analyses were interpreted as restricted to GA. There is the possibility these values may be comparable to states with a similar latitude as GA, although different exposure patterns and different environmental laws may make inter-state comparison difficult. Also, birth years of the members were not received, thus this study could not correct for the potential confounding of age. Lastly, using the remaining county population as controls for this study may not be the most robust method for obtaining controls. A better method would be to use those who are also registered as family members of the members of the NMSS-GA, who may be at a higher genetic risk for MS.

\section{Conclusions and Recommendations for Future Research and Policy}

There may be a role of environmental air pollutants in the start and progression of Multiple Sclerosis (MS). In this study, the best model for predicting the female and total prevalence of MS in GA included both the per-capita income and coarse particulate matter (PM10). PM-10 along with other environmental air pollutants had highly significant associations with the MS rates in GA, along with evidence of a possible dose response. Moreover, a potential biochemical mechanism does exist. While we do not know the true effects of environmental air pollutants through this study or others, we should explore PM-10 and other air pollutants people are widely exposed to.

It is important to note the exact details of the biochemical mechanism that leads to MS is not currently known. Thus, further study is warranted and desperately needed. Future research should be done using the reported dates of diagnosis, to be able to assess yearly incidence as well 
as prevalence. Then, relative risk could be calculated as a true measure of risk, and not OR, which is only an estimate. Also, including the month and year of birth in subsequent studies will facilitate eliminating the ever-present confounding of age. Also, collecting ethnicity-data would be beneficial, because MS has been more common among some races than others (Keegan and Noseworthy 2002; Rosati 2001). This will allow future research to also control for racial differences. Lastly, more robust studies, such as prospective studies that are nested in the past, using various data available, may help provide more robust data for further analysis.

From a policy point of view, a MS registry is desperately needed. While we do have selfreported data that may be somewhat accurate, a universal definition and universal data collection would help scientists solidify the epidemiology of MS and conclusions from these studies. This registry must include important demographic information such as date of birth, race, date of diagnosis by a physician, and county and state of residence. Without a registry, MS data may continue to be underreported. Also, MS research has been supported, and should continue to be supported across the world. This disease has been known for a long time, yet, there is not a concrete list of causal factors. More research may help to bring light and consensus among the many factors that may influence the start and progression of MS, as well as how many people are diagnosed with MS and the common and diverse exposures that they may have.

The distribution and determinants of disease is the foundation of epidemiology. Countylevel, or lower, graphic representations of MS are important. While MS may seem to be equally distributed throughout the state, it was not in this study. Through finding high-risk counties and determining their differences from low-risk counties, we may be able to gather further crucial information about MS. 
As it has for hundreds of years, the question of nature versus nurture rages on. This debate centers on whether genetics or our environment leads more directly to our behaviors and to our diseases. It seems that MS may be a point of synthesis, for it embodies strong genetic and environmental factors. May we work quickly to elucidate this relationship in MS, for lives depend upon it. 


\section{REFERENCES}

Akhyani N, Berti R, Brennan MB, Soldan SS, Eaton JM, McFarland HF, et al. 2000. Tissue distribution and variant characterization of human herpesvirus (HHV)-6: increased prevalence of HHV-6A in patients with multiple sclerosis. J Infect Dis 182(5):1321-1325.

Anderson DW, Ellenberg JH, Leventhal CM, Reingold SC, Rodriguez M, Silberberg DH. 1992. Revised estimate of the prevalence of multiple sclerosis in the United States. Ann Neurol 31(3):333-336.

Baum HM, Rothschild BB. 1981. The incidence and prevalence of reported multiple sclerosis. Ann Neurol 10(5):420-428.

Bolviken B, Celius EG, Nilsen R, Strand T. 2003. Radon: a possible risk factor in multiple sclerosis. Neuroepidemiology 22(1):87-94.

Bom KEDaP. 2007. Particle Toxicology. Boca Raton, FL:CRC Press.

Cantorna MT, Hayes CE, DeLuca HF. 1996. 1,25-Dihydroxyvitamin D3 reversibly blocks the progression of relapsing encephalomyelitis, a model of multiple sclerosis. Proc Natl Acad Sci U S A 93(15):7861-7864.

Cantorna MT, Woodward WD, Hayes CE, DeLuca HF. 1998. 1,25-dihydroxyvitamin D3 is a positive regulator for the two anti-encephalitogenic cytokines TGF-beta 1 and IL-4. J Immunol 160(11):5314-5319.

Catanzaro M, Weinert C. 1992. Economic status of families living with multiple sclerosis. Int J Rehabil Res 15(3):209-218.

CDC UatWHO. 2001. Epi Info 6.

Cepok S, Zhou D, Srivastava R, Nessler S, Stei S, Bussow K, et al. 2005. Identification of Epstein-Barr virus proteins as putative targets of the immune response in multiple sclerosis. J Clin Invest 115(5):1352-1360.

Dal Canto MC, Melvold RW, Kim BS, Miller SD. 1995. Two models of multiple sclerosis: experimental allergic encephalomyelitis (EAE) and Theiler's murine encephalomyelitis virus (TMEV) infection. A pathological and immunological comparison. Microsc Res Tech 32(3):215-229.

de la Maza M, Garcia J, Bernal J, Fuentes M. 2000. [A review of the epidemiology of multiple sclerosis in Mexico]. Rev Neurol 31(5):494-495.

de Rezende PA, Arruda WO. 1996. [Genetic aspects in multiple sclerosis: I. Twin studies]. Arq Neuropsiquiatr 54(3):433-438.

Dyment DA, Ebers GC, Sadovnick AD. 2004. Genetics of multiple sclerosis. Lancet Neurol 3(2):104-110.

Ebers GC, Kukay K, Bulman DE, Sadovnick AD, Rice G, Anderson C, et al. 1996. A full genome search in multiple sclerosis. Nat Genet 13(4):472-476.

Fazekas F, Barkhof F, Filippi M, Grossman RI, Li DK, McDonald WI, et al. 1999. The contribution of magnetic resonance imaging to the diagnosis of multiple sclerosis. Neurology 53(3):448-456.

Freedman DM, Dosemeci M, Alavanja MC. 2000. Mortality from multiple sclerosis and exposure to residential and occupational solar radiation: a case-control study based on death certificates. Occup Environ Med 57(6):418-421. 
Haahr S, Plesner AM, Vestergaard BF, Hollsberg P. 2004. A role of late Epstein-Barr virus infection in multiple sclerosis. Acta Neurol Scand 109(4):270-275.

Hansen T, Skytthe A, Stenager E, Petersen HC, Kyvik KO, Bronnum-Hansen H. 2005. Risk for multiple sclerosis in dizygotic and monozygotic twins. Mult Scler 11(5):500-503.

Henry J, et al. . 2007. Investigation of a Cluster of Multiple Sclerosis in Two Elementary School Cohorts. Journal of Environmental Health 69(10):34-38.

Hernan MA, Olek MJ, Ascherio A. 2001. Cigarette smoking and incidence of multiple sclerosis. Am J Epidemiol 154(1):69-74.

Hogancamp WE, Rodriguez M, Weinshenker BG. 1997. The epidemiology of multiple sclerosis. Mayo Clin Proc 72(9):871-878.

Hong J, Zang YC, Tejada-Simon MV, Li S, Rivera VM, Killian J, et al. 2000. Reactivity and regulatory properties of human anti-idiotypic antibodies induced by $\mathrm{T}$ cell vaccination. $\mathrm{J}$ Immunol 165(12):6858-6864.

Ingalls TH. 1986. Endemic clustering of multiple sclerosis in time and place, 1934-1984. Confirmation of a hypothesis. Am J Forensic Med Pathol 7(1):3-8.

Ito H, Yamasaki K, Kawano Y, Horiuchi I, Yun C, Nishimura Y, et al. 1998. HLA-DPassociated susceptibility to the optico-spinal form of multiple sclerosis in the Japanese. Tissue Antigens 52(2):179-182.

Keegan BM, Noseworthy JH. 2002. Multiple sclerosis. Annu Rev Med 53:285-302.

Kong H, Baerbig Q, Duncan L, Shepel N, Mayne M. 2003. Human herpesvirus type 6 indirectly enhances oligodendrocyte cell death. J Neurovirol 9(5):539-550.

Kurtzke JF. 2000. Multiple sclerosis in time and space--geographic clues to cause. J Neurovirol 6 Suppl 2:S134-140.

Landrigan PJ, Gehlbach SH, Rosenblum BF, Shoults JM, Candelaria RM, Barthel WF, et al. 1975. Epidemic lead absorption near an ore smelter. The role of particulate lead. N Engl J Med 292(3):123-129.

Levin LI, Munger KL, Rubertone MV, Peck CA, Lennette ET, Spiegelman D, et al. 2003. Multiple sclerosis and Epstein-Barr virus. Jama 289(12):1533-1536.

---. 2005. Temporal relationship between elevation of epstein-barr virus antibody titers and initial onset of neurological symptoms in multiple sclerosis. Jama 293(20):2496-2500.

Lunemann JD, Edwards N, Muraro PA, Hayashi S, Cohen JI, Munz C, et al. 2006. Increased frequency and broadened specificity of latent EBV nuclear antigen-1-specific T cells in multiple sclerosis. Brain 129(Pt 6):1493-1506.

Mayer J. 1981. Georgraphical Clues about Multiple Sclerosis. Annals of the Association of American Geographers 71(1):28.

Microsoft-Corporation. 2004. Microsoft Excel 2004 for Mac.

Munger KL, Zhang SM, O'Reilly E, Hernan MA, Olek MJ, Willett WC, et al. 2004. Vitamin D intake and incidence of multiple sclerosis. Neurology 62(1):60-65.

NL Sicotte ea. 2002. Treatment of multiple sclerosis with the pregnancy hormaone estriol. Annuals of Nuerology 52(4):421-428.

Ogawa G, Mochizuki H, Kanzaki M, Kaida K, Motoyoshi K, Kamakura K. 2004. Seasonal variation of multiple sclerosis exacerbations in Japan. Neurol Sci 24(6):417-419.

Oikonen M, Laaksonen M, Laippala P, Oksaranta O, Lilius EM, Lindgren S, et al. 2003. Ambient air quality and occurrence of multiple sclerosis relapse. Neuroepidemiology 22(1):95-99. 
Oksenberg JR, Baranzini SE, Barcellos LF, Hauser SL. 2001. Multiple sclerosis: genomic rewards. J Neuroimmunol 113(2):171-184.

Rosati G. 2001. The prevalence of multiple sclerosis in the world: an update. Neurol Sci 22(2):117-139.

Soldan SS. 2003. Immune modulation in multiple sclerosis patients treated with the pregnancy hormone estradiol. J Immunol 171(11):6267-6274.

Soldan SS, Berti R, Salem N, Secchiero P, Flamand L, Calabresi PA, et al. 1997. Association of human herpes virus 6 (HHV-6) with multiple sclerosis: increased IgM response to HHV6 early antigen and detection of serum HHV-6 DNA. Nat Med 3(12):1394-1397.

Sospedra M, Martin R. 2005. Immunology of multiple sclerosis. Annu Rev Immunol 23:683747.

Sospedra M, Zhao Y, zur Hausen H, Muraro PA, Hamashin C, de Villiers EM, et al. 2005. Recognition of conserved amino acid motifs of common viruses and its role in autoimmunity. PLoS Pathog 1(4):e41.

Spach KM, Hayes CE. 2005. Vitamin D3 confers protection from autoimmune encephalomyelitis only in female mice. J Immunol 175(6):4119-4126.

SPSS. 2005. SPSS for Windows.

Sumaya CV, Myers LW, Ellison GW, Ench Y. 1985. Increased prevalence and titer of EpsteinBarr virus antibodies in patients with multiple sclerosis. Ann Neurol 17(4):371-377.

Tejada-Simon MV, Zang YC, Hong J, Rivera VM, Zhang JZ. 2003. Cross-reactivity with myelin basic protein and human herpesvirus-6 in multiple sclerosis. Ann Neurol 53(2):189-197.

Thompson AJ, Polman CH, Miller DH, McDonald WI, Brochet B, Filippi MMX, et al. 1997. Primary progressive multiple sclerosis. Brain 120 ( Pt 6):1085-1096.

Virtanen JO, Zabriskie JB, Siren V, Friedman JE, Lyons MJ, Edgar M, et al. 2005. Colocalization of human herpes virus 6 and tissue plasminogen activator in multiple sclerosis brain tissue. Med Sci Monit 11d(3):BR84-87.

Wandinger K, Jabs W, Siekhaus A, Bubel S, Trillenberg P, Wagner H, et al. 2000. Association between clinical disease activity and Epstein-Barr virus reactivation in MS. Neurology 55(2):178-184.

Weinshenker BG. 1998. The natural history of multiple sclerosis: update 1998. Semin Neurol 18(3):301-307.

Williamson D, et al. 2007. Prevalence of Multiple Sclerosis in 19 Texas counties, 1998-2000. Journal of Environmental Health 69(10):41-45.

Williamson DM, Henry JP. 2004. Challenges in addressing community concerns regarding clusters of multiple sclerosis and potential environmental exposures. Neuroepidemiology 23(5):211-216. 
Appendices A-C 
Appendix A. Selected Variables and Correlations with Multiple Sclerosis Prevalence (caption shows “Table 3”) (Mayer 1981)

TABlE 3.-SELECTED VARIABlES AND CorRelations with Multiple Sclerosis Prevalence

\begin{tabular}{lc}
\hline \multicolumn{1}{c}{ Variable } & $\begin{array}{c}\text { Correlation } \\
\text { coefficient }\end{array}$ \\
\hline Mean annual hours of sunshine & -.88 \\
Steel consumption (tons/capita) & +.85 \\
Physicians per capita & +.85 \\
Literacy rate & +.84 \\
Latitude (population centroid) & +.77 \\
Gross energy consumption (megawatt & \\
$\quad$ hours per capita) & +.76 \\
Mean annual temperature & -.70 \\
Infant mortality & -.69 \\
GNP per capita & +.65 \\
Food consumption (caloric per capita) & +.59 \\
\hline
\end{tabular}

Source: Leibowitz and Alter, op. cit., footnote 4, p. 261.

Many different factors like mean annual house of sunshine, mean annual temperature and infant mortality were found to be protective of Multiple Sclerosis. Contrarily steel consumption, number of physicians per capita, literacy rate, latitude from equator, gross energy consumption, gross national product per capita and food consumption were all associated with higher rates of $M S$

(Mayer 1981) 
Appendix B: Figures 1, 2 and 3 (Rosati 2001)

Figures 1, 2 and 3 show Geographical Information Systems maps of Multiple Sclerosis prevalence (per 100,000) in the United States, Africa and around the United Kingdom, respectively. (Rosati 2001)

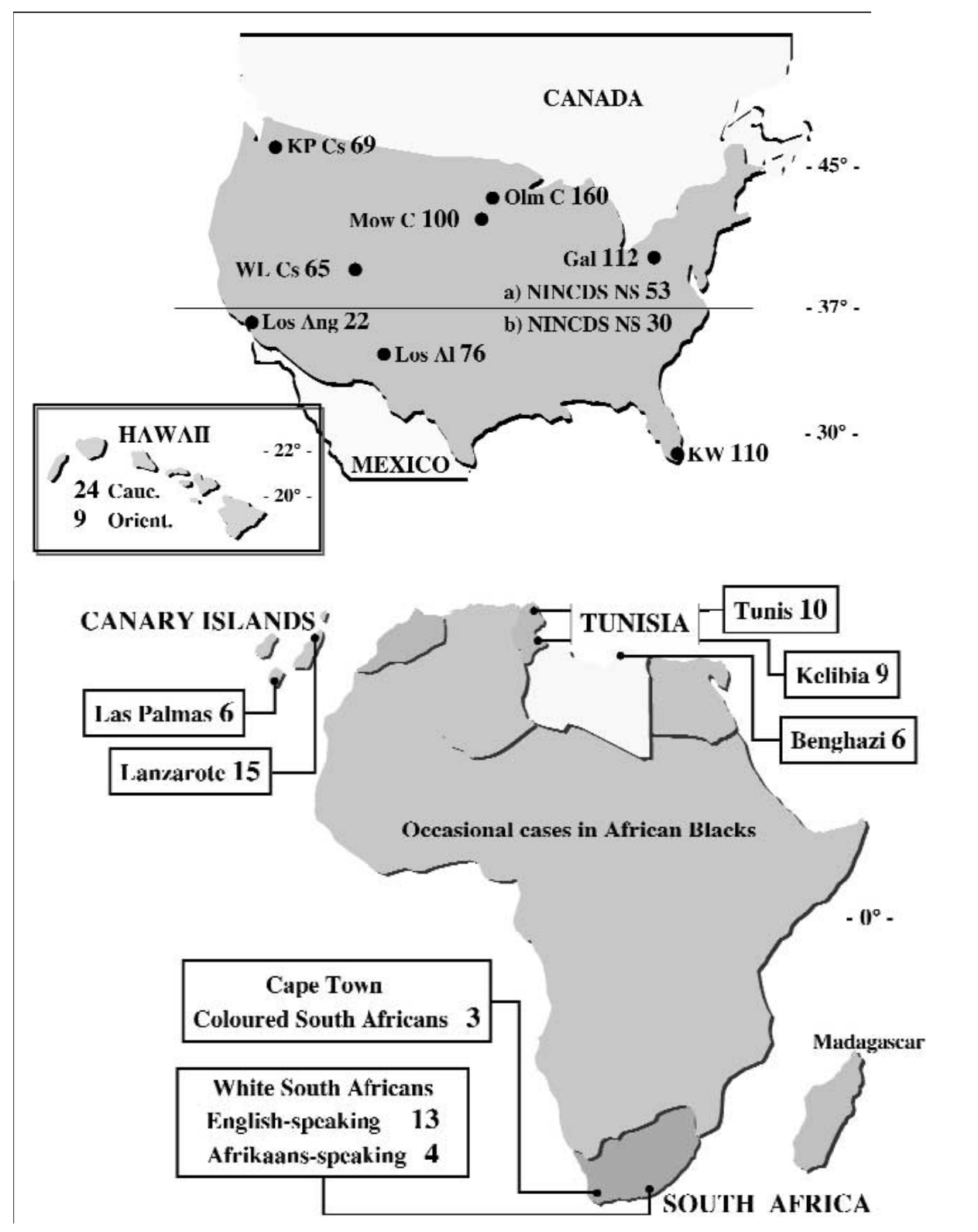




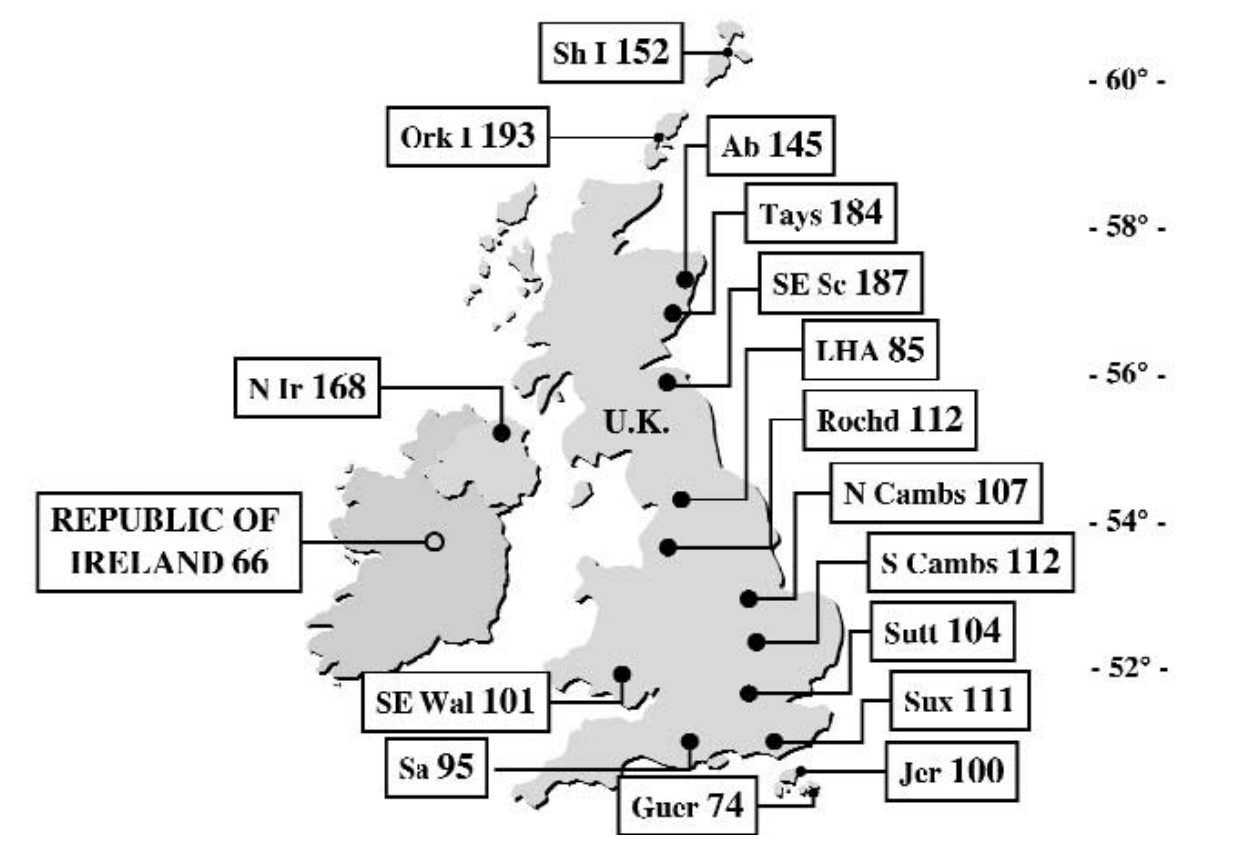

In all three of these Geographic Information System (GIS) models, Rosati et al. show that there are significant geographical influences that may influence the rate of MS in several countries. (Rosati 2001) 
Appendix C: Crude and adjusted odds ratios (95\% Confidence Intervals) for mortality from Multiple Sclerosis associated with indicators of exposure to sunlight and socioeconomic status, USA, 1984-1985 (Freedman et al. 2000)

\begin{tabular}{|c|c|c|c|c|}
\hline \multicolumn{5}{|c|}{$\begin{array}{l}\text { Appendix } 3 \text { Crude and adjusted ORs (95\% CIs) for mortality from Multiple Sclerosis } \\
\text { associated with indicators of exposure to sunlight and socioeconomic status, USA, 1984- } \\
95\end{array}$} \\
\hline & \multicolumn{2}{|c|}{ Multiple Sclerosis } & \multicolumn{2}{|c|}{ Skin cancer } \\
\hline & Crude & Adjusted* & Crude & Adjusted \\
\hline \multicolumn{5}{|c|}{ Residential Sunlight } \\
\hline Low & 1 & 1 & 1 & 1 \\
\hline Moderate & $\begin{array}{l}0.58 \text { (0.54 to } \\
0.62)\end{array}$ & $\begin{array}{l}0.59(0.55 \text { to } \\
0.63)\end{array}$ & $\begin{array}{l}1.12 \text { (1.04 to } \\
1.20)\end{array}$ & $\begin{array}{l}1.15 \text { (1.07 to } \\
1.23)\end{array}$ \\
\hline High & $\begin{array}{l}0.55 \text { ( } 0.51 \text { to } \\
0.59)\end{array}$ & $\begin{array}{l}0.53(0.48 \text { to } \\
0.57)\end{array}$ & $\begin{array}{l}1.15 \text { (1.07 to } \\
1.24)\end{array}$ & $\begin{array}{l}1.24(1.15 \text { to } \\
1.35)\end{array}$ \\
\hline \multicolumn{5}{|c|}{ Occupational } \\
\hline Indoor & 1 & 1 & 1 & 1 \\
\hline Mixed & $\begin{array}{l}0.87 \text { (0.77 to } \\
0.97 \text { ) }\end{array}$ & $\begin{array}{l}0.89 \text { (0.78 to } \\
1.02)\end{array}$ & $\begin{array}{l}1.30 \text { (1.19 to } \\
1.42)\end{array}$ & $\begin{array}{l}1.03 \text { (0.93 to } \\
1.14)\end{array}$ \\
\hline Outdoor & $\begin{array}{l}0.40(0.33 \text { to } \\
0.47)\end{array}$ & $\begin{array}{l}0.74 \text { (0.61 to } \\
0.89)\end{array}$ & $\begin{array}{l}1.53 \text { (1.40 to } \\
1.68)\end{array}$ & $\begin{array}{l}1.21 \text { (1.09 to } \\
1.34)\end{array}$ \\
\hline \multicolumn{5}{|c|}{ Socioeconomic status: } \\
\hline 1 Low & 1 & 1 & 1 & 1 \\
\hline 2 & $\begin{array}{l}1.36 \text { (1.19 to } \\
1.55)\end{array}$ & $\begin{array}{l}1.00 \text { (0.88 to } \\
1.15)\end{array}$ & $\begin{array}{l}0.92 \text { (0.84 to } \\
1.0)\end{array}$ & $\begin{array}{l}0.93 \text { (0.85 to } \\
1.01)\end{array}$ \\
\hline 3 & $\begin{array}{l}2.45 \text { (2.19 to } \\
2.75)\end{array}$ & $\begin{array}{l}1.90 \text { (1.68 to } \\
2.13)\end{array}$ & $\begin{array}{l}0.90 \text { ( } 0.83 \text { to } \\
0.97)\end{array}$ & $\begin{array}{l}0.89 \text { (0.82 to } \\
0.96)\end{array}$ \\
\hline 4 & $\begin{array}{l}3.08 \text { (2.73 to } \\
3.49)\end{array}$ & $\begin{array}{l}2.26 \text { (1.99 to } \\
2.57)\end{array}$ & $\begin{array}{l}0.87 \text { ( } 0.79 \text { to } \\
0.95)\end{array}$ & $\begin{array}{l}0.90 \text { (0.82 to } \\
1.00)\end{array}$ \\
\hline 5 High & $\begin{array}{l}3.39 \text { (2.89 to } \\
3.99)\end{array}$ & $\begin{array}{l}3.07 \text { (2.59 to } \\
3.62)\end{array}$ & $\begin{array}{l}1.19(1.04 \text { to } \\
1.36)\end{array}$ & $\begin{array}{l}1.07 \text { ( } 0.94 \text { to } \\
1.23)\end{array}$ \\
\hline \multicolumn{5}{|c|}{$\begin{array}{l}\text { * Adjusted ORs were calculated with logistic regression, adjusting for age, sex, race and } \\
\text { socioeconomic status, except in the case of socioeconomic status where adjustments } \\
\text { were for age, sex and race. }\end{array}$} \\
\hline \multicolumn{5}{|c|}{$\begin{array}{l}\text { Residence sunlight was defined as residing in a region both at birth and at the time of } \\
\text { death. Regions are defined in Appendix } 1 \text {. Subjects who resided in different regions at } \\
\text { birth and at the time of death were excluded. }\end{array}$} \\
\hline \multicolumn{5}{|c|}{$\begin{array}{l}\text { Occupational analysis was limited to those subjects whose usual occupation was } \\
\text { classified as highly or moderately active to exclude those whose indoor jobs reflected } \\
\text { restricted job options due to the disabilities of their disease. Homemakers were also } \\
\text { excluded. }\end{array}$} \\
\hline
\end{tabular}

Freedman et al. show that residential sunlight is protective of $M S(O R=0.53)$. They also show state that under the highest sun exposure white men, white women, black men and black women (adjusted $O R=0.57,0.49,0.44,0.59$, respectively[data not shown]) have similar rates. (Freedman et al. 2000) 